\title{
EXPANDING OLDENBURG: A QUANTITATIVE STUDY OF THE ASSOCIATION BETWEEN PERCEPTIONS OF THIRD PLACES AND SOCIAL CAPITAL IN WELLINGTON NEIGHBOURHOODS
}

\author{
Grace Emily Eda Turner
}

Thesis

ENVIRONMENTAL STUDIES 591

2019

A 120-point thesis submitted to Victoria University of Wellington as partial fulfilment of requirements for the degree of Master of Environmental Studies

School of Geography, Environment and Earth Sciences

Victoria University of Wellington

June 2019 



\section{Abstract}

A neighbourhood with a well-designed and high-quality built environment has been shown to have a positive impact on residents' physical and social wellbeing, and their overall quality of life. There is a plethora of research demonstrating how walkable, dense, connected, and mix land-use neighbourhoods improve people's physical health however, empirical evidence supporting the built environment's association with social well-being and social capital remains somewhat elusive. Interest in the relationship between walkability and social capital is growing momentum but considerations of other features of the built environment, such as third places remains sparse. Empirical assessments of the built environment and social capital have been conducted in Europe, North America or Australia, and studies of this relationship in a New Zealand context are almost non-existent.

This thesis aims to address these gaps by investigating the association between residents' perceptions of third places in their neighbourhood and two dimensions of social capital: sense of community (SoC) and neighbouring in three neighbourhoods in Wellington, New Zealand. Specifically, this thesis' core objectives are to identify what types of places New Zealanders perceive as third places, the meaning and value they attach to third places, and to explore the association between SoC, neighbouring and people's perceptions of third places.

Data was obtained from a cross-sectional survey $(n=160)$ and analysed using linear regression. Respondents most commonly perceive third places as either places of nature or as places that host activities and facilitate social interaction. For residents, it is important that third places are inclusive and accessible. The perceived quality of third places was significantly and positively associated with SoC. This relationship appears to be unaffected by demographic variables. The findings of this study provide scope for local policy makers and planners to provide for the presence of high-quality third places that are of nature or host activities to encourage social interaction between residents in new neighbourhoods.

Key words: Third place; Oldenburg; social capital; sense of community; neighbouring; built environment; New Zealand 


\section{Acknowledgements}

I would first and foremost like to acknowledge the scholarship funding I received from the Where do we Dance? project as part of the National Science Challenge 11: Building Better Homes, Towns and Cities. I feel very lucky to have contributed to this important project.

I would like to express my gratitude to all residents of Lyall Bay, Island Bay and Karori who completed the survey, and to the people who shared their further thoughts and opinions about their neighbourhood at the end of the survey. Without your participation, this thesis would not have been possible.

To my supervisor, Dr. Wokje Abrahamse, thank you for your very valuable and constructive feedback on the draft versions of this thesis and for the help you provided me with statistics. I appreciate your patience, encouragement and time you have given me over the past year.

To my parents, family, and friends I would like to express my great appreciation for your endearing support and encouragement throughout my study. To mum, thank you for all of the emotional support and care you gave me during this time and the accountability you put on me to stay focussed and push on ahead. Thank you, Dad, for your encouragement and for financially supporting me during the last half of 2018 so I could completely dedicate myself to this thesis full-time. Thank you to my darling Ellen, my best friend Evey and my step-dad for helping me distribute my survey advertisements in letterboxes in the hot summer weather.

To Elaine, Emma, Katy, Jerry and Sky thank you for your emotional support and academic advice throughout the past year. The supportive 'family' culture we created in the office made hard and long days that much easier. To have made such great friends whilst writing this thesis is something I truly appreciate. 


\section{Table of Contents}

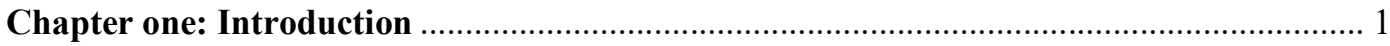

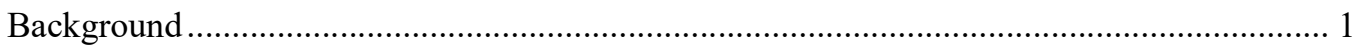

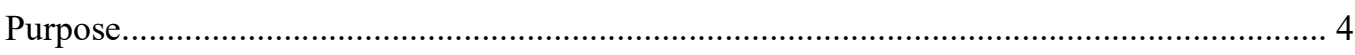

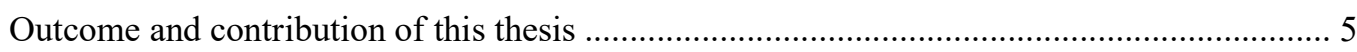

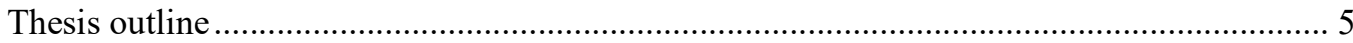

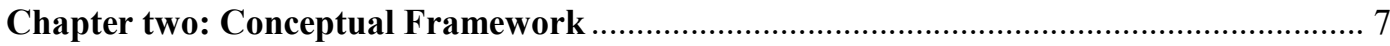

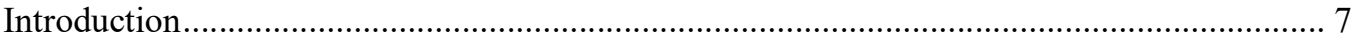

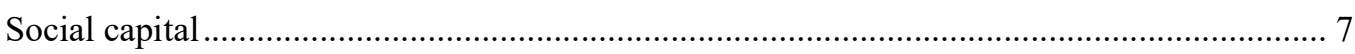

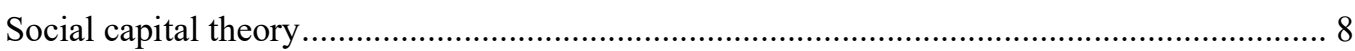

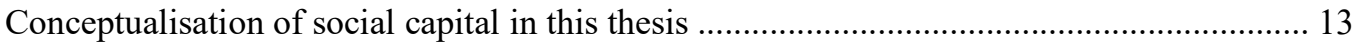

A community psychology perspective of social capital....................................................... 13

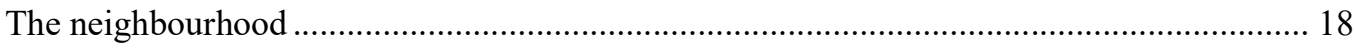

Justification for using social capital as a conceptual framework ............................................ 19

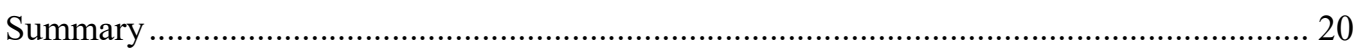

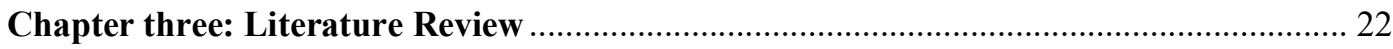

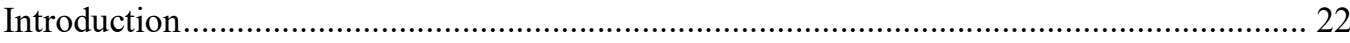

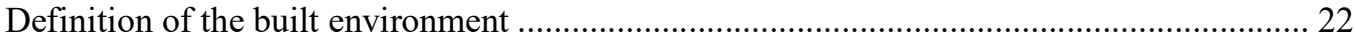

The association between the built environment and social capital ...................................... 23

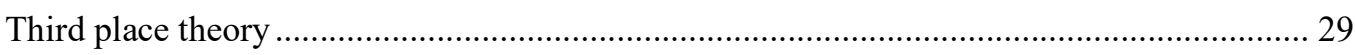

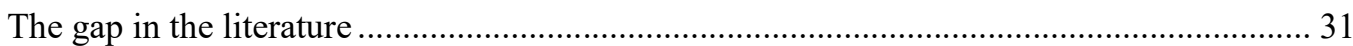

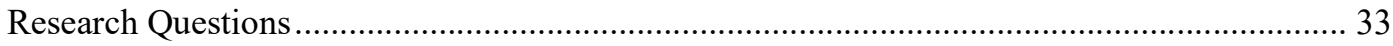

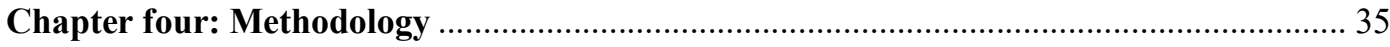

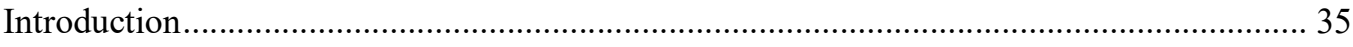

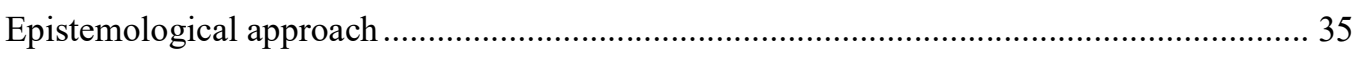

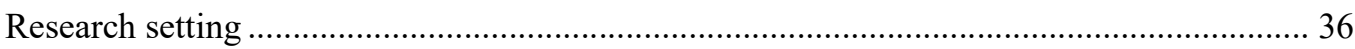

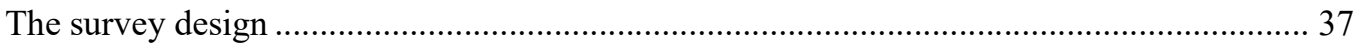

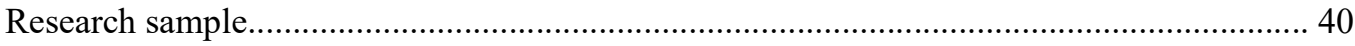

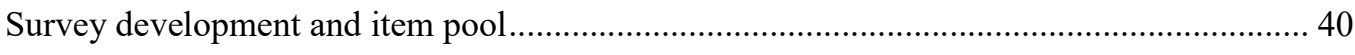

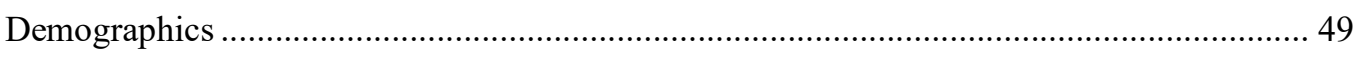

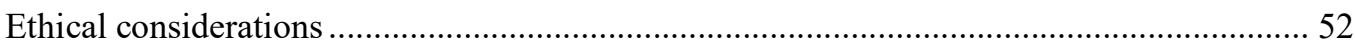

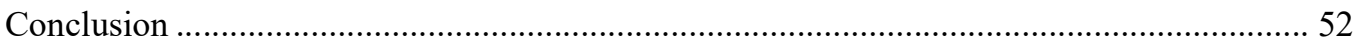

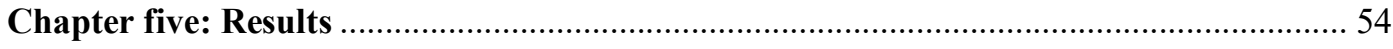

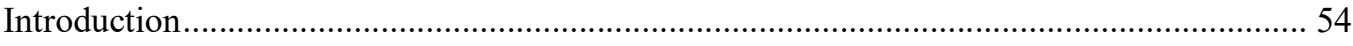

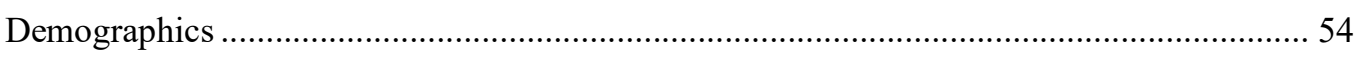

Research Question 1: Respondents' perceptions of third places ......................................... 57

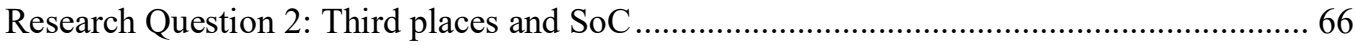


Research Question 3: Third places and neighbouring .........................................................6

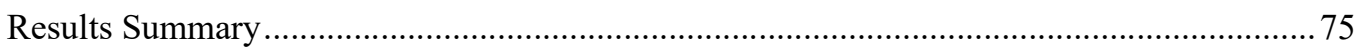

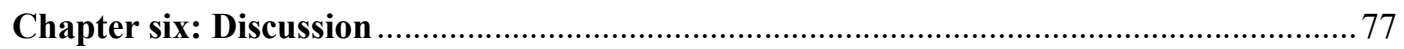

Research Question 1: The meaning and value of the third place........................................... 77

Research Questions 2 and 3: Third places and Social Capital................................................8 81

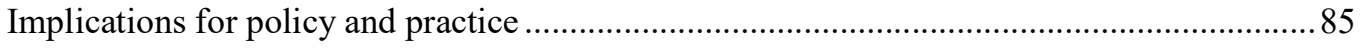

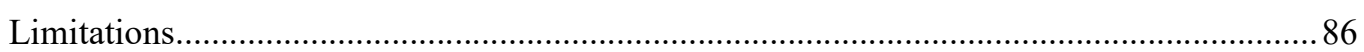

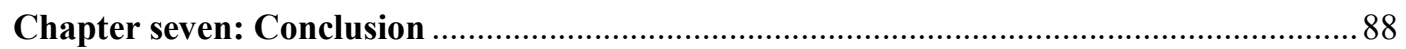

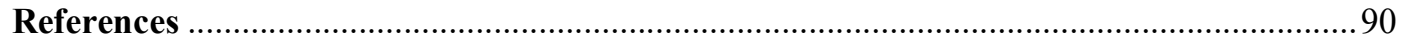

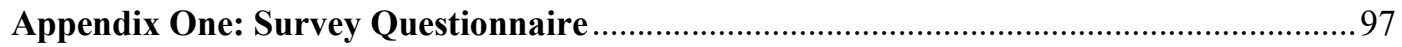

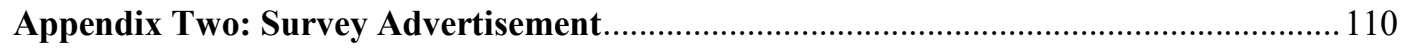




\section{List of Figures}

Figure 1: Respondents perceptions of local third places ..................................... 48

Figure 2: Respondents' favourite places in their neighbourhood .............................. 48

Figure 3: Map of respondents' approximate location in Lyall Bay ............................. 51

Figure 4: Map of respondents' approximate location in Island Bay ...........................51

Figure 5: Map of respondents' approximate location in Karori ............................... 52

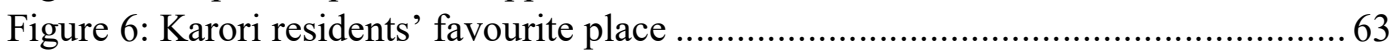

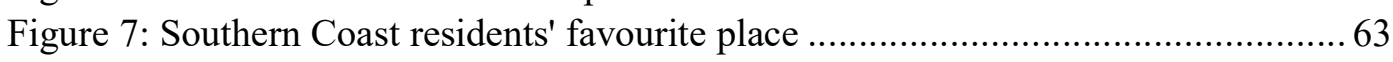

\section{List of Tables}

Table 1: Overview of social capital theories (adapted from Winter, 2000 para. 26).... 10

Table 2: Perkins and Long (2002) four dimensions of social capital, p. 294).............. 15

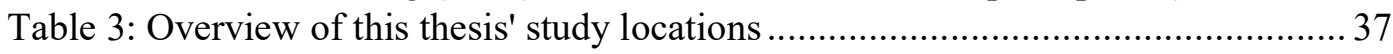

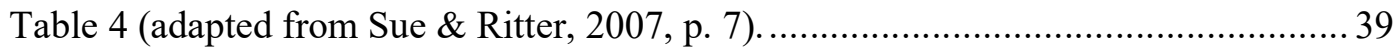

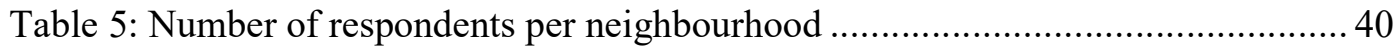

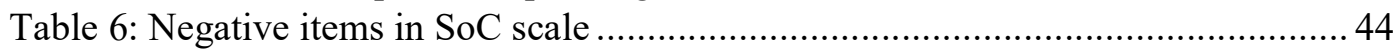

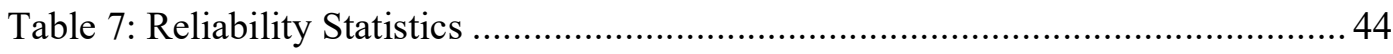

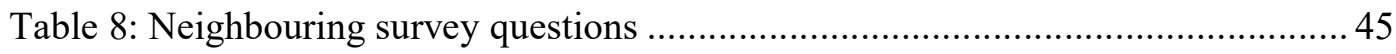

Table 9: Demographics descriptive and Pearson correlation statistics........................ 56

Table 10: How respondents met others in their neighbourhood ...............................58

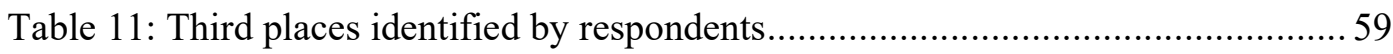

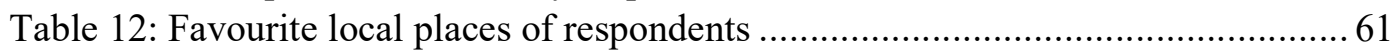

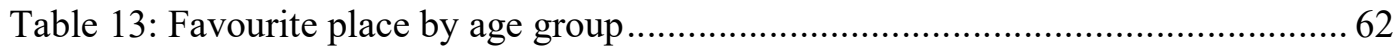

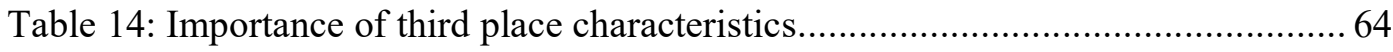

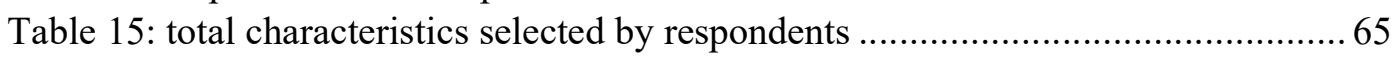

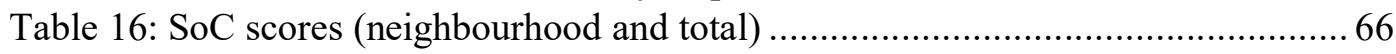

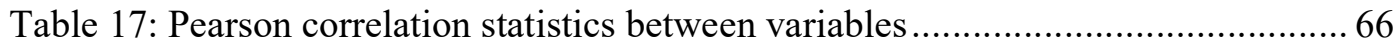

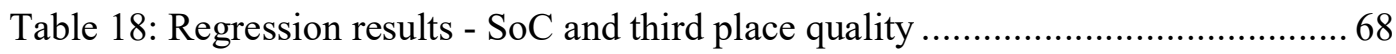

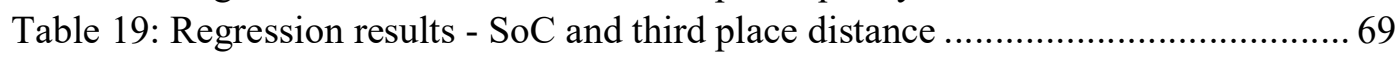

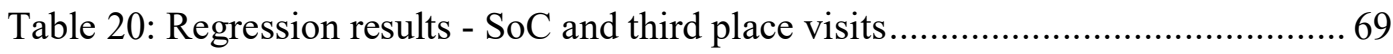

Table 21: Descriptive statistics for neighbouring scores ...................................... 70

Table 22: Pearson correlation statistics for neighbouring scores .............................. 71

Table 23: Regression results - neighbouring 1 and third place quality ....................... 72

Table 24: Regression results - neighbouring 2 and third place quality ..................... 72

Table 25: Regression results - neighbouring 1 and third place distance...................... 73

Table 26: Regression results - neighbouring 2 and third place distance...................... 73

Table 27: Regression results - neighbouring 1 and third place visits .......................... 74

Table 28: Regression results - neighbouring 2 and third place visits ......................... 74 



\section{Chapter one: Introduction}

The purpose of this introduction chapter is to provide background on this thesis' overall objectives. This chapter provides justification for why the objectives of this thesis are valuable and are of broad and current interest in a modern New Zealand context. To begin, an overview of this thesis' intervention logic is provided followed by the purpose statement and the intended outcome and contribution of this thesis. The chapter ends with an outline of how this thesis is structured. Chapter one serves only to brief the reader about this thesis' intent. The topics of interest to this thesis are multi-faceted and very complex and cannot be appropriately summarised in one chapter. Following chapters two (conceptual framework) and three (literature review) the research questions and aims of this thesis are therefore provided.

\section{Background}

Fifty years ago, the global population was approximately 3.5 billion. At present it is estimated to be at 7.6 billion, and by 2050 it is projected to reach 9.7 billion. New Zealand mirrors the global population trend where over the past 50 years the population has nearly doubled in size from 2.7 million to 4.7 million people, and by 2068 it could reach 7.9 million (Stats NZ, 2016). In two of New Zealand's main centres population growth from 2013-2023 is expected to increase by 47 per cent in central Auckland and by 25 per cent in Wellington (Infometrics, 2016). Approximately 86 per cent of $\mathrm{New}$ Zealand's population live in urban centres, and population growth in the larger cities has resulted in serious social and infrastructural problems including increasing house prices, homelessness, and congestion of roads (Productivity Commission, 2017). If the population projections are correct, or even an underestimation, there will be significant added costs and pressures on cities and towns to upgrade and provide vital infrastructure, affordable housing, and amenities to match growth.

In the New Zealand Productivity Commission's report Better Urban Planning Report 2017 it is argued that most New Zealand councils have policies intended for creating compact urban form for their cities however, many councils have struggled to achieve their goals. The Productivity Commission argue that cities have become more compact however, growth has largely been accommodated for by development of land in outer suburbs (Productivity Commission, 2017). In Wellington, the Wellington City Council (the Council) believes that the city can accommodate an increasing population however, 
it will have to grow upward as well as outward (Forbes, 2016). Included in the Council's Urban Growth Plan 2014 is a strategy for urban growth, which is to direct it around the central city, in selected suburban centres that can support intensification, and in greenfield areas (WCC, 2015). In Wellington an increased rate of housing intensification has occurred over the past decade in the Central Business District where a surplus of lower-grade office buildings has been converted into apartments (Infometrics, 2016). However, plans to develop extensive greenfield sites, such as Stebbings Valley and Lincolnshire Farm to the north of the city, are a key part of the Council's long-term vision for urban development, and to support an increasing population (WCC, 2015).

The Council's Chief City Planner argues that while it is feasible to accommodate an increasing population in Wellington, there is a risk that developers will be focussed on 'packing people in' and on their profit margins rather than on good design (WCC, 2015). There is merit in the Chief City Planner's argument as well-designed and liveable neighbourhoods that include places for interaction benefit their inhabitants and contribute to successful towns and cities. As this thesis proceeds it will become clear that providing for increased demand for housing and infrastructure to support growing populations in cities should not just be about building houses, but also about building lively neighbourhoods.

The physical characteristics of a city, including its neighbourhoods, have a significant impact on residents' travel behaviours, economic viability, housing market dynamics, social equity, and energy use (Raman, 2010). Not only this, the physical characteristics of a city can also enhance opportunities for social exchange and feelings of responsibility or they can inhibit them which then creates conditions that allow for crime and other social problems (Corcoran, Zahnow, Wickes \& Hipp, 2017). The physical characteristics of a city and its neighbourhoods refer to the built environment, which include streetscapes, roads, parks, public and private spaces, commercial and industrial buildings, and greenspace. In recent decades many scholars from various fields relating to urban studies, have reinforced that it is the built environment of cities and neighbourhoods that support, facilitate, and promote public life (Metha, 2007). Jane Jacobs, an influential urban theorist, argues that to create vibrant urban communities they must be dense, have a mixed urban layout and be well-designed (from Raman, 2010). Considering this, if greenfield development (and the redevelopment of brownfield areas) in Wellington is to occur over the next decade the planning and 
design of neighbourhoods should consider the impacts on residents' experiences of urban life, and on their social, economic and cultural wellbeing.

The association between the built environment of cities and neighbourhoods and peoples' wellbeing has led to research exploring what (and how) specific features of the built environment affect people's experience of urban life. Over the past few decades a significant body of research has emerged exploring the relationship between features of the built environment and physical health. This research has been driven by concerns over the trends in the pervasiveness of obesity, and efforts from the planning and public health sectors to link neighbourhood features with physical activity (French, Wood, Foster, Giles-Corti, Frank \& Learnihan, 2014). Research in this area has tended to focus on the walkability, street connectivity, and land-use of cities and neighbourhoods. Generally, it has been found that residents living in highly-walkable neighbourhoods (defined as having greater residential density, more land-use mix and higher connectivity) tend to engage in more physical activity (Van Dyck, Cardon, Deforche, Sallis, Owen \& De Bourdeaudhuij, 2010). An emerging area of research has also begun to explore the relationship between the built environment and social well-being/mental health, although empirical evidence remains elusive. Evidence suggests that there is an association between features of the built environment and individuals' sense of community (SoC) and willingness to interact with others in their neighbourhood (Francis, Giles-Corti, Wood, \& Knuiman, 2012). What has been found is that highlywalkable neighbourhoods where people have access to local amenities tend to have residents that perceive their quality of life and social well-being as high.

If local planners, developers and policymakers in New Zealand recognise the evidence that supports a relationship between the built environment, and physical health and social well-being, new neighbourhoods would be walkable, dense, have good land-use mix and street connectivity. A lot of the research and evidence on the implications of the built environment has been conducted in Australia and Europe, and North America. However, investigations of how features of the built environment impact on peoples' experiences of urban life and/or physical and mental health is generally sparse in a New Zealand context, and it is not known if the evidence from overseas is cross-applicable. There is a growing body of research in New Zealand that has investigated the association between the built environment and physical activity (Hinckson, McGrath, Hopkins, Oliver, Badland, Mavoa \& Kearns, 2014; Witten et al., 2012); however, research on social well-being and the built environment remains elusive. An 
investigation into the association between the built environment and social well-being is warranted in New Zealand because (data from 2014 census) one third of New Zealanders said they were lonely, and 20 per cent said they would seek treatment for depression or anxiety in that year (White, 2018). The built environment can help facilitate social interaction between residents in a neighbourhood, which in turn increases people's social well-being and quality of life.

The built environment is a broad term that encompasses many features of the urban built form. As articulated in this chapter, the most commonly researched feature of the built environment, in relation to physical health and social well-being outcomes, is walkability. Other important features include density and land-use, and the presence of neighbourhood amenities. These features are further discussed in chapter three. To ensure this master's thesis retains a tightly-focussed scope only one feature (and the least researched) of the built environment will be investigated, which is the presence of neighbourhood amenities. Neighbourhood amenities can also be conceptualised as 'third places' a term coined by Oldenburg and Brissett (1982) that refers to the meeting or gathering places that exist outside the home and workplace. These places are generally publicly accessible and provide opportunities for residents to have contact and proximity with others in their neighbourhood. A further discussion of third place theory is provided in chapter three.

In most Western cultures, it is commonplace to have some locations traditionally associated with informal social interaction however, we do not know enough about these places in a New Zealand context. The purpose of this thesis is to investigate the association between one feature of the neighbourhood built environment: third places and people's social well-being. Social well-being is conceptualised as 'social capital' in this thesis. A definition and overview of social capital are provided in chapter two.

\section{Purpose}

This thesis investigates the association between residents' perceptions of their neighbourhood third places and their self-rated social capital. This thesis specifically chose to evaluate existing neighbourhoods and their physical features to help improve future urban environments and neighbourhoods. This is because communities can implement practices known to be successful in existing New Zealand neighbourhoods. The place of research for this thesis is Wellington, New Zealand, and specifically three Wellington neighbourhoods: Island Bay, Karori, and Lyall Bay. More information on the study location and these three neighbourhoods is provided in chapter four. 


\section{Outcome and contribution of this thesis}

This thesis aims to contribute to the literature by providing empirical evidence supporting the association between third places (as a feature of a neighbourhood's built environment) and social capital. The knowledge generated in this thesis is of interest to those building, designing or redeveloping neighbourhoods and to those who wish to help build social capital in a neighbourhood and thereby improve the quality of life of residents. This thesis also aims to challenge the salience of Oldenburg's (1989) third place theory, which is discussed further in chapter three.

\section{Thesis outline}

This research comprises seven chapters. Beyond this introduction, chapter two provides an extensive summary of the conceptual framework that guides this research, which is social capital. Social capital is a contested, broad and complex social science concept and many researchers criticise others who operationalise social capital without acknowledging its complexities and downfalls. Considering this, a detailed summary of its definition, dimensions and interpretation is given as well as an acknowledgement of its criticisms. Chapter two also sets out how social capital is defined in this thesis.

Chapter three provides a summary of the relevant research that this study draws on. The chapter begins by defining the built environment, followed by an overview of the research that has been conducted by the health sector. Next, the chapter delves into the association between social capital and the built environment, specifically four features: walkability, neighbourhood design, density, and the presence of local amenities. The chapter proceeds to define third places and provides an overview of third place theory as articulated by Oldenburg (1989). The chapter ends with the thesis' research questions.

Chapter four explains the methodological approach of this thesis and how and where the research took place. This chapter begins with the epistemological approach and research setting of this thesis followed by an overview of the research design, methods of data collection and statistical analyses used to answer the key questions of this study.

Chapter five presents the results of this thesis. The chapter is ordered in accordance with the order of this thesis' research questions. The initial section of the chapter presents the demographics of respondents, followed by the results of research questions one, two and three. 
Chapter six compares the findings of this thesis with those found in related literature. The relevance of this thesis for policy and practice is discussed, followed by the limitations of this study. Potential considerations for future research are provided.

Chapter seven concludes the thesis with a concise summary of its key objectives and findings. 


\section{Chapter two: Conceptual Framework}

\section{Introduction}

This research is interested in the social role and importance of third places in a neighbourhood and their association with social capital. The chapter begins with an introduction to social capital and its theoretical foundations, including a brief overview of the theories put forward by the three most influential social capital theorists: Pierre Bourdieu, James Coleman and Robert Putnam. Next, this chapter discusses the various dimensions (bonding/bridging and structural/cognitive) and levels (micro, meso, and macro) of social capital that are important for any researcher to consider when refining their own conceptualisation of the concept. As this research is concerned with the perceptions of residents in a neighbourhood, this chapter explains and provides justification for focusing on the micro-level dimensions of social capital, including bonding social capital and cognitive social capital. This chapter then provides an overview of how this research will conceptualise social capital, which is specifically through a community psychology lens. A brief discussion on community psychology and its key principles are then provided. Finally, this chapter ends with an overview of two of the four dimensions of social capital, as defined by Perkins and Long (2002): SoC and neighbouring, which are the main dependent variables investigated in this research.

\section{Social capital}

Social capital is a contested social science concept as there is an assortment of definitions in the academic literature (Wood \& Giles-Corti, 2008). The origin of the concept is credited to different scholars however, in his popular book Bowling Alone: The Collapse and Revival of American Community, Robert Putnam (2000) identified Louis Hanifan as the first author to use the term. This recognition has since been generally accepted (DeFilippis, 2001). Hanifan originally used the concept of social capital to describe the social role of community schools and local developments facilitated by social meeting places in the United States (Peoples, 2015). Hanifan (1916) described it as representing good will, fellowship, sympathy, and interaction between a group of individuals and families who make up a social unit (Aldrich \& Meyer, 2015;

Pooley, Cohen \& Pike, 2005). Hanifan's use of social capital as a theoretical concept in the early $20^{\text {th }}$ century did not trigger any further academic interest, and some argue that the term nearly disappeared (Woolock \& Narayan, 2000). There were a few exceptions. For example, Jane Jacobs (1961) used the term in her celebrated title The Life and 
Death of Great American Cities, where she applied it to urban life in the 1960s describing social networks as a city's irreplaceable social capital (Westlund, 2006; Wood \& Giles-Corti, 2008; Woolcock, 1998). Homans, an exchange theorist also used 'social capital' to extend the economic concept of physical capital, and Loury, an economist used it to criticise the neoclassical theories of racial income equality (Portes, 1998).

\section{Social capital theory}

There was a rediscovery of 'social capital' in the latter half of the $20^{\text {th }}$ century with the release of seminal works by Pierre Bourdieu, James Coleman, and Robert Putnam. Influenced by the work of these three scholars, social capital research exploded and has since been adopted by several academic disciplines, including in sociology, psychology, economics, political sciences, anthropology, development studies, education and health (Wood, Giles-Corti \& Bulsura, 2012). Social capital research is now also conducted in a range of settings and systems including in education, government, families, business and voluntary organisations (Pooley et al., 2005). Because of its use in a variety of academic disciplines and settings, social capital theory does not have 'clear-cut' assumptions that are acknowledged and accepted universally. An explanation for what has caused social capital to be a diversely applied concept is the disparate theoretical contributions that were made by its founding scholars.

\section{Pierre Bourdieu's social capital theory}

The first systematic contemporary analysis of social capital was made by Pierre Bourdieu (Portes, 1998). Bourdieu conceptualises social capital as one of four types of capital, in addition to economic, cultural and symbolic capital (Aldrich \& Meyer, 2015). Bourdieu is concerned with social capital's ability to generate economic resources, where he defined it as "the aggregate of the actual or potential resources that are linked to a possession of a durable network of more of less institutionalised relationships of mutual acquaintance or recognition" (in Aldrich \& Meyer, 2015 p. 256). For Bourdieu, the main reason for individuals to engage in and maintain links in a social network is that it provides access to a group's resources (Tzanakis, 2013; Winter, 2000). Central to Bourdieu's theory was that the amount of social capital an individual has is impacted by their power and position in social networks (Peoples, 2015). Portes (1998) summarised Bourdieu's version of social capital as comprised of two central claims, where 1) it is the social relationship itself that gives people access to resources held by their associates, and 2) it is the quantity and quality of those resources. Bourdieu thereby believed that social capital is a resource held by an individual. 


\section{James Coleman's social capital theory}

James Coleman is often credited as another important contributor to social capital theory as he used the concept throughout much of his work to understand the relationship between educational achievement and social inequality (Baron, Field \& Schuller, 2000). Coleman constructs a very similar theoretical understanding of social capital to Bourdieu however, he uses different terminology to define it, uses it for different purposes, and operates within a different theoretical tradition (Winter, 2000). Coleman defines social capital as "a particular kind of resource available to an actor, comprising of a variety of entities which contain two elements: they all consist of some aspect of social structures, and they facilitate certain actions of actors within the structure" (Baron et al., 2000, p. 214). Coleman argues that the resources endowed by social capital might also be shaped by the level of reciprocity (including trust), information channels and flow of information, and norms enforced by sanctions (Bhandari \& Yasunobu, 2009). Coleman's argument operates as “if person A does something for person B and trusts B to reciprocate in the future, this establishes an expectation in person A and obligation on the part of person B" (Winter, 2000 p. 3). Like Bourdieu, Coleman believes social capital to be a resource that is accessible to an individual in pursuit of certain interests or goals (Adler \& Kwon, 2002). The way Winter (2000) explains it, Bourdieu is interested in social capital as a resource to economic capital for individuals, whereas Coleman is interested in social capital (found in family and community networks) as a resource to human capital for individuals.

\section{Robert Putnam's social capital theory}

Arguably, Bourdieu and Coleman initiated the beginning of social capital research and theory development. However, Robert Putnam and his study of democratic institutions in Italy and the perceived decline of civic engagement in America escalated its popularity significantly (Baron et al., 2000; Winter, 2000). Putnam defines social capital as the features of social life, such as the networks, norms, and trust that facilitate action and cooperation for mutual benefit (Aldrich \& Meyer, 2015). These three features ('networks', 'norms' and 'trust') now dominate contemporary conceptual discussion (Baron et al., 2000). Winter (2000) argues that although the terminology shifts somewhat, Putnam's definition essentially follows Coleman's conceptualisation of social capital as the networks and norms that facilitate collective action. In contrast to Bourdieu's and Coleman's interpretation of social capital as a resource primarily for the individual, Putnam elevated it to a feature of large population aggregates (Tzanakis, 2013). For example, Bourdieu did not discuss social capital as a resource of 
communities and Coleman did not place major emphasis on it in his work. However, Putnam's major focus was on group-level social capital, conceptualised as cooperative relationships leading to democracy and membership with civic groups (Pooley et al., 2005).

\section{A common link between the three founding social capital theorists}

Winter (2000) argues that the conceptualisations of social capital by Bourdieu, Coleman and Putnam overlap and that social capital is effectively a resource (whether of the individual or group) for collective action. Andriani (2013) argues that all three present a common view that the interactions between people make possible the production and maintenance of this social asset. The key difference in their theories is that they employ the concept of social capital to understand different types of collective action and conduct their analyses on different social scales (Winter, 2000). Bourdieu was concerned with the ability of social capital to generate economic resources, Coleman focused on the structure of social relationships, and the acquisition of human capital in the form of education, and Putnam considered social capital in terms of cooperative relationships leading to democracy and membership with civic groups (Pooley et al., 2005; Stone, 2001). Table 1 summarises this differentiation (adapted from Winter, 2000).

\begin{tabular}{llll} 
& Definition & Purpose & Analysis \\
\hline Pierre Bourdieu & $\begin{array}{l}\text { Resources that } \\
\text { provide access to } \\
\text { group goods }\end{array}$ & $\begin{array}{l}\text { To secure } \\
\text { economic capital }\end{array}$ & $\begin{array}{l}\text { Individuals in class } \\
\text { competition }\end{array}$ \\
\hline James Coleman & $\begin{array}{l}\text { Aspects of social } \\
\text { structure that actors } \\
\text { can use as } \\
\text { resources to }\end{array}$ & $\begin{array}{l}\text { To secure human } \\
\text { capital }\end{array}$ & $\begin{array}{l}\text { Individuals in } \\
\text { family and } \\
\text { community settings }\end{array}$ \\
& $\begin{array}{l}\text { achieve their } \\
\text { interests }\end{array}$ & \\
\hline Robert Putnam & $\begin{array}{l}\text { Trust, norms and } \\
\text { networks that } \\
\text { facilitate } \\
\text { cooperation for } \\
\text { mutual benefit }\end{array}$ & $\begin{array}{l}\text { To secure effective } \\
\text { democracy and }\end{array}$ & $\begin{array}{l}\text { Regions in national } \\
\text { settings }\end{array}$ \\
& & \\
\end{tabular}

Table 1: Overview of social capital theories (adapted from Winter, 2000 para. 26).

\section{The multi-faceted nature of social capital}

In addition to the different theoretical conceptualisations, social capital also has different dimensions and levels of analysis (Bhandari \& Yasunobu, 2009). The most common dimensions of social capital are 'bonding and bridging' and 'structural and cognitive' that are summarised below. Social capital can also exist at different levels 
including at the micro-, meso-, and macro-level, which demonstrates that social capital can be defined, operationalised, and measured in a wide range of ways (Bhandari \& Yasuobu, 2009).

\section{Bonding vs. bridging social capital}

Bonding social capital consists of trust and reciprocity in close networks and helps the process of 'getting by' in daily life (Stone, 2001). While social capital can build strong ties, it can also lead to the exclusion of those who do not qualify or fit into a group (Baron et al., 2000). Bridging social capital on the other hand, helps the process of 'getting ahead' as it consists of multiplex networks which may make more accessible the resources and opportunities which exist in one network to a member of another (Stone, 2001). Authors, such as Bourdieu focus on bridging ties and view social capital as a resource that is generated from a social tie to a focal actor in a social network (Adler \& Kwon, 2002). For example, the actions of individuals (and groups) can be heavily influenced by their direct and indirect links to other people in social networks (Adler \& Kwon, 2002). In comparison, authors of the bonding view of social capital (such as Coleman and Putnam) argue that the social capital of a group is not so much in the group's external ties to people as it is instead the links between individuals or groups within its internal structure (Adler \& Kwon, 2002). Bonding social capital is found in horizontal links between people who share similar characteristics from homogeneous social groups; for example, family members, neighbours, close friends and work colleagues (Baldwin \& King, 2018; Grootaert, Narayan, Jones \& Woolcock, 2004). Bridging social capital is found in vertical links between groups of people who have very different characteristics from each other (Claridge, 2004; Grootaert et al., 2004). The distinction between bonding and bridging social capital is prevalent in academic discourse because authors use it to more thoroughly conceptualise the terms (Claridge, 2004). For example, Patulny and Svendsen (2007) argue that there is an empirical lag in research because researchers do not properly distinguish between bonding and bridging types of social capital. This thesis is concerned with individuallevel perceptions in a neighbourhood, and it will thus focus primarily on bonding social capital because 1) a neighbourhood is a homogenous social group made up of individuals who share similar socioeconomic characteristics, and 2) the intention is to make a useful empirical contribution to the literature.

\section{Structural vs. cognitive social capital}

The second dimension of social capital includes structural and cognitive social capital (Claridge, 2004; Nordstrom, 2015). Structural social capital refers to the ways in which 
individuals organise themselves on a social level through networks, patterns of civic engagement, institutions and associations (Baldwin \& King, 2018; Sanyal \& Routray, 2016). Structural social capital is specifically concerned with network size, diversity, and density to access information and power (Nordstrom, 2015). Some authors argue that the bonding and bridging dimensions of social capital are part of the structural dimension (Baum \& Ziersch, 2003). On the other hand, cognitive social capital focuses on an individual's experiences of their social environment (Nordstrom, 2015).

Cognitive social capital focusses on values, beliefs, attitudes, and behavioural norms that predispose people towards mutually beneficial collective action (Baldwin \& King, 2018; Claridge, 2004; Krishna \& Shrader, 1999). Research on cognitive social capital has largely been conducted in the psychology discipline where studies focus on the element of 'trust' that is a person's perceptions of the trustworthiness of the social environment (Moore \& Kawachi, 2017). Scholars argue that the cognitive form of social capital does not make much sense without the structural form, and that both dimensions are interwoven and complementary (Baldwin \& King, 2018). This thesis focusses on cognitive social capital as people's perceptions of their social and built environments is key to this thesis's research questions.

\section{Levels of analysis: micro-, meso- and macro-}

Another distinction that enables researchers to narrow their focus of social capital is by the breadth of its unit of observation (Grootaert \& van Bastelaer, 2002). In a review of the literature, Bhandari and Yasunobu (2009) identify that social capital can be analysed at the micro-, meso-, or macro-level. Social capital at the micro level focuses on both the cognitive and structural elements of social capital, specifically the nature and forms of cooperative behaviour, including the norms, values, and networks of horizontal relationships among individuals, households and neighbours (Bhandari \& Yasunobu, 2009; Grootaert \& van Bastelaer, 2002). Social capital at the meso level focuses on structural social capital and the structures that enable cooperation such as the networks of vertical and horizontal relationships that facilitate interactions among groups, communities, institutions and organisations (Bhandari \& Yasunobu, 2009). Social capital at the macro level focuses on the conditions (positive or negative) for cooperation, such as the formalised institutional relationships and structures that govern the political regime, civil society, the rule of law and government (Bhandari \& Yasunobu, 2009; Grootaert \& van Bastelaer, 2002). It is important to acknowledge that social capital can manifest and be shaped and destroyed at all levels of the social structure by individuals, families and groups, and broader system determinants such as 
public policy, economics, politics and the physical environment (Wood, 2006). The levels of social capital can complement each other, especially when national institutions provide an enabling environment in which local groups or associations can develop (Grootaert \& van Bastelaer, 2002). In saying this, local forms of social capital can develop because of both 'good' and 'bad' government (Grootaert \& van Bastelaer, 2002). This thesis is concerned with the perceptions of individuals residing in neighbourhoods (and bonding and cognitive social capital) therefore the level of analysis in this research will be at the micro level. While this thesis does not analyse social capital at a level beyond that of the micro, it is acknowledged that certain factors and power dynamics at the macro and meso levels can shape how social capital is manifested at the micro level.

\section{Conceptualisation of social capital in this thesis}

Most contemporary authors recognise the difficulties in defining social capital, so it is very common to find articles that include a discussion of the concept's intellectual origins and an acknowledgement of how it is diversely applied (Adam \& Roncevic, 2003). The section above has attempted to articulate the complexities, differing conceptualisations, and multifaceted nature of social capital as a theoretical concept. Most contemporary definitions of social capital have evolved from one of the three main theories postulated by Pierre Bourdieu, James Coleman and Robert Putnam however, these theories in themselves are heterogeneous as many scholars writing within their specific school of thought have adapted their own variations (Adam \& Roncevic, 2003; Wood \& Giles-Corti, 2008). For epistemological reasons it has been argued that it is not possible to devise a single concept of social capital (Adam \& Roncevic, 2003). Considering this, most definitions used in academic literature are different however, all include networks, norms and trust, and some reference to mutual goals or benefits as core ingredients (Wood \& Giles-Corti, 2008). The ongoing confusion as to what is meant by social capital has eventuated in contemporary conceptualisations that often reflect the bias of the disciplinary orientation of the authors (Pooley et al., 2005).

\section{A community psychology perspective of social capital}

Wood (2006) argues that researchers who operationalise social capital need to clearly locate the concept within a specific framework or context of analysis, and acknowledge the definitional perspective taken. Researchers who have explored the relationship between social capital and the built environment come from a range of academic 
disciplines and conceptualise the term differently. This research acknowledges that social capital can exist in many forms and manifestations that defy a simple conceptualisation. Subscribing to an existing definition in the literature may not capture the complexities and intricacies of the wider debate and re-inventing a definition would only add to the myriad of conceptualisations already available.

Considering this, this research will not strictly subscribe to a definition of social capital however, it will be guided by its conceptualisation in community psychology.

Community psychology is generally understood as the study of the relationship between social systems and individual wellbeing in the community context (Hanlin, Bess, Conway, Evans, McCowen, Prilleltensky \& Perkins, 2008). As a discipline, it is concerned with understanding the factors that impact upon individuals' health and wellbeing and how to promote those (positive) outcomes (Hanlin et al., 2008). The central idea of community psychology is that people's functioning, including their health, can only be understood by appreciating the social contexts within which they are placed (Orford, 2008). A community psychology perspective on social capital is useful in this research because a large proportion of research looking at the nexus between the built environment and 'social outcomes' in a neighbourhood has been measured by psychological concepts. For example, community psychologists have studied many integrally linked cognitions and behaviours such as social support, empowerment, SoC, citizen participation and neighbourliness, and their relationship with the built environment (Perkins \& Long, 2002; Saegert \& Carpiano, 2017). These 'cognitions' and 'behaviours' are very similar to components of individual-level measures of social capital, including the bonding and cognitive dimensions. Furthermore, ideas in community psychology theory at the micro (or individual) level can enrich sociological and community development uses of social capital at the meso and macro levels (Saegert \& Carpiano, 2017).

Perkins and Long (2002) are the most widely-cited community psychologists who operationalise social capital. This research will be guided by their definition of social capital that is the "norms, networks, and mutual trust of 'civil society' facilitating cooperative action among citizens and institutions" (Perkins \& Long, 2002, p. 291). As shown in Table 2, the authors argue that social capital is made up of four distinct components: 1) SoC or trust in one's neighbour, 2) empowerment or the efficacy of organised collective action, 3) neighbouring behaviour, and 4) participation in community organisations (Perkins \& Long, 2002). Only the informal dimensions of 
Perkins and Long's (2002) definition of social capital (SoC and neighbouring behaviour) will be measured in this research because the principal aim of this research is to examine third places as informal gathering places (which will be discussed in chapter three). An overview of SoC and neighbouring behaviour as measures of social capital is provided in Table 2 .

\begin{tabular}{l|l|l|}
\multicolumn{1}{l}{ Cognition/Trust } & \multicolumn{1}{l}{ Social Behaviour } \\
\cline { 2 - 3 } Informal & Sense of community & Neighbouring \\
Formally & Collective efficacy & Citizen participation \\
Organised & & \\
\hline
\end{tabular}

Table 2: Perkins and Long (2002) four dimensions of social capital, p. 294).

\section{Sense of Community}

SoC is a popular concept in community psychology first defined by Sarason (1974) and then refined and extensively developed by McMillan and Chavis (1986). Sarason originally defined the concept as "the sense that one was part of a readily available mutually supportive network of relationships" Sarason (1974, p. 1). Sarason (1974) argued that the basic characteristics of SoC includes the perception that one is like other people, has an interdependence with other people, has a willingness to maintain an interdependence by giving to other people, and has the feeling that one is part of a larger dependable and stable structure (Obst, Smith \& Zinkiewicz, 2002). SoC is concerned with how individuals are connected to and influenced by their most important social settings and is used by researchers to understand how individuals relate to their communities (Kingston, Mitchell, Florin \& Stevenson, 1999). The popularity of SoC as a conceptual tool has been attributed to its implications for planning and social intervention evaluation, as it has been used in several indexes of quality life and individual wellbeing (Mannarini, Tartaglia, Fedi \& Greganti, 2006). Researchers have associated $\mathrm{SoC}$ with various prosocial behaviours including life satisfaction, perception of safety and security, and social and political participation (Kingston et al., 1999; Mannarini et al., 2006). At the neighbourhood level, researchers have associated SoC with fear of crime, neighbourhood attachment, community involvement, and improved community problem coping skills (Wood, 2006). Some researchers argue that the application of SoC is not limited to a geographical region and extend to include religious organisations, high schools, universities, and treatment programs (Francis et al., 2012; Kingston et al., 1999). 
Sarason's (1974) introduction of the concept prompted many researchers to theorise about and debate the dimensions that underlie the construct which led to the development of several measurement scales (Obst et al., 2002). Like social capital, the literature on SoC has proliferated however this has led to methodological confusion and a lack of strong theory building of the concept (Obst et al., 2002). However, the conceptualisation of SoC by McMillan and Chavis (1986) is the primary theoretical anchorage for most studies on SoC (Mannarini et al., 2006). McMillan and Chavis (1986) define SoC as consisting of four elements: membership, influence, reinforcement, and shared emotional connection (Obst et al., 2002). Membership refers to the sense of feeling part of a group (Lochner, Kawachi \& Kennedy, 1999); influence, is a refers to sense that the individual matters to the group, and that the group can influence its members, thereby creating cohesiveness through community norms (Lochner et al., 1999); reinforcement is that for a group to maintain a strong sense of togetherness, the individual-group association must be rewarding for its members (Chavis, Hogge, McMillan \& Wandersman, 1986); and finally, a shared emotional connection that is a sense of feeling connected to the shared history in the community (Lochner et al., 1999).

Perkins and Long (2002) argue that concepts and research from community psychology can inform community development practice by reframing social capital theory. It must be noted that some scholars have indicated that SoC should be viewed as a

psychological construct and a correlate of social capital (e.g. Pooley et al., 2005), while others conceptualise SoC as part of an individual's social capital (e.g. Perkins et al., 2002). In saying this, whatever the chosen perspective, SoC is like social capital in that it is a systems level conception and is concerned with the processes and attachments that exist between people and their social milieu (Wood, 2006). The complexity of defining and operationalising social capital has meant that the relationship between social capital and SoC has also not been well documented (Xu, Perkins \& Chow, 2010). Regardless, both social capital and SoC are useful indicators that can be used to predict community social participation (Xu et al., 2010). This thesis is guided by Perkins and Long (2002)'s conceptualisation of social capital therefore SoC is conceptualised as an informal component of an individual's social capital.

\section{Neighbouring}

Another dimension of Perkins and Long (2002)'s social capital that is measured in this research is neighbouring. Neighbouring refers to informal mutual assistance and 
information sharing among neighbours that help residents become better acquainted and encourage them to discuss shared problems (Perkins \& Long, 2002). A popular conceptualisation of neighbouring is that of Unger and Wandersman (1985). They define it as "the social interaction, the symbolic interaction, and the attachment of individuals with the people living around them and the place in which they live" (Unger \& Wandersman, 1985, p. 141). The extent to which residents are willing to greet and visit one another can serve as a source of social belonging and lessen feelings of social isolation (Unger \& Wandersman, 1985). Concrete examples of neighbouring behaviour include borrowing or lending tools, informal visiting, and asking for help in an emergency (Unger \& Wandersman, 1985).

Neighbouring is often measured by the frequency of social interaction individuals have with those who live around them and in their neighbourhood. There are two components of neighbouring: 1) social networks and 2) social support that are distinctively different and are discussed in more detail below because they are measured (as components of neighbouring) in this research. Both social support and social networks are important resources for coping with stressors, promoting psychological adjustment, and improving the quality of life (Unger \& Wandersman, 1985).

\section{Social networks}

Social networks refer to an individual's connection to others without regard to the supportive content of the ties (Unger \& Wandersman, 1985). Social networks are an example of structural social capital and are used to describe or measure social relationships, linkages, or patterns of ties, and the flow of resources between individuals (Unger \& Wandersman, 1985). The social network of individuals in a neighbourhood provide access to resources which are important for both individual-level wellbeing and for the internal functioning of the neighbourhood itself (Unger \& Wandersman, 1985).

\section{Social support}

Social support refers to the multiple resources that are provided by the supportive interpersonal relationships among neighbours, including personal/emotional, instrumental, and informational (Unger \& Wandersman, 1985). There are two types of personal/emotional support: sociability and socioemotional. Sociability can be described as the casual interaction between neighbours that does not have to involve a transfer of goods or services or obligations of reciprocity and requires a low level of acquaintanceship (Unger \& Wandersman, 1985). Socioemotional support refers to the intimate relationships (such as friendship) which have been associated with 
neighbourhood satisfaction and attachment (Unger \& Wandersman, 1985). Secondly, instrumental support refers to the informal help mainly provided in the short term and in the case of emergencies (Unger \& Wandersman, 1985). Thirdly, informational support refers to the act of neighbours providing each other information as they interact. For example, neighbours serve as information and referral sources for parents looking for family day-care or when providing each other with up to date information on activities or events going on (Unger \& Wandersman, 1985).

\section{The neighbourhood}

This final section of the chapter discusses the meaning of the neighbourhood and justifies why it is used as the place of research in this thesis.

\section{Definition}

There is no universal way to define neighbourhood however, traditionally it has been characterised as a social area, communal living space, or natural unit within both urban and rural settings (Jenks \& Dempsey, 2007; Whitehead, 2003). A city's neighbourhoods range in diversity, with variations in their size, geography and socioeconomic status of residents however, internally those neighbourhoods are very homogeneous (Banwell, 2017). Volker, Flap and Lindenberg (2006) argue that people chose to reside in areas with people of similar demographics, and assert the idea that neighbourhoods are more homogenous in term of race, ethnicity, and socioeconomic status than cities and countries. The most common interpretations of the neighbourhood are either as a physical construct (used to describe the area in which people live) or as a social construct (used to describe the people who live there) (Jenks \& Dempsey, 2007). Conceptualising the neighbourhood as a physical site means that it is defined by its 'fixed boundaries' such as a postal code or census data (Jenks \& Dempsey, 2007). The conceptualisation of a neighbourhood as a physical unit has been very popular in geography and urban planning literature. However, critics argue that it is a narrow geographical definition used often for research or administrative purposes, and the use of such boundaries may have little bearing on the definition of the neighbourhood according to residents or other stakeholders (Banwell, 2017; Freiler, 2004; Jenks \& Dempsey, 2007). Alternative interpretations of the neighbourhood from urban ecology, behavioural science and psychology focus on its social fabric, stressing that they do not pre-exist as physical entities before they are constituted as social objects (Whitehead, 2003). Banwell (2017) states that neighbourhood boundaries are best determined by the individuals who live in them, according to their perceptions and feelings about where they live and the relationships that they have with that site. Those that conceive the 
neighbourhood as a social construct, argue that neighbourhoods do not always have objective features that are experienced and/or perceived by residents in the same capacity (Freiler, 2004). The distinctiveness and identity of a place is most meaningfully defined by those who live there (Jenks \& Dempsey, 2007). This research defines the neighbourhood as a social object with social, symbolic and physical boundaries that are defined subjectively by the individuals who live within them.

\section{Why focus on the neighbourhood?}

Interest in understanding the importance of place-based communities, such as neighbourhoods has gained traction in recent decades. French et al. (2014) argue that even though trends in globalisation, communication, and mobility have challenged the notion of 'local community', individuals are increasingly looking for local belonging and identity in a modern and variable world. Resources within the neighbourhood will always serve a function for less mobile residents such as people working from home, the elderly, parents of young children, single car households, and the socioeconomically disadvantaged (Francis et al., 2012). In addition, having others that live nearby provides for unique opportunities for social interaction and support, such as collecting mail, watching children in emergencies, or surveillance of people's homes (Francis et al., 2012). As a physical site, the neighbourhood allows residents to perform the duties of their everyday life (e.g. shopping), access community support services and institutional resources (schools and libraries), and demonstrate informal surveillance and social control (Freiler, 2004). Interest in the neighbourhood has also grown because of how its social and physical environments can influence the physical and mental health of its residents (Francis, 2010). It is generally acknowledged that the chances of meeting fellow residents increase when people spend more time in their communities (van den Berg, Aretze \& Timmermans, 2015). This is important because individuals who are actively involved and socially engaged with members of their communities are more likely to live longer and be physically and mentally healthier (Leyden, 2003). The neighbourhood can also offer a sense of familiarity and security to the individuals who live within them (Power \& Wilson, 2000).

\section{Justification for using social capital as a conceptual framework}

The benefits of social capital have been examined in at least eight separate fields of inquiry: child welfare, schooling and education, community life, work and organisations, democracy and governance, economic development, criminology, and public health (Baldwin \& King, 2018; Kawachi \& Berkman, 2000). At the neighbourhood level, cognitive social capital can increase feelings of security and self- 
esteem within communities and between them (Harpham et al., 2002). In addition, neighbourhood social capital has been associated with a variety of outcomes relating to community life including, reduced rates of violent crime, delinquency, decreased fear of crime, and increased neighbourhood stability (Oidjarv, 2018). It has been argued that neighbourhoods with high levels of social capital provide mutual support and surveillance and are more likely to be effective in resisting 'not in my backyard' type collective actions or organising against local environment hazards (Jones \& Shen, 2014; Veenstra, Luginaah, Wakefield, Birch, Eyles \& Elliot, 2005). High levels of social capital in the neighbourhood have also been linked to a reduction in risk of a variety of health problems (such as obesity) and an overall improvement in individual and community health (Oidjarv, 2018). Campbell, Wood and Kelly (1999) found that neighbourhoods with bigger networks and higher levels of civic engagement had better health outcomes. Neighbourhoods that have high levels of social capital are also more able to exercise social control over deviant health behaviours, such as smoking and alcohol abuse (Poortinga, 2006). Social capital has also been positively associated with a community's quality of life and development. Social capital can generate a variety of local resources that residents can individually and collectively draw on for practical and emotional support (Du Toit et al., 2007). For example, research examining the recovery of communities following a natural disaster found that neighbourhood social networks provided financial support such as loans/gifts for property repair, and non-financial resources such as search and rescue, debris removal, and emotional support (Aldrich \& Meyer, 2015).

\section{Summary}

If the presence of social capital in the neighbourhood has various individual and community outcomes for residents, and if Woolcock's (2001) assumption that "the well- connected are more likely to be hired, housed and happy" (p. 68) then the question arises as to how neighbourhood social capital manifests. Research suggests that the presence of social capital in the neighbourhood can depend on the sociodemographic characteristics of its residents however, a growing body of literature has shown that other contextual aspects of a community's environment may shape social capital in a way independent of demographic variables (Wood et al., 2012). For example, studies have found that differences in neighbourhood social capital remained after adjusting for age, gender, marital status, race and other socioeconomic factors (Wood et al., 2012). Research exploring other contextual aspects of a community's environment emerged in the late 1990s, and a multitude of environmental factors including the built environment 
were identified as having a significant influence on social capital in the neighbourhood (Mohnen, Volker, Flap, Subramanian \& Gronewegen, 2015; Wood et al., 2008).

Chapter three explores the relationship between social capital and the built environment in more detail. 


\section{Chapter three: Literature Review}

\section{Introduction}

This chapter begins with a definition of the built environment and why it is an important feature of a neighbourhood. The initial section of this chapter emphasises health outcomes that have been linked to the built environment of a neighbourhood and how these outcomes are indirectly facilitated by social capital. The next section of this chapter provides a brief overview of the empirical research that has investigated the association between the built environment and social capital. This is followed by a detailed breakdown of the four main features of the built environment that have been explored in the literature: walkability, neighbourhood design (street connectivity and land use), density, and the presence of local amenities. It is acknowledged that many of the built environment's physical features complement one another, and there is no 'one' feature that builds (or erodes) social capital in a neighbourhood. However, to narrow this research down, only one feature of the built environment will be empirically assessed, which is local amenities. This decision resides on the fact that we do not know enough about how individuals use urban spaces in their neighbourhoods and how these can foster social capital and cohesion in a New Zealand context. Oldenburg and Brissett (1982)'s conceptualisation of local amenities as 'third places' is operationalised in this research, and the last section of this chapter includes a discussion of the concept and a definition that will be used in this research. Finally, this chapter ends with the identified gaps in the literature and presents the research questions that will guide this study.

\section{Definition of the built environment}

The built environment (also used interchangeably in the literature with physical environment) is broadly defined as "the way we design and build our communities and neighbourhoods" (Leyden, 2003, p. 1546). The built environment refers to features of the urban built form, including: streetscapes, housing, commercial and industrial buildings, roads, greenspace, parks and most other public and private spaces (Banwell, 2017). In addition to these physical attributes, some researchers have also included area history, traffic flow, cleanliness and maintenance of public spaces, perceptions of safety and community security, zoning and land use mix, and population density as features of the built environment (Renalds, Smith \& Hale, 2010; Wood, Shannon, Bulsura, Pikora, McCormack \& Giles-Corti, 2008). The built environment can be defined by the observable physical characteristics of a geographical area or by residents' perceptions of those physical characteristics (Araya, Dunstan, Playle, Thomas, Palmer \& Lewis, 2006). 
French et al. (2014) argue that the importance of perceptions of social capital should not be underestimated because the appearance of the neighbourhood (and its physical features) lead individuals to make inferences about their fellow residents, and this influences interactions within the neighbourhood. It is acknowledged that the built environment and its physical features are indirectly influenced by national and local political ideology, policy and planning processes (Banwell, 2017).

Over the past few decades interest in the built environment has been largely driven by concerns over the trends in the prevalence of obesity, and efforts from the planning and public health sectors to link neighbourhood features with physical activity (French et al., 2014). In a widely-cited literature review on the built environment, Renalds et al. (2010) identify that the built environment has been studied in relation to three main areas of interest: physical activity, obesity, and mental health. It has been argued that the built environment can directly impact on residents' health from overcrowding, noise, indoor air quality and light (Evans, 2003). However, relevant to this research is the indirect influence that the built environment has on health as researchers have argued that the built environment impacts on mental health by indirectly facilitating components of social capital including social support, social networks and SoC (Du Toit et al., 2007; Evans, 2003; Francis, 2010; Walsh \& LaJoie, 2018). For example, a built environment that is poorly maintained, has derelict buildings and covered in rubbish may affect the sense of social cohesion in the neighbourhood, and the combination of both may lead to poorer mental health among its residents (Araya et al., 2006). In turn, low social cohesion might lead to a poorer built environment as residents might not be interested in maintaining their common areas (Araya et al., 2006). Furthermore, poor mental health among residents may also lead to less interest in keeping up the neighbourhood and interacting with others (Araya wet al., 2006). The point to be made is that exploring the relationship between social capital and the built environment is an important topic for policymakers and planners to understand as it is central to a healthy community where people support one another in aspects of daily life and can develop to their fullest potential (Renalds et al., 2010).

\section{The association between the built environment and social capital}

The built environment and its physical features can determine the presence of social capital in a neighbourhood however, this relationship has not been widely researched (Mazumdar, Learnihan, Cochrane, \& Davey, 2018). The research that does exist in this area has focused on the effect of specific aspects of the built environment on specific 
domains of social capital (Mazumdar et al., 2018). For example, researchers have empirically tested the association of the built environment with many different components of social capital including (but are not limited to) SoC, collective efficacy, social cohesion, social ties, place attachment, and social interaction. Wood and GilesCorti (2008) thematically break down the literature on social capital and its relationship with the built environment into three categories: studies of the relationship between social capital and macro level environmental trends (including crime, and neighbourhood stability); meso-level exploration of the relationship between social capital and aspects of neighbourhood context or design; and micro-level investigations of the nexus between social capital and specific neighbourhood attributes and features. There are a variety of features of a neighbourhood's built environment that can influence social capital however, the most commonly studied features are: density, walkability, pedestrian friendly design, and local amenities/third places (Banwell, 2017; Scott, Dolan, Banwell, Witten \& Kearns, 2015). Additional features of the built environment that have been explored include: the presence of incivilities (Chavis et al., 1986; Perkins), housing design (Cattell, 2001), openness of house frontage to street (Plas \& Lewis, 1996), access to nature and outdoor spaces (Francis et al., 2012; Hanibuchi, Kondo, Nakaya, Shirai, Harai \& Kawachi, 2012; Nasar \& Julian, 1995). The section below discusses the research conducted on the four most commonly studied features.

\section{Neighbourhood walkability}

Walkability is a measure of how easy it is for residents to go for walks, and to walk or cycle to destinations (Banwell, 2017; Scott et al., 2015). The walkability of a neighbourhood can increase opportunities for local social interaction and the development of a SoC among residents (Du Toit et al., 2007). This assumption is based on the idea that more walkable neighbourhoods increases the chances of residents bumping into one another and contribute to feelings of safety (Banwell, 2017). Studies have found that more walkable neighbourhoods promote frequent social interactions, social networks, and a SoC (Scott et al., 2015). In a widely cited study, Leyden (2003) empirically tests whether the walkability of a neighbourhood affects the degree to which people are involved in their communities and with each other. Leyden (2003) found that individuals who live in walkable mixed land-use neighbourhoods reported higher levels of social capital compared to those living in car-oriented neighbourhoods. Leyden (2003) found that those who live in more walkable neighbourhoods were more likely to 
know their neighbours, participate politically, trust others and be socially engaged (Leyden, 2003).

Wood et al. (2010) conducted a study examining the relationship between SoC, walking and neighbourhood design characteristics and found that $\mathrm{SoC}$ is enhanced by living in geographical areas that encourage leisure walking. In a similar study, French et al. (2014) tested the influence of walkability on SoC and found that SoC was positively associated with walking for transport. The authors also found that perceiving the neighbourhood to be safe, seeing neighbours when out, and having local interesting sites in the neighbourhood have been positively associated with SoC (French et al., 2014). Wood et al. (2008) also found that residents who perceive their neighbourhood walking environment to be safe and interesting were more likely to rate their SoC highly. While it may seem intuitive that a more walkable built environment would lead to higher levels of social capital, evidence to date is mixed and inconclusive (Du Toit et al., 2007; French et al., 2014). In their study of neighbourhood determinants of social capital among older adults in Japan, Hanibuchi et al. (2012) found that neighbourhood social capital was consistently more likely to be linked to the broader historical and geographic context of a particular neighbourhood than to features of the built environment - specially measured by walkability. Nasar (2003) also found that, although higher-density and mixed-use developments (two key walkability features) were associated with lower rates of car use, no evidence was found that this increased SoC (Du Toit et al., 2007).

\section{Neighbourhood design: street connectivity and land use}

The design of a neighbourhood influences the opportunities for individuals to meet one another (Banwell, 2017). As a feature of neighbourhood design, its layout can help bring residents together because street patterns can influence how individuals move and interact with others in the neighbourhood (Banwell, 2017). In their recent literature review on the association between social capital and the built environment, Mazumdar et al. (2018) found that most research examining the relationship between street network design and social capital is predominately from the urban design discipline. Mazumdar et al. (2018) identifies studies that found neighbourhoods who had traditional 'grid' street networks have higher $\mathrm{SoC}$ and residents having more social contacts. In saying this, their review also found a study that showed no relationship between street design and social capital (Mazumdar et al. (2018). Furthermore, evidence is mixed as Wood et al. (2012) found that people who lived in neighbourhoods with conventional street 
networks (characterised by cul-de-sacs) have higher social capital than those who live in those with mixed or traditional street networks.

As another feature of neighbourhood design, mixed land use planning has been shown to promote walking behaviour and this in turn can increase SoC (Leyden, 2003). In saying this, Wood et al. (2010) found that mixed-land use has a negative relationship with SoC. The authors argue that it could be explained by the 'outsider or stranger' hypothesis where the greater the land use mix, especially, the presence of more retail and commercial areas, the more likely there will be an increase in strangers visiting the area (Wood et al., 2010). Residents of that particular neighbourhood may report lower levels of SoC because they feel less 'at home' in their neighbourhood (Wood et al., 2010). An increased density of retail or commercial areas is also associated with more traffic and congestion (Wood et al., 2010). It has been empirically proven that residents who live on busy roads are less likely to know their neighbours, suggesting that the presence of traffic and strangers means residents are less likely to spend time on the street and socially interact with others (Appleyard, 1981). French et al. (2014) found that perceived street connectivity was positively associated with $\mathrm{SoC}$ in the neighbourhood however, similar to Wood et al. (2010) the authors found that the perceived presence of traffic hazards were negatively associated with SoC (French et al., 2014).

\section{Neighbourhood density}

Mazumdar et al. (2018) also identify twelve studies that explore the relationship between density and social capital. It is generally acknowledged that the overall relationship between social capital and density is negative (Mazumdar et al., 2018). In their study of the association between social capital and objective and perceived features of the built environment, French et al. (2014) found that residential density was the only objective feature to be negatively correlated with SoC. This finding was similar to that of Wood et al. (2008) who found that residential density did not predict SoC. A possible explanation for this relationship is that in lower density neighbourhoods, residents must seek out neighbours for interaction, whereas in higher density neighbourhoods, residents are exposed to frequent incidental contacts with a higher number of unfamiliar people, and in effect actively withdraw to minimise these interactions (French et al., 2014). Other studies such as Skjaeveland and Garling (1997) found that residential density was negatively associated with supportive acts of neighbouring, and Kearny (2006) found that residents with more private space were slightly more inclined to know 
and interact with other residents in their neighbourhood. Raman (2010) found that lowdensity neighbourhoods were associated with widely dispersed social networks and activities with very few strong relationships, while in high density neighbourhoods, residents had smaller social networks but stronger ties were found. Wilson and Baldassare (1996) found that privacy was positively associated with SoC in a neighbourhood, and the authors argued that privacy lowers levels of personal stress through regulation of social life and enhancing community connectedness (Francis, 2010).

\section{Neighbourhood amenities}

To account for the negative associations between high density neighbourhoods and social capital, Chu et al. (2004) argue that it is important to have 'escape' amenities or destinations available. Underpinning the claims of policymakers and practitioners to make neighbourhoods better places to live in by creating and providing for social spaces, is the belief that social interaction in the neighbourhood enhances residents' quality of life (Hickman, 2013; Jeffres, Bracken, Jian, \& Casey, 2009). The presence of local amenities in urban neighbourhoods has emerged as an important feature of active and liveable communities. Local amenities are part of the social infrastructure of a neighbourhood's built environment and include shops, parks, schools, health and community services, cafes, and recreation or cultural facilities (Banwell, 2017). These features of the built environment serve as 'meeting places' where residents can informally or formally socially interact with one another (Banwell, 2017). Empirical studies have proven that local amenities provide places for residents to meet and get to know one another (Scott et al., 2015). For example, Francis et al. (2012) found that the most common areas for social interaction in a neighbourhood are public open space, schools, shops, and community centres. Van den berg (2015) found empirical evidence that the likelihood of interacting with a local tie (someone based within a 1 kilometre range) is affected by the presence of facilities in a neighbourhood. Specifically, the authors found that three types of facilities in a neighbourhood: supermarkets, primary schools and outdoor sport facilities, were highly correlated with the likelihood of interacting with fellow residents. Similarly, Williams and Pocock (2010) also found that social capital in a master planned community neighbourhood was associated with the presence of centralised facilities, recreation areas, community groups and events that brought residents together. Hickman (2013) found from 180 in-depth interviews with residents from six deprived neighbourhoods in the United Kingdom that most residents valued neighbourhood social interaction, and that much of the local social interaction 
occurred in local shops or amenities. These places can also help create informal neighbouring through the availability of opportunities for casual interaction between neighbours (Wood et al., 2008). In their study of the relationship between social capital and aspects of the built environment Wood et al. (2008) found that the perceived quality of facilities and proximity to a shop were positively associated with social capital however, the number of destinations within 800 metres was negatively associated with social capital. The authors argue that it is possible that an optimum number and mix of destinations is required to increase social capital (Wood et al., 2008). Francis et al. (2012) also found a positive association between the quality of local shops and public open space with $\mathrm{SoC}$, and that perceptions of the quality of public open space was equally, if not more influential than the number or size of public space. French et al. (2014) reinforce the importance of perceptions, as in their study they found that positive perceptions of infrastructure for walking, neighbourhood aesthetics, and safety were all associated with a greater SoC. The authors argue that the importance of perceptions should not be underestimated as the appearance of neighbourhood features lead people to make inferences about residents, and this influences SoC (French et al., 2014). In a study of the relationship between bridging social ties and the built environment in a neighbourhood, Cabrera and Najarian (2015) found that residents who made use of their local shops and businesses had more spatial bridging ties than those who did not.

Research on the association between local amenities/destinations and social capital has also been linked to other features of the built environment, including accessibility and walkability. For example, Lund (2003) found that pedestrian travel is higher in neighbourhoods that have access to local amenities. Scott et al. (2015) argue that local shops, parks, and cafes that residents can walk to, instead of having to travel over major road intersections along the way, shape residents' experiences of their neighbourhood and therefore increase the likelihood of meeting and socialising with other residents in ways that enhance their individual well-being. Lund (2003) found that when combined with pedestrian-friendly street networks, the presence of local amenities in a neighbourhood can increase walking and neighbour interaction within a community. Residents who walk around their neighbourhood are also more likely to interact with and form relationships with others (Lund, 2003). Mazumdar et al. (2018) identified that most research on this topic found that increases in social capital result from better destination access, including increased knowing of neighbours, social engagement, and an increased SoC. Mazumdar et al. (2018) also claim that the majority of articles on this 
topic found the overall relationship between social capital and access to destinations to be statistically significant.

\section{Third place theory}

In their study of the relationship between four public spaces and $\mathrm{SoC}$ in residents of new housing developments in Perth, Francis et al. (2012) adopted Oldenburg's (1989) concept of 'third place'. The authors focused on public open space, community centres, schools and shops and defined them as "the meeting or gathering places that exist outside the home and workplace that are generally accessible by members of the public, and which foster resident interaction and opportunities for contact and proximity" (Francis et al., 2012, p. 402). Francis et al.'s (2012) study of SoC and public spaces has similar intentions to this research, therefore following their lead, 'third places' will be used in this research to conceptualise 'local amenities'.

In the 1980s sociologist Ray Oldenburg argued that there existed a 'social malaise' where Americans were increasingly unwilling to interact socially with others outside of home and work (Hickman, 2013). Home and the workplace are considered to be the first and second places respectively where individuals spend much of their lives (Hawkins \& Ryan, 2013). These places are inherent to everyday life while third places are the neutral places where people can socialise and relax (Hawkins \& Ryan, 2013; Laing \& Royle, 2013). The concept 'third place' was coined by Oldenburg and Brissett (1982) and came about from the authors' interest in the 'decline of American community life' and their belief that the loss of such places is the result of many individuals spending most of their time at work or home (Laing \& Royle, 2013; Slater \& Koo, 2010). In other words, Oldenburg and Brissett (1982) asserted that individuals live in a 'two-stop model of existence' where they operate between two poles of work and home, causing a loss in social relationships (Purnell, 2014).

Oldenburg and Brissett (1982) define third places as those that "exist outside the home and beyond the 'work lots' of modern economic production, and are places where people gather primarily to enjoy each other's company" (p. 269). Oldenburg argues that examples of third places include bars, coffee shops and barbers. In his 1999 title The Great Good Place, Oldenburg details some of the specific characteristics of third places including 1) they are on neutral ground. Third places must be places where individuals can come and go as they please, and places where all are welcome and no one plays host; 2) they are a leveller. By their nature, third places must be inclusive. They have to 
be accessible to the general public, and there is no set formal criteria of membership and exclusion; 3 ) conversation is the main activity. Even though the setting of the third place may be for drinking, or exercising, or activity, individuals are maintained in pleasurable and entertaining conversation (Oldenburg, 1999); 4) they are accessible. There are no "physical, policy, or monetary barriers to entrance" (Jeffres et al., 2009, p 335); there are 'regulars'; 5) they have a low profile. Oldenburg purports that third places as physical features of the built environment are often plain and ordinary looking; 6) the mood is playful. Oldenburg argues that when people visit third places they feel an "urge to revisit, reimagine, and recapture the experience of that place; and lastly 7) it serves as a home away from home, offering a friendly environment (Oldenburg, 1999).

Oldenburg attests that third places are 'essential' to community and public life as they provide health benefits, offer social interaction, are a cure against loneliness and are places where people can gauge a sense of reality through conversation (Slater \& Koo, 2010). Oldenburg claims that third places are crucial to the social well-being and psychological health of individuals and communities, and are essential to civic engagement, informal social control, grassroots democracy, and the development of cohesion and a SoC (Hawkins \& Ryan; Williams \& Hipp, 2019). Williams and Hipp (2019) argue that there are two pathways by which third places can contribute to greater levels of social capital. Firstly, third places provide the normative context for interaction between residents and secondly, they offer a means by which they can assess the trust worthiness of other residents (Williams \& Hipp, 2019). This claim was also reiterated by Scott et al. (2015) who in their literature review found that residents value having local amenities in their neighbourhoods to build and maintain loose social ties, develop trust, cooperation norms and reciprocity (Scott et al., 2015). William and Hipp (2019) also argue that third places help facilitate neighbourhood sentiment by their role in providing material and social resources and simply by acting as a symbol of place and of sociality in place (Williams \& Hipp, 2019). Oldenburg's claims are sociological, and it has been argued that his work "relies on personal experience and arguments drawn from anecdotal observation" (Williams \& Hipp, 2019, p. 68). Hickman (2013) reasserts this claim by arguing that Oldenburg's work could be criticised on multiple levels however, the most important being that it is not empirically informed. Considering this, this research will conceptualise third places as defined by Williams and Hipp (2019): 
"Third places are physical locales and normative contexts conducive to (or explicitly designed for) social interaction and sociality." (Williams \& Hipp, 2019, p. 69)."

\section{The gap in the literature}

Since Oldenburg first articulated the notion of third places, or "places conducive to social interaction and community outside of home and work, the idea has captured the imagination of scholars and the public more broadly" (Williams \& Hipp, 2019, p. 68).

For example, researchers have attempted to conceptualise third places as farmer's markets (Tiemann, 2008), as festivals (Hawkins \& Ryan, 2013), as bookshops (Laing \& Royle, 2013), as mainstream art venues (Slater \& Koo, 2010), as libraries (Lawson, 2004), as sports clubs (Mair 2009), as football stadiums and music clubs (Jacke, 2009); as homes (Purnell, 2015), and as coffee shops (Waxman, 2006). There also exists literature that is entirely focused on understanding the specific physical characteristics of third places (Mehta \& Bosson, 2010; Waxman, 2006). However, despite the popularity of the concept, empirical assessments of the role of third places in a neighbourhood remains limited (Williams \& Hipp, 2019). In addition, despite a few studies there lacks empirical evidence on the public's perception of such places, and whether they contribute to the quality of life in communities (Hickman, 2013; Jeffres et al., 2009). The British seem to dwell in pubs, the Chinese dance on the streets at dusk yet there is no obvious New Zealand equivalent, and no research has been conducted to seek this out. In light of this, this research aims to find out what places New Zealanders claim as their third place, and what is the meaning and value of these places to them. Oldenburg's seven characteristics provide a good starting point to attribute to New Zealanders third places however, his claims are arguably 'out-dated' and may not be applicable cross-culturally (from an American context to a New Zealand context). For example, a review of the literature finds that some research has attempted to challenge Oldenburg's (1999) characteristics of third places (Hawkins \& Ryan, 2013; Purnell, 2015; Slater \& Koo, 2010), some have criticised third place theory in general (Hickman, 2013; Williams \& Hipp, 2019; Yuen \& Johnson, 2017), and in context of technological change in the $21^{\text {st }}$ century, some have challenged the notion that third places are 'placebased' (Soukup, 2006).

"Despite the burgeoning literature, there are many theoretical, knowledge and intervention gaps to be filled in order to flesh out the exact nature, magnitude and pathways of the relationship between the design and attributes of physical environments 
and social capital" (Wood \& Giles-Corti., 2008, p. 160). As this chapter has highlighted, there are many features of the built environment that have been proven to have positive or negative relationships with social capital. For example, walkability and the ease that residents have to get around their neighbourhood have been shown to have a positive relationship with social capital however, high density housing has been shown to have a negative relationship. Based on the literature, the presence of local amenities or third places in a neighbourhood has been shown to have a positive statistically significant relationship with social capital. Empirical studies have found that the perceived quality, distance to/walkability and presence of third places is positively associated with social capital however, there may be an inverse relationship depending on how many third places are present in a neighbourhood. This research intends to produce consistent findings with existing literature and test perceived quality and distance/access to third places. What has not been looked at in the literature however, is whether how often residents visit their third places may also be associated with components of social capital, such as SoC and neighbouring. In light of this, this research is interested in the relationship between presence of third places in a neighbourhood with residents' perceptions of their perceived quality, distance/access to, and frequency of visitation to third places. Most of the empirical research on third places has been conducted by the urban planning field in large scale surveys where 'place' is decontextualized, or in qualitative studies that cannot generalise the findings (Williams \& Hipp, 2019). However, there are a few studies (Francis et al., 2012; French et al., 2014; van den Berg et al., 2015; Wood et al., 2008) used a cross-sectional survey to test the relationship between third places and social capital in a neighbourhood. In light of this, this research aims to be consistent with the existing literature on this topic, and will therefore operationalise quantitative research methods. Most research in this area have also used more than one neighbourhood as a case study therefore three suburbs of the Wellington region in New Zealand have been chosen as sites of intervention. These three suburbs are Lyall Bay, Island Bay, and Karori. These suburbs have been chosen as they have varying socioeconomic demographics and this will provide for comparability. Furthermore, all three suburbs are characterised by either traditional (grid) or conventional street networks, and based on the literature, they are 'more walkable' and make it easier for residents to access their third places (Mazumdar et al., 2018). More information on these three suburbs is provided in chapter four. 


\section{Research Questions}

As articulated in chapter one, the guiding principle behind this Master's thesis is to understand how the built environment in a neighbourhood can help contribute to successful cities that benefit their inhabitants. Specifically this research is concerned with one specific feature of the built environment: the third place, and how it is associated with individual level social capital of residents in a neighbourhood. However, before delving into the third place - social capital nexus, the meaning and value of third places for New Zealanders remains to be addressed. This research aims to identify what New Zealanders perceive to be their 'third place' in their neighbourhood and the characteristics they associate with that place. Once established, this research is interested in whether specific attributes of those third places, including perceived quality, distance to, and frequency of visitation is associated with individual social capital. The rationale for studying this relationship is that how we provide for, incorporate and design third places in a neighbourhood may impact on residents' social capital and thereby their health, both physical and mental. Research looking specifically at the association between local amenities/destinations and social capital exists however, all studies bar one (Francis et al., 2012) do not conceptualise this feature of the built environment through the lens of Oldenburg's 'third place'. In addition to there being scant research specifically dedicated to exploring the relationship between third places and social capital, there is none in New Zealand that has considered this relationship. Furthermore in regard to the literature on the third place, only a few (Jeffres et al., 2010) actually ask respondents what they perceive these places to be, as most just assume or select particular examples (e.g. café, school, library) of third places in their empirical analyses. Consequently, third places and their association with social capital is a topic that has been significantly underexplored in the built-environment and social capital literature, and especially so in a New Zealand and community psychology context. The research questions below attempt to address these gaps and shed light on the value of 'third places' in general.

\section{RQ1: What is the meaning and value of third places for New Zealanders?}

SRQ1.1: What places in their neighbourhood do residents congregate at that are outside of their home and workplace?

SRQ1.2: What characteristics as defined by Oldenburg do residents attribute to their third place? 
RQ2: What is the relationship between residents' perceptions of their third place and Sense of Community in a neighbourhood?

SRQ2.1: What is the association between distance to residents' third place and their Sense of Community?

SRQ2.2: What is the association between frequency of visitation to residents' third place and their Sense of Community?

SRQ2.3: What is the association between perceived quality of residents' third place and their Sense of Community?

RQ3: What is the relationship between residents' perceptions of their third place and neighbouring?

SRQ3.1: What is the association between distance to residents' third place and neighbouring?

SRQ3.2: What is the association between frequency of visitation to residents' third place and neighbouring?

SRQ3.3: What is the association between perceived quality of residents' third place and neighbouring? 


\section{Chapter four: Methodology}

\section{Introduction}

This chapter provides an overview of the research design, methods of data collection and statistical analyses used to answer the key questions of this study. A postpositivist worldview was adopted in this research, with quantitative methods used for data collection. This chapter begins by discussing the epistemological approach and rationale for using quantitative research methods. Next, it provides a brief overview of the research setting. Following this, an outline of the study design, including an explanation of the study method and recruitment process is provided. The development of the survey tool is also discussed in detail where justification (based on existing research) for the questions and scales is given. This section also includes sample characteristics and addresses particular statistical measures that need to be established before analysis can be undertaken. Finally, the last section of this chapter considers what approach to data analysis was used to help answer the main questions of this study.

\section{Epistemological approach}

Quantitative research is an approach for testing objective theories by examining the relationships between variables (Creswell \& Creswell, 2018). Quantitative methods are particularly useful for testing hypotheses and theories and generally rely on predetermined research questions, conceptual frameworks and study design (Francis, 2010). In contrast to qualitative research, samples in quantitative research are usually much larger and are based on highly-developed and codified methods of analysis (Francis, 2010). A strength of employing a quantitative approach is that it allows for the ability to generalise study findings to broader populations that share similar characteristics to the sample however, this is dependent on whether one has a representative sample (Francis, 2010). The findings of quantitative research are also more objective and less influenced by the interpretations of the researcher (Francis, 2010). In saying this it is important to be aware of 'researcher degrees of freedom' where it is common practice for quantitative researchers to explore various analytic alternatives to their null hypothesis searching for results that yield statistical significance, and then to report only what 'worked' in their study (Simmons, Nelson, \& Simonsohn, 2011). It is also important to acknowledge that quantitative research is limited by the questions and response categories contained within a survey instrument (Francis, 2010). In consequence, quantitative methods can be weak in understanding the context of the research and the specific voices of participants (Francis, 2010). 
During the latter half of the $19^{\text {th }}$ century and throughout the $20^{\text {th }}$ century, research studies that used quantitative methods invoked postpositivism, and were largely from the domain of psychology (Creswell \& Creswell, 2018). Postposivitism derives from positivism which is an "organised method for combining deductive logic with precise empirical observations of individual behaviour in order to discover and confirm a set of probabilistic causal laws that can be used to predict general patterns of human activity" (Neuman, 2005, p. 82). Many versions of positivism exist, and varieties include logical empiricism, naturalism, behaviourism and postpositivism (Neuman, 2005). Postpositivism derived from positivism. It challenges the traditional notion of the absolute truth of knowledge and recognises that one cannot be completely sure of certain claims of knowledge when studying human behaviour and actions (Creswell \& Creswell, 2018). The philosophical stance of postpositivism is that 'causes determine effects or outcomes' (Creswell \& Creswell, 2018). Postpositivism is also reductionist in that its intent is to reduce ideas into a small, discrete set to test, such as the variables that comprise hypotheses and research questions (Cresswell \& Cresswell, 2018).

\section{Research setting}

This research is concerned with social capital at the neighbourhood level and data was exclusively collected in three Wellington neighbourhoods, which were Karori, Lyall Bay and Island Bay. These neighbourhoods were chosen as sites of research because they have residents from varying physical geographies and socio-economic populations and diverse housing types, street widths and traffic levels, walkability and access to shops, schools and community facilities.

\section{Karori}

Karori is one New Zealand's biggest neighbourhoods with a population of more than 14,736. It is located on the Western edge of the urban area of Wellington City, approximately four kilometres from the city centre. Karori is bounded by the neighbourhoods of Wilton in the north, Highbury in the east, Brooklyn and Owhiro Bay and Makara in the south and west. Karori has a mix of traditional street design in its centre and in its eastern boundaries, and conventional street design in its northern, southern and western boundaries. Karori is connected by Karori Road, a large artery road that extends for approximately three kilometres. Along Karori road are a diverse range of small businesses and eateries. There are also two main shopping areas along Karori Road, Marsden Village and the centre of Karori which includes a mall, library, two petrol stations, two banks, various cafes and food outlets and other small businesses. 


\section{Island Bay}

Island Bay is a seaside neighbourhood with a population of approximately 8,523 . Island Bay is the most southerly neighbourhood in Wellington and is bounded by the neighbourhoods of Berhampore in the north, Houghton Bay on the east, Owhiro Bay in the west, and Cook Strait in the south. Island Bay is mainly characterised by traditional street networks and is connected by The Parade, an artery road that is approximately 1.7 kilometres. Along the Parade are a diverse range of small businesses and eateries, including a cinema, supermarket, library, bowling club and community centre.

\section{Lyall Bay}

Lyall Bay is a small seaside neighbourhood with a population of more than 2,600. It is located on the Southern coast of Wellington bounded by the neighbourhoods of Kilbirnie in the north, Rongotai in the east, Melrose in the west, Houghton Bay in the south-west and Cook Strait in the south. Lyall Bay is characterised mainly by a traditional street network design and is connected by Onepu Road, an artery road that (from the beginning of Lyall Bay's northern boundary) runs for 700 metres to connect to Lyall Parade that runs perpendicular down the Bay's southern boundary on the coast. Along both Lyall Parade and Onepu Road are various small businesses, eateries and two surf clubs. Lyall Bay contains Wellington's largest beach that is very popular for swimming and surfing.

Additional information about each neighbourhood, including its geographical features, population density and deprivation scores is listed in Table 3.

\begin{tabular}{|l|l|l|l|}
\hline Feature & Karori & Lyall Bay & Island Bay \\
\hline $\begin{array}{l}\text { Pop change 2006- } \\
2013\end{array}$ & 672 & -33 & 273 \\
\hline Density p-ha & 8.54 & 44.92 & 5.38 \\
\hline Traffic & Local/Artery & Local/Artery & Local /Artery \\
\hline Primary schools & $2+2$ private & 1 & $1+1$ private \\
\hline Library & 1 & 0 & 1 \\
\hline Sports groups & 6 & Yes & Yes \\
\hline Faith groups & Yes & Yes & Yes \\
\hline $\begin{array}{l}\text { Public open space } \\
\text { Parks, greenbelts }\end{array}$ & $\begin{array}{l}\text { Beach boulevard, } \\
\text { public walkway }\end{array}$ & $\begin{array}{l}\text { Parks and beach } \\
\text { boulevard }\end{array}$ \\
\hline $\begin{array}{l}\text { Access to natural } \\
\text { environments }\end{array}$ & Edge hills & Beach & Beach \\
\hline
\end{tabular}

Table 3: Overview of this thesis' study locations

\section{The survey design}

\section{Rationale}

The association between the built environment and social capital is a multifaceted and complex research area. Different studies from varying disciplines have used a range of 
methods to investigate different aspects of this relationship however, quantitative approaches are overwhelmingly the most popular. The primary purpose of this study is to empirically evaluate whether the presence of third places in a neighbourhood is associated with certain cognitive and structural predictors of individual social capital. Research on the association between the built environment and social capital is often criticised because there is a large diversity of measurement techniques used to explore this relationship. In effect, for reasons of consistency and comparability this study mirrors the approach taken by other empirical studies researching the association between certain features of the built environment and their association with social capital, which is to employ a survey instrument. In addition, a survey was chosen for this study because it acts as a suitable mechanism for measuring the degree or association between two or more variables, which is the aim of this study (Creswell \& Creswell, 2018). Survey research is widely regarded as being quantitative and positivistic (De Vaus, 2014). A survey design provides a quantitative description of trends, attitudes and opinions of a population by studying a small sample of that population (Creswell \& Creswell, 2018).

\section{Form of data collection}

The data collection for this research was conducted through a cross-sectional online survey instrument using the Qualtrics platform and it consisted of eight key sections. Attached as Appendix One is a copy of the survey questionnaire. This study used an online survey in comparison to a paper survey. This decision was made based on several reasons. Changes in living patterns, reduced response rates and changes in telephone technology are making it more challenging to conduct surveys using traditional methods (de Vaus, 2014). In current day society a larger proportion of the population are online, and 80.8 per cent of households in the Wellington region have access to the internet, therefore an online survey appeared to be the most viable option for recruiting as many participants as possible (de Vaus, 2014). This research was confined to three suburbs, and internet and mobile surveys are effective for gathering information quickly and relatively inexpensively from geographically dispersed participants. Despite the notable strengths of using an online survey, it is not appropriate for every research project (Sue $\&$ Ritter, 2007). For example, 88.2 per cent of households in Karori have access to the internet, 76 per cent in Lyall Bay and 80 per cent in Island Bay however, the sample is limited because it is only available to those who are computer savvy and have access to the internet (Sue \& Ritter, 2007). Samples derived from digital surveys are unlikely to be representative of the general population however, they can be a very useful means of 
obtaining representative samples of specific populations, including neighbourhoods.

There exist many other benefits and disadvantages of using an online survey, which are summarised in Table 4.

\begin{tabular}{l|l} 
Benefits & Disadvantages \\
\hline Can be low cost & Coverage bias (research sample not representative) \\
Fast & Reliance on software \\
Efficient & Too many digital surveys, causing overload \\
Contingency questions & \\
Effective & \\
Direct data entry & \\
Wide geographic reach &
\end{tabular}

Table 4 (adapted from Sue \& Ritter, 2007, p. 7).

Overall, the use of an online survey was deemed to be the most effective and efficient instrument to gather the information required for this thesis. The survey was built and launched on Qualtrics as Victoria University of Wellington has a licence agreement with this service. The online survey instrument was designed to account for respondents accessing the survey in different formats (either on a computer or handheld electronic device). The online survey was also cross-sectional, where data was collected in one specific point of time. A cross-sectional survey was used in this research because it is not costly to perform and does not require a lot of time. Despite the advantages of using a cross-sectional survey there are various drawbacks associated with this approach. For example, it is difficult to make causal inference, and it only provides a 'snapshot' meaning that the situation may provide differing results if another timeframe had been chosen or if the survey were to be repeated.

\section{Recruitment}

The survey was open throughout the period between 7 October 2018 and 13 November 2018. The survey was advertised primarily through mail advertisements and social media. A copy of the survey advertisement is attached as Appendix Two. Over 750 flyers were dropped in letter boxes in the three chosen suburbs of Lyall Bay, Island Bay and Karori. Households that displayed a 'No Junk Mail', 'No Circulars' or 'No Advertising Material' sticker on their letterboxes were excluded from the mail drop. The advertisement included a hyperlink and QR code to access the survey online. The survey advertisement was also posted on public community Facebook group pages (with the consent of the page administrator) and on the website Neighbourly.co.nz. To encourage residents' to participate in the survey, all respondents had the option to enter 
the draw to win one of four $\$ 100$ supermarket vouchers. Four respondents were then selected at random after the survey had close and deemed winners of the prize.

\section{Research sample}

In total 195 individuals accessed the survey, and 193 consented to taking part. To be eligible for the survey, respondents had to reside in either Karori, Lyall Bay or Island Bay. A question asking where residents lived was used to identify those eligible. 11 respondents indicated that they did not reside in any of the three chosen suburbs and were subsequently redirected to an end of survey message and thereby excluded from partaking in the survey. In effect, out of the 193 who consented to participating in the survey, 182 respondents were eligible. Of these 182 respondents, 147 completed the survey. Partial data of an additional 13 respondents will be used in the analysis section of this research because they answered all the social capital related questions and initial demographic questions. In total, the responses of 160 participants will be analysed in this research. As depicted in Table 5, of the 160, 18 were from Island Bay, 43 were from Lyall Bay, and 99 were from Karori. Due to the low number of responses from Island Bay, the data of both Lyall Bay and Island Bay will be lumped together, and referred to as the 'Southern Coast suburbs'. This research will analyse the data collectively however, the 'Southern Coast suburbs' description will only be used where data comparisons are made between the suburbs.

\begin{tabular}{|c|c|c|}
\hline \multicolumn{2}{|c|}{ Suburb Frequency } & Percent \\
\hline Lyall Bay & 43 & 26.9 \\
\hline Island Bay & 18 & 11.3 \\
\hline Karori & 99 & 61.9 \\
\hline Total & 160 & 100.0 \\
\hline
\end{tabular}

Table 5: Number of respondents per neighbourhood

\section{Survey development and item pool}

This section explains why and how specific questions for the survey were used. This study began with a comprehensive literature review to locate what was already known about the relationship between the built environment, specifically third places and concepts related to social capital. The literature review helped to determine the quality, methods and limitations of related previous research, thereby guiding the design of the questionnaire items for the survey. Similar to the approach taken by Francis (2010), the survey sourced literature from a variety of academic disciplines due the multifaceted nature of this research's area of interest. These disciplines included public health, environmental psychology, community psychology, urban planning, and sociology. 


\section{Item pool}

Items included in the survey instrument were comprised of original and established measurement items identified in the literature review. The items chosen for this study measured:

- Length of residency (years)

- Household composition (demographics)

- Own/rent household

- Time spent in neighbourhood during week and weekend (hours)

- Bonding social capital (quantity and strength of network ties)

- Reciprocity (frequency of interaction)

- Satisfaction with neighbourhood relationships

- SoC Index

- Where respondents met people within the neighbourhood

- What places respondents perceive to be 'third places' in their neighbourhood

- Respondents' favourite place in their neighbourhood

- Proximity of respondents' favourite place from their household

- Perceived quality of respondents' favourite place

- Characteristics of respondents' favourite place (as defined by Oldenburg, 1989)

- Frequency of visits to respondents' favourite place

- Civic engagement (participation in neighbourhood activities)

- Socio-demographic characteristics.

\section{Overview of survey questions}

The survey was divided into eight main sections and together the survey had 55 questions, including a question at the end of the survey for participants to provide feedback, and an option to enter the prize draw. To prevent survey fatigue, the survey incorporated open-ended and closed-ended questions that were displayed in several different formats. The close-ended questions comprised of 'tick the box' methods and ranking attitudinal responses on a seven-point Likert scale. Open-ended survey questions, where the respondent typed directly into a boxed area were used only in the 'third place' section as it allowed residents to be specific and provide detailed information about their favourite place in the neighbourhood.

\section{Determination of eligibility}

A screening question was used at the beginning of the survey to determine whether respondents resided in one of three suburbs that would make them eligible to take part 
in the survey. Respondents who selected that they lived in Island Bay, Lyall Bay or Karori were then prompted to the next part of the survey. Respondents who had selected that they resided none of the suburbs listed were redirected to an end of survey message.

\section{Measurement of social capital}

This section provides background on, and justification for the questions used to measure social capital in the survey. In social capital literature, there is a large variety of how the concept is operationalised and measured (Adam \& Roncevic, 2003). It has been argued that the lack of a clear link between theory and measurement has, in some cases, led to the use of questionable indicators of social capital (Paxton, 1999). For example, social relationships, collective efficacy, social cohesion, social networks, social support, social ties, SoC and social integration are only a selection of indicators that have been used to measured social capital. These concepts are often used interchangeably however, they all subtly contribute to, or are connected to social capital (Banwell, 2017). Patulny and Svendsen (2007) argue that the problem of including every indicator/measure of social capital that currently exists is diminishing by the growing acceptance of social capital being comprised of networks, norms of trust and cooperation (Patulny \& Svendsen, 2007). Regardless, it is still very common for researchers to rely upon unidimensional measures of the concept, and these researchers often do so with minimal empirical or conceptual regard to the relationships between the said dimension and other key elements of social capital (Stone, 2001). For example, some studies have assessed social capital solely in terms of network density, while others have relied purely on a measure of trust (Krishna \& Shrader, 1999). In saying this, some researchers use a combination of measures of network density and particular proxies for evaluating the strength of relevant norms (Krishna \& Shrader, 1999). Krishna and Shrader (1999) argue that neither an exclusively networks-based (structural) nor an entirely norms-dependent (cognitive) measure suffices for scaling social capital. Several scholars have argued that the structural elements of social capital (including networks) must be assessed independently of the cognitive elements (norms, values, attitudes and beliefs) because the cognitive elements predispose people towards mutually beneficial collective action and the structural elements facilitate such action (Krishna \& Shrader, 1999). Both the structural and cognitive dimensions of social capital are important, and Krishna and Shrader (1999) argue that both dimensions should be measured to accurately find the aggregate amount of social capital that exists within a community. 
In light of this, both the cognitive and structural dimensions of social capital will be measured. Predictors of the structural dimension of social capital that are measured in this research include bonding network ties, specifically their strength and quantity, which are facets of the social capital dimension 'neighbouring'. Predictors representing the cognitive dimensions that are measured in this research include reciprocity and cooperation, which are facets of the social capital dimension 'SoC. These dimensions tie into the definition of social capital used in the research by Perkins and Long (2002). Perkins and Long's (2002) definition include four dimensions of social capital, and SoC and neighbouring are classified as 'informal'. As described in chapter two, third places are informal gathering places that facilitate social interaction, so this research will only measure the informal dimensions of social capital to keep the research specific. A few questions have also been included that relate to one of Perkins and Long's (2002) 'formal' dimension of 'citizen participation' because they have been shown to be strongly correlated with SoC and neighbouring however, will be used just for reference.

\section{Sense of Community}

To measure SoC, the widely cited and most influential 12-item Sense of Community Index, developed by Perkins, Flourin, Rich, Wandersman, and Chavis (1990) was used. Perkins et al.'s (1990) scale was informed by McMillan and Chavis's (1986) definition of SoC, and on a larger, more complicated SoC instrument developed by (Chavis et al., 1986). Respondents were asked to rate on a seven point Likert-scale how strongly they agreed with 12 statements that are separated into four subscales with three items each. These subscales correspond to the four elements of SoC conceived by McMillan and Chavis (1986) which are: membership, influence, reinforcement, and a shared emotional connection. The Index was chosen to measure $\mathrm{SoC}$ in this research because it has been specifically designed to measure SoC within a neighbourhood, and it is the most widely operationalised measure of the concept (Francis et al., 2012). Perkins et al. (1990) SoC scale includes both positive and negative statements, which is an approach commonly used to lessen the acquiescent response bias (Qasem \& Gul, 2014). This approach acts to reduce response speed and promote cognitive reasoning in the respondents (Salazar, 2015). This approach holds the assumption that negative and positive items/statements are essentially equivalent and by reverse scoring the negative items, the resulting composite score should reduce any response bias (e.g., participants ticking 'strongly agree' for every question) (Qasem \& Gul, 2014). Four out of the 12 statements from Perkins et al.'s (1990) SoC scale that are negatively worded, as shown in Table 6. 


\begin{tabular}{l|l} 
Statement & \\
\hline Second & People in this neighbourhood do not share the same values \\
\hline Sixth & Very few of my neighbours know me \\
\hline Eighth & I have almost no influence over what my neighbourhood is like \\
\hline Eleventh & $\begin{array}{r}\text { People in my neighbourhood generally don't get along with each other } \\
\text { Table 6: Negative items in SoC scale }\end{array}$
\end{tabular}

Table 6: Negative items in SoC scale

For the purposes of analysis, these four statements were recoded so that a higher score on this item reflected a higher SoC. The internal consistency reliability score of the Sense of Community Index is good, with an internal reliability of $\alpha=0.78$, shown in Table 7. This is comparable with other studies that have reported a Cronbach's alpha coefficient of 0.8 (Francis et al., 2012). The removal of any of the twelve statements did not result in any increases in the alpha score, so all twelve items were retained for the analysis. The twelve items were added and each respondent's SoC score is reported as the mean score across the twelve statements.

\begin{tabular}{c|c|r} 
Cronbach's Alpha & $\begin{array}{c}\text { Cronbach's Alpha Based } \\
\text { on Standardized Items }\end{array}$ & N of Items \\
\hline .784 & .806 & 12 \\
\hline Table 7: Reliability Statistics
\end{tabular}

\section{Neighbouring}

Perkins and Long (2002) measure neighbouring behaviour using the mean score of five scale items including how many times in the past year neighbours (none, $1-2$, or several) asked respondents to: watch their home while they were away, to loan food or a tool, to help in an emergency, to offer advice on a personal problem, and to discuss a neighbourhood problem (Perkins \& Long, 2002). Two questions (including one scale similar to the one developed by Perkins and Long (2002)) were used in this research however, the questions used in this survey were also informed by Cheshire's (2015) study of the normative practices of neighbouring in an urban context. Cheshire (2015) argues that while getting to know one's neighbours may be easy, the types of interactions that occur among neighbours, and the relationships that form are complex. Cheshire (2015) identifies five different types of neighbouring interactions: bonds, attachments, transactions, interdependencies, and hostilities. The neighbouring questions used in this survey were based on a combination of both Perkins and Long's (2002) neighbouring scale and Cheshire's (2015) five types of neighbouring interactions. In addition, they were informed by Francis (2010)'s survey because it 
helps to identify structural social capital in a neighbourhood. Of note, there are several questions in this survey that have been informed and influenced by Francis (2010) as her research is on similar subject matter. The first set of questions relating to neighbouring asked respondents to indicate how many neighbours they have that they felt comfortable engaging in certain neighbouring interactions with. These set of questions asked participants to indicate how many neighbours (none, 1-2, 3-5, 6-7, 8 or more) they have that fit with each of the five different types of neighbouring interactions. These five types of neighbouring interactions and their accompanied survey questions are provided in Table 8 .

\begin{tabular}{l|l|l}
$\begin{array}{l}\text { Neighbouring } \\
\text { interaction }\end{array}$ & Description & Survey question \\
\hline Bonds & $\begin{array}{l}\text { Neighbours socialise together, } \\
\text { participate in family events, and } \\
\text { provide mutual support that goes } \\
\text { beyond the usual forms of } \\
\text { neighbourly 'helpfulness' }\end{array}$ & $\begin{array}{l}\text { How many neighbours do } \\
\text { you have that you feel } \\
\text { comfortable talking to } \\
\text { about private matters or } \\
\text { call on for help? }\end{array}$ \\
\hline Attachments & $\begin{array}{l}\text { Differ from 'bonds' by degree } \\
\text { where neighbour relations are based } \\
\text { primarily on a shared recognition of } \\
\text { the value of good neighbour } \\
\text { relations rather than any attachment } \\
\text { to neighbours as individuals }\end{array}$ & $\begin{array}{l}\text { How many neighbours do } \\
\text { you have that your } \\
\text { household would have } \\
\text { over for a cup of tea or } \\
\text { dinner once in a while? }\end{array}$ \\
\hline Transactions & $\begin{array}{l}\text { Neighbours exchange small } \\
\text { favours, but interactions are rarely } \\
\text { overtly sociable and are based on a } \\
\text { relationship of peaceful coexistence }\end{array}$ & $\begin{array}{l}\text { How many neighbours do } \\
\text { comfortable asking to look } \\
\text { after your mailbox if you } \\
\text { went on holiday? }\end{array}$ \\
\hline Interdependencies & $\begin{array}{l}\text { Neighbours share 'friendly } \\
\text { distance' where interactions are } \\
\text { very rare or simply absent }\end{array}$ & $\begin{array}{l}\text { How many neighbours do } \\
\text { you have that you don't } \\
\text { know well but would smile } \\
\text { at or have an informal chat } \\
\text { if you saw them on the } \\
\text { street? }\end{array}$ \\
\hline Hostilities & $\begin{array}{l}\text { Neighbour relations are negative } \\
\text { you have that you do not } \\
\text { get along with or do not } \\
\text { like? }\end{array}$ \\
\hline
\end{tabular}

Table 8: Neighbouring survey questions

In addition to measuring the quantity of neighbouring interactions, this research also measured the frequency of interactions. The second set of questions were represented as a six-item scale including five questions asking participants about how often (never, once a year, a few times a year, at least once a month, at least once a week, almost daily) they engage in neighbouring behaviours. The five questions were all examples of 
the three most common types of neighbouring interactions: attachments, transactions and interdependencies. For example, to measure the frequency of 'attachments' the survey asked: How often have you participated in an activity with a neighbour (ex: had dinner together, had a street $B B Q$, went for a walk)?, and to measure 'transactions' the survey asked: How often have you given help to a neighbour (ex: lent a tool, gave spare baking ingredient, looked after mailbox or animal while on holiday)? The justification for including a second scale measuring the frequency of interaction is to provide for a more in-depth understanding of structural social capital in the neighbourhood. In addition to the six-item scale measuring frequency, participants also had the option to select 'does not apply to me'. Only one participant selected this option for the fourth question in the scale: How often have you received help to a neighbour (ex: lent a tool, gave spare baking ingredient, and looked after mailbox or animal while on holiday)? This answer was recoded as 'user-missing data' and excluded from the analysis. The internal reliability of this neighbouring scale was $\alpha=0.878$. The removal of any of the five questions did not result in an alpha increase, so all five were left in for the analysis.

To find the total 'neighbouring' score, a different approach was taken in comparison to the SoC scale. Results from the neighbouring scale will be discussed in general where overall percentages will be provided to demonstrate what the most common type of interactions participants have with their neighbours. As discussed, the neighbouring questions concern: 1) how many neighbours people have for five different levels of interaction (smiling at on the street to personal relationship); and 2) how often people interact with their neighbours (from how often they talk in the street to how often they have them over for dinner, as a few examples). In effect, the initial section of the results chapter will show the most common types of interactions participants have with their neighbours and a summary of how often participants interact with them. The 'neighbouring' scores that will be used to examine the association with the quality, distance and frequency of visitation to third places will be derived from the overall totals of each of the neighbouring questions. Therefore, two neighbouring scores will be used in this research: quantity of neighbours (total amount) and quality of neighbours (frequency of interaction). For quantity, what this means is that the total amount of neighbours a participant has in their neighbourhood (whether or not their interactions are only limited to a smile) will be totalled. The decision to aggregate the total amount of neighbours for each participant was made because regardless if neighbours smile at each other in the street or have neighbours over for a cup of tea, they are still 
'neighbouring' behaviours (Perkins \& Long, 2002). A total score based on the second neighbouring question measuring quality, will be calculated similar to $\mathrm{SoC}$ where the average score (based on the Likert-scale) for each question will be calculated. This is explained further in chapter six.

To reinforce the two neighbouring questions, the survey also contained a question asking participants about how satisfied they are with the relationship they have with fellow residents. This question was a modified version of the one used by Francis (2010) and was used in this study to gauge the relative importance participants attribute to engaging in neighbouring interactions. For example, one may assume that maintaining only 'transactional' or 'interdependent' relationships with neighbours may be negative however, respondents' may actually be satisfied with these types of relations.

\section{Third places}

This research is concerned about the meaning and value New Zealanders attach to third places. The survey contained open-ended questions that provided respondents the opportunity to identify third places in their neighbourhood, and also their own third place. A question asking participants about where they met fellow residents in their neighbourhood was adopted from Francis' (2010) PhD thesis as part of the University of Western Australia's RESIDential Environments Project. The benefit of this question is that it provides useful information regarding what types of places or environments foster and promote social interaction between residents. The survey also contained an open-ended question asking residents to identify third places in their neighbourhood. This question was based on Oldenburg's (1989) conceptualisation of the term and was presented in the survey as: Within your neighbourhood, what places do you think host frequent, casual, voluntary and happily anticipated gathering of people? The question also included a caveat for respondents to not think of places that were the first (home) or second place (work). Figures 1 and 2 capture some of the most popular words respondents used to describe these places. These word clouds are graphical representations of word frequency, which visually demonstrate the most popular words used to describe third places by respondents. The bigger the word corresponds with how often it was used by participants. Word clouds are a good visualisation technique and have been placed in this chapter to show the 'overall picture' of this thesis' results (Heimerl , Lohmann, Lange, \& Ertl, 2014). More analysis on respondents' perceptions of third places is provided in chapter four. 


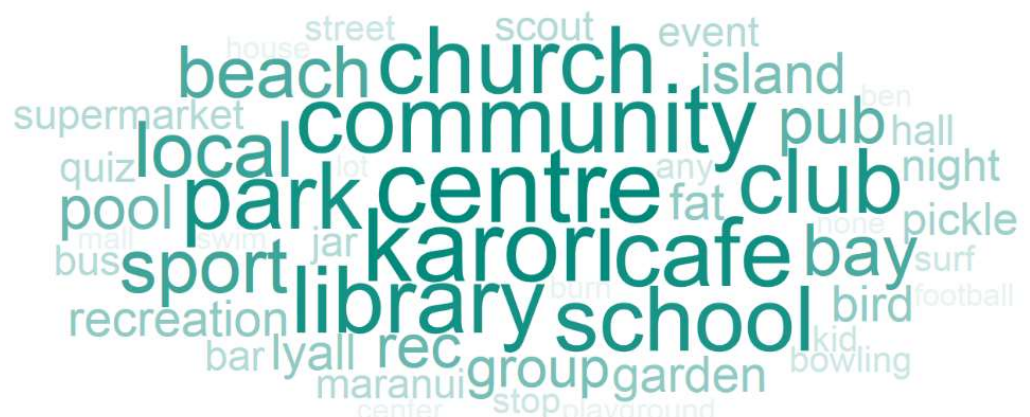

Figure 1: Respondents perceptions of local third places

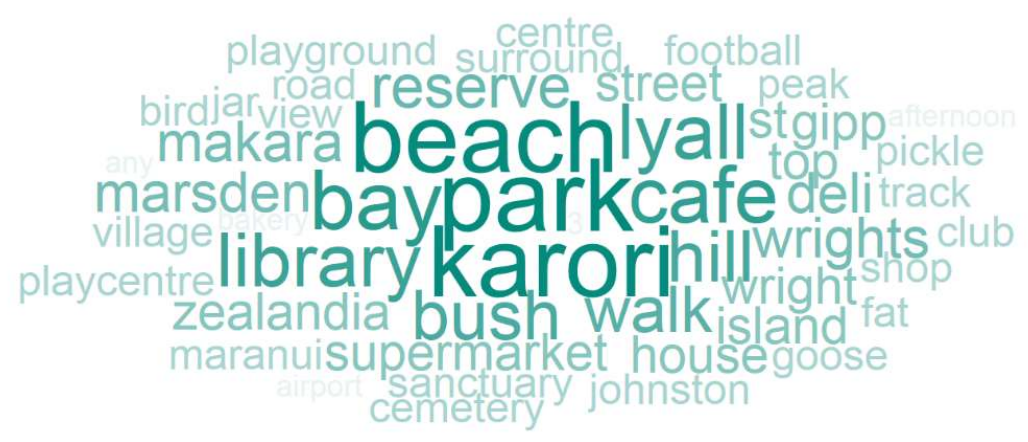

Figure 2: Respondents' favourite places in their neighbourhood

Following the identification of respondents' favourite place in their neighbourhood, the survey asked respondents to select up to eight characteristics (no minimum or maximum) that describe their favourite place in the neighbourhood. All eight characteristics were defined by Oldenburg (1989) as central to a 'third place'. This is an original item that was developed for this study as it helps answer the first research question of this study. Furthermore, as mentioned in chapter three, literature on third places has begun to challenge the salience of some of Oldenburg's (1989) third place characteristics, therefore this study aims to produce similar findings to these studies but in a contemporary New Zealand context.

\section{Dimensions of the third place: distance, quality and frequency of visits}

The 'third place' section of the survey also contained questions asking participants about how far away they live from their favourite place, their perception of its quality, and how often they visit that place. Measuring distance to third places was included in the survey because the literature indicates that the proximity to a particular place or space can predict its use (Francis, 2010; Wood et al., 2008). Furthermore, as seen in chapter three pedestrian travel is higher in neighbourhoods that are 'walkable' and have accessible third places. Walking around the neighbourhood or to local third places 
increases chance encounters between residents and opportunities for social interaction. In light of this, the survey question was worded as the 'walkable distance' (5 minutes, 15 minutes, more than 15 minutes) to the participants' favourite place, from their home. Measuring respondents' perceptions of the quality of their third place was included in this research because it is a factor that is not well researched in the literature. The quality of third places and their features is under researched because it is difficult to quantify and/or generalise across multiple studies (Mazumdar et al., 2018). In saying this, perceptions of quality have been found to be positively associated with social capital (Francis et al., 2012; Wood et al., 2008). This research used a modified version of a survey question developed by Francis (2010), which asked respondents to indicate on a seven-point Likert scale how much they agree ('strongly agree' to 'strongly disagree') with nine different statements regarding the quality of their favourite place. An eighth point was included in the scale as 'does not apply' as for example, one of the statements 'it has adequate seating' may not be an applicable feature of a particular type of place, such as walking tracks. The internal reliability of this scale was $\alpha=0.788$. The removal of any of the nine statements did not result in an alpha increase, so all nine were left in for the analysis. Finally, the frequency of how often respondents visit their third place was also examined because it has not been explored in the literature in depth. In her study, Francis (2010) asked participants about the frequency with which they used public space. This question was asked based on public space acting as a "potential mediator of the relationship between physical environment factors and mental health" (Francis, 2010, p. 43). This study therefore used a modified version of a survey question developed by Francis (2010), which asked respondents to indicate how often (from 'never' to 'daily') they visit their favourite place in their neighbourhood.

\section{Demographics}

The first section of the survey included questions asking how long participants have lived in their neighbourhood, what street they reside on, who they live with, if they own or rent their house, and the total the amount of time they spend in their neighbourhood during the week and on the weekends. In addition, the final section of the survey included questions asking about the participant's personal characteristics. These included standard questions about age, gender, ethnicity, education, and income. Demographic questions were included in the survey to capture the overall characteristics of the sample population in each suburb. In addition, these demographic variables were identified in the literature as showing an empirical association with some of the components of social capital that are investigated in this study. For example, 
individual-level variables such as length of residence, having children and neighbourhood-level variables (such as homogeneity among residents) influence the degree to which neighbours are sources of mutual aid (Unger \& Wandersman, 1985).

An open-ended question was also included in this section asking respondents what street they live on to determine if there was an even physical dispersion of respondents in each suburb. Figures 5, 6 and 7 are maps of each suburb that demonstrate the physical distribution of respondents in each suburb. The 'pink-house' icon represent the streets that respondents live on. As this research conceptualises a neighbourhood as a site that is defined subjectively by the individuals that live within them, this research does not exclude participants that live beyond the officially defined boundaries set by local government of the respective suburbs. What was found from the survey, was that a small number of respondents did reside outside of the 'official' boundary of the neighbourhood (as defined by the local Council) however, considered themselves to live in the suburbs chosen for this research. This was only true from respondents who selected 'Lyall Bay' as their neighbourhood. Visually, Figures 3, 4 and 5 demonstrate that responses from residents in Lyall Bay and Karori were evenly distributed 
throughout the neighbourhood however, in Island Bay respondents tended to live closer to the outskirts.

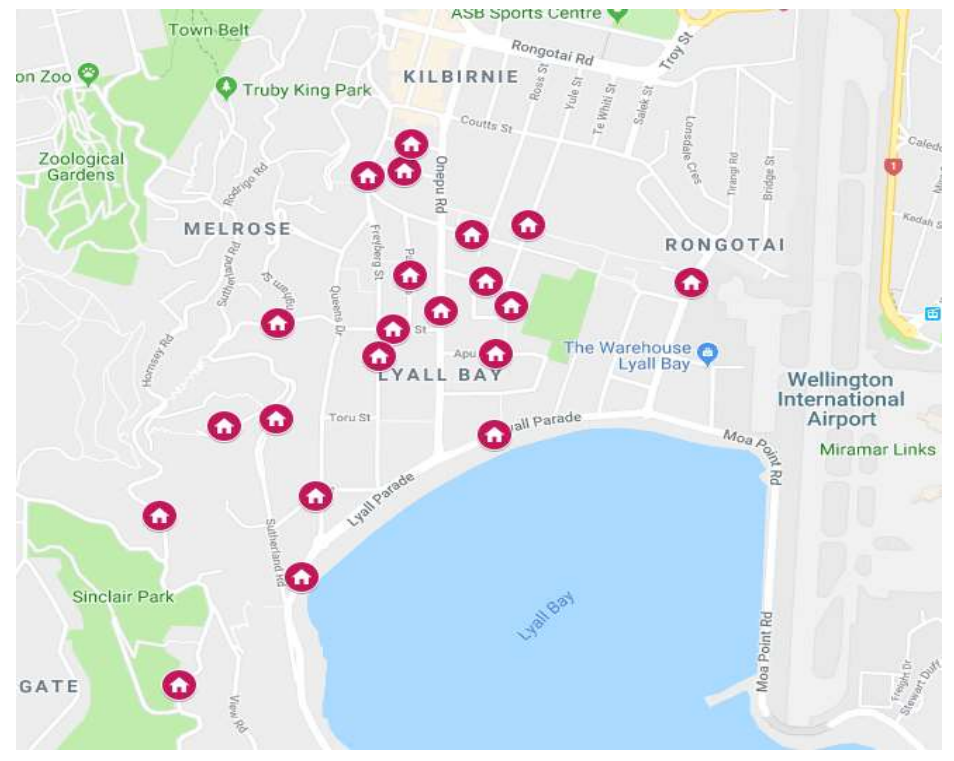

Figure 4: Map of respondents' approximate location in Lyall Bay

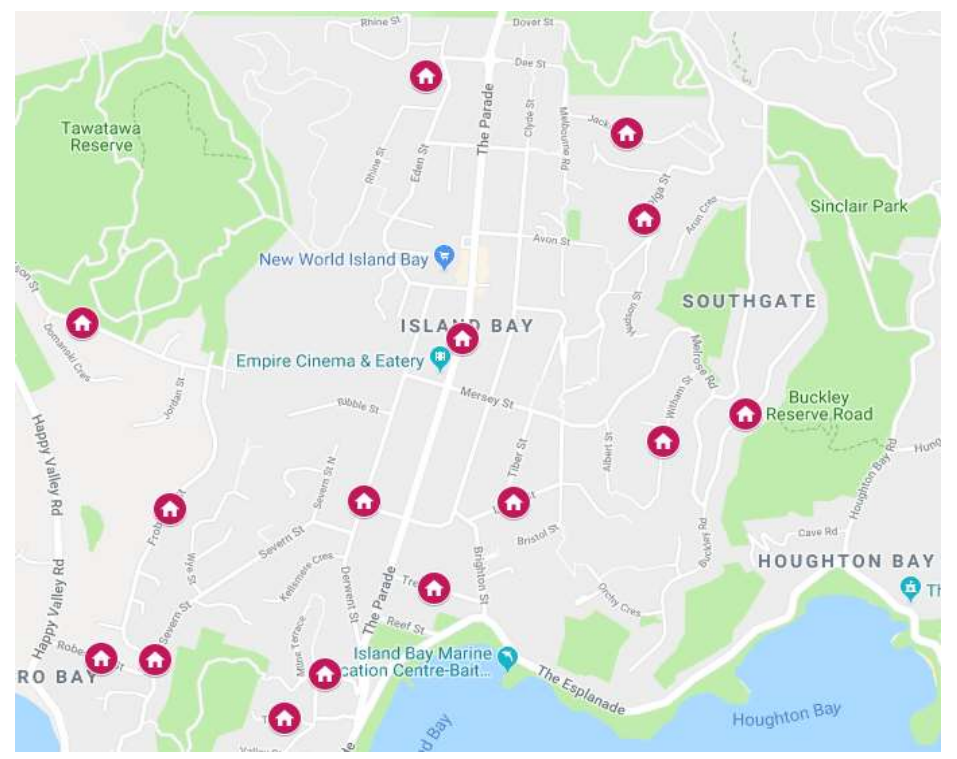

Figure 3: Map of respondents' approximate location in Island Bay 


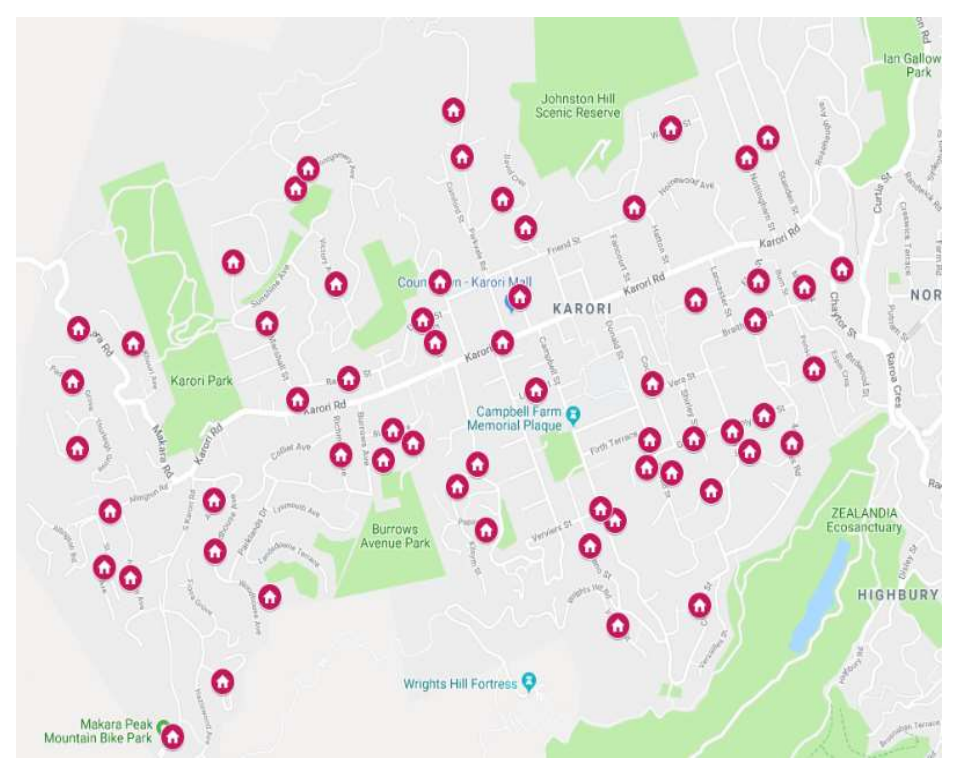

Figure 5: Map of respondents' approximate location in Karori

\section{Ethical considerations}

Ethics approval was sought from Victoria University of Wellington's Human Ethics Committee for this research. The major ethical consideration in this research was to ensure that all respondents' survey responses would be treated anonymously and confidentially in order to guarantee that individuals could not be personally identified. To mitigate this concern, the data collected in this research was aggregated in the analysis phase thereby making it difficult to discern individual respondents. Ethics approval was granted on 21 September 2018 (approval number 0000026271). Participants were required to indicate their consent to participate in the survey and were only prompted to complete the full survey after indicating that they had read and understood the Participant Information Sheet, which is attached to the Survey Questionnaire.

\section{Conclusion}

After data cleaning, certain variables were recoded where necessary so that higher values of scores reflect higher levels of that construct. The scales were then tested for internal reliability, which have been reported in this chapter. Upon establishment of the method, research sample (including demographics), and reliabilities of the measurement 
scales, further analysis proceeded to obtain the results. The analysis was conducted on International Business Machines (IBM) Statistical Package for Social Sciences (SPSS) version 25 where the association between variables were investigated in aggregate, and for each suburb (Karori and Southern Coast suburbs) using appropriate statistical methods. The next chapter is organised into sections relevant to each research question in this thesis, and a brief account of what was done and why is provided in order to lay out the results for interpretation in chapter six: the discussion. 


\section{Chapter five: Results}

\section{Introduction}

This chapter is organised in accordance with this study's research questions. The initial section of this chapter summarises the demographics of respondents, including their association with the social capital dimensions: SoC and neighbouring. The purpose of the first research question was to identify what New Zealanders think of as third places in their neighbourhood and what value they attach to them. In light of this, the initial section of this chapter focuses on the open-ended questions in the survey as it provides an overview of the meaning and value respondents attribute to these places. Upon identifying local third places and the favourite places of respondents in their neighbourhood, this section also considers how closely aligned Oldenburg's (1989) third place characteristics are with the ones considered important or meaningful by the survey respondents. Once we know what New Zealanders third places are, their association with social capital in the neighbourhood is explored, which is the purpose of second and third main questions of this research. For the rest of this chapter, the relationship between the informal elements of social capital (neighbouring and SoC) and features of third places (quality, frequency of visitation, and walkable distance) are explored. This section also includes separated results for Karori and the Southern Coast suburbs to see if any comparisons can be made.

\section{Demographics}

Of the 160 respondents who answered the initial set of demographic questions, the majority have lived in their neighbourhoods for a long time. 39 per cent of respondents have lived in their suburb for more than ten years, followed by 25 per cent for $5-10$ years, 17 per cent for $2-5$ years, 8 per cent for $1-2$ years, and 11 per cent for less than a year. Respondents were mostly living with their wife/husband/or partner (43 per cent), and with their children (32 per cent). The demographic composition of households also include those that live with flatmates ( 7 per cent), live alone ( 7 per cent), live with their parents ( 4 per cent), live with their siblings ( 3 per cent), and 'other' ( 4 per cent) which included living with stepchildren, parents-in-law, exchange student and in a university hall of residence. The majority of respondents own or partly own their own home (57 per cent). 11 per cent of respondents' households are held in a family trust, and 32 per cent selected 'Neither of these'. Respondents do not spend much time in their neighbourhood during the week. 48 per cent of respondents spend $0-10$ hours in their neighbourhood during the week, followed by 19 per cent who spend $11-20$ hours, 17 
per cent who spend $41-50$ hours, 9 per cent who spend $21-30$ hours, and 7 per cent who spend $31-40$ hours. On the weekend, the reverse occurs where 83 per cent of respondents spend most of their time in the neighbourhood (11-20 hours). 17 per cent of respondents spend $0-10$ hours in their neighbourhood on the weekend.

Of the 147 respondents who answered the demographic questions at the end of the survey, the overall sample (the three suburbs combined) consisted overwhelmingly of women. 75 per cent of survey respondents were female (110), 23 per cent were male, 1.3 per cent (2) were non-binary and 0.7 (1) were other. Respondents were mainly middle age, with the largest portion (31 per cent) of respondents in the $35-44$ age bracket, and the second largest ( 26 per cent) in the $45-55$ age bracket. Other age groups ranged, where 8 per cent were in the $18-24$ age group, 14 per cent were in the 25 - 34 age group, 15 per cent were in the 55 - 64 age group, and 5 per cent were in the $65-74$ age group. In addition, there was one respondent who was under the age of 18 and one respondent who was over the age of 75 . Most respondents (73 per cent) identified as New Zealand European and this was followed by 'Other' (17 per cent), Māori (7 per cent), Samoan (1 per cent), Cook Islands Maori (1 per cent), and Indian (1 per cent). The sampled population were highly educated with 35 per cent of respondents indicating that they had a Bachelor's degree, and 29 per cent with a postgraduate degree. 18 per cent of respondents had an occupational certificate or diploma, 15 per cent had a secondary school qualification, and 3 per cent had no formal qualification. Most respondents were affluent individuals as 31 per cent earn more than $\$ 100,000.15$ per cent earn between $\$ 80,001$ and $\$ 100,000,14$ per cent earn $\$ 60,001-\$ 80,000,18$ per cent earn $\$ 40,001$ - $\$ 60,000,10$ per cent earn $\$ 20,000$ - $\$ 40,000$, and 10 per cent earn less than $\$ 20,000.23$ respondents indicated that they preferred not to answer this question. As discussed in the previous chapter, demographic variables have been identified in the literature as showing an empirical association with components of social capital, such as SoC and neighbouring. A Pearson product-moment correlation analysis was performed to assess the relationship between respondents' SoC and neighbouring, with most demographic variables measured in this research. Table 9 presents the Pearson correlation coefficients $(r)$ for the correlations between SoC, neighbouring and the demographic variables. 


\begin{tabular}{l|l|l|l|l|l|l} 
& $\boldsymbol{M}$ & $\boldsymbol{S D}$ & $\boldsymbol{N}$ & SoC & Neighbouring 1 & Neighbouring 2 \\
\hline $\begin{array}{l}\text { Years } \\
\text { (neigh) }\end{array}$ & 3.76 & 1.33 & 160 & $.291^{* *}$ & $.443^{* *}$ & $.391^{* *}$ \\
$\begin{array}{l}\text { Age } \\
\text { Gender }\end{array}$ & 3.48 & 1.38 & 147 & $.225^{* *}$ & $.316^{* *}$ & $.262^{* *}$ \\
$\begin{array}{l}\text { Educatio } \\
\text { n }\end{array}$ & 3.7 & 1.14 & 147 & .076 & $.164^{*}$ & $.234^{* *}$ \\
$\begin{array}{l}\text { Income } \\
\text { Child } \\
\text { home }\end{array}$ & 4.09 & 1.72 & 124 & .007 & -.022 & $.197^{*}$ \\
$\begin{array}{l}\text { Married/ } \\
\text { Partner }\end{array}$ & .62 & .50 & 160 & $.261^{* *}$ & $.228^{* *}$ & -.028 \\
$\begin{array}{l}\text { Homeow } \\
\text { ner }\end{array}$ & 1.68 & .47 & 160 & .108 & .154 & $.207^{* *}$ \\
\end{tabular}

Preliminary analysis showed relationships to be linear in nature as assessed by scatter plots, with the data exhibiting a few outliers. The analysis was run twice, including and excluding the outliers however, this did not affect the results so the outliers were included in the analysis. All variables were evaluated to be normally distributed by the Shapiro-Wilks test ( $p>0.05$. As seen in Table 9, there were statistically significant small positive correlations between SoC and the amount of years lived in the neighbourhood, age, children at home, and whether the respondent owned their home, $r$ $=.291, r=.225, r=.261$, and $r=.264$, all $p<.005$ respectively. This means that people who have lived in their neighbourhood for longer, are older, have dependent children and/or are homeowners tend to have a higher SoC. There was a small positive correlation between SoC with gender and marital status however both were not statistically significant, $r=.140, r=.108$ respectively. There was no correlation between SoC and education and income, $r=.076$ and $r=.007$ respectively. This means that how educated one is or how much one earns does not affect their SoC. As seen in Table 9, there were statistically significant moderate correlations between years lived in the neighbourhood, age, and homeownership with 'neighbouring 1' which is an acronym for the amount of neighbours respondents know in their neighbourhood, $r=$ $.443, r=.316, r=.319$, all $p<0.005$ respectively. This means that people who have lived in their neighbourhood for longer, are older, and own their own home tend to know more people in their neighbourhood. There were also statistically significant positive small correlations between the amount of neighbours a respondent knew with education and with whether the respondent had children living at home, $r=.234$ and $r=$ .228 , all $p<.005$ respectively. A statistically significant positive small correlation between the amount of neighbours and gender also was found, $r=.164, p<.05$. There 
was no correlation between the amount of neighbours a respondent knew with income and marital status. The final component of social capital that was correlated with demographics was the second measure of neighbouring: frequency of interaction; acronym given 'neighbouring 2'. Similar to the first measure of neighbouring, there was a statistically significant positive moderate correlation between years lived in the neighbourhood and the frequency of interaction a respondent has with their neighbours, $r=.391, p<.005$. Statistically significant positive small correlations were also found for frequency of interaction with neighbours and age, children living at home, and homeownership, $r=.262, r=.187, r=.195, r=.207$, and $r=.242$, all $p=.005$ respectively. This means that people who are older, have dependent children and/or own their own home tend to interact with their neighbours more often. There was no correlation found for income and marital status with frequency of interaction a respondent had with their neighbours, $r=-.028$, and $r=.043$ respectively. While the relationship between components of social capital and demographic variables is not central to this research, the analysis performed above was included because it reiterates the findings of previous research in related literature that the built environment is not the only contextual aspect of a community's environment that can influence social capital in the neighbourhood.

\section{Research Question 1: Respondents' perceptions of third places}

The first research question asked about the meaning and value of third places for New Zealanders. To answer this question, two sub-questions were used. The first subquestion aimed to identify where residents of a neighbourhood congregate at that are outside of their home and workplace. Included in the survey were three questions that were developed to answer this sub-question, by asking respondents about their opinion of places in their neighbourhood that they believe host frequent, casual, voluntary and happily anticipated gatherings of people. These questions obtained information about how respondents met others in their neighbourhood, what places they think fit Oldenburg's (1989) third place definition, and what their favourite place is in the neighbourhood. Two of the three survey questions were open-ended, allowing respondents to freely consider their own perceptions of third places and include as much information on the issue as they would like. Included in chapter four was a summary of the most popular words that were used by respondents. Using open-ended questions prompted a process of recoding the responses into descriptive categories making it 
easier to analyse. This section will report the results for each of the three questions in order of appearance in the survey.

\begin{tabular}{r|c}
$\begin{array}{r}\text { Where respondents met } \\
\text { in the neighbourhood }\end{array}$ & \# of respondents \\
\hline Through children/school & $68(43 \%)$ \\
Met in street & $50(31 \%)$ \\
Being neighbours & $48(30 \%)$ \\
Through pets & $37(23 \%)$ \\
Bus-stop & $30(19 \%)$ \\
Through community & $26(16 \%)$ \\
group & \\
Through sport & $24(15 \%)$ \\
Met at local shops & $21(13 \%)$ \\
Met at local café & $18(11 \%)$ \\
Met in park/bushland & $16(10 \%)$ \\
Through clubs & $12(8 \%)$ \\
Through church & $12(8 \%)$ \\
Online & $5(3 \%)$ \\
Met at community & $1(1 \%)$ \\
garden & \\
Other & $26(16 \%)$ \\
Does not apply to me & $5(3 \%)$ \\
The &
\end{tabular}

The first question in the survey that helps to identify where residents of a neighbourhood congregate at that are outside of their home and workplace, asked respondents to identify how they met fellow residents in their neighbourhood. Table 10 summarises these responses. Interestingly, the most commonly cited ways in which residents met others in their neighbourhood were not from visiting 'third places' (as conceptualised by Oldenburg) but through their children (43 per cent), in the street (31 per cent), being neighbours ( 30 per cent) or through their pets ( 23 per cent). It must be noted that 52 per cent of total respondents indicated that they had children living at home, and this may be why there was a high number of respondents who cited that they met others in their neighbourhood through their children. Towards the bottom of the list are references to Oldenburg's version of third places, including the local shops, cafés, clubs and church however, less than 20 per cent of respondents noted these as important for facilitating relationships with fellow residents. As mentioned in chapter four, the benefit of asking this question is that it helps to understand what types of environments help foster and promote social interaction between residents. Based on the data it appears that having children attending school in the neighbourhood, walking or being 
'out' and 'about' on the street, and living near others are the most common avenues to get to know others in one's neighbourhood.

As it now has been established, residents most commonly meet one another in environments that are not classically known as third places. A question was included in the survey asking respondents for their perceptions of what constitutes a third place in their neighbourhood. The question referred to Oldenburg's definition of a third place as a place that hosts frequent, casual, voluntary and happily anticipated gatherings of people. Table 11 summarises the types of third places listed by respondents.

\begin{tabular}{r|c} 
Types of third place & $\begin{array}{c}\text { \# of } \\
\text { respondents }\end{array}$ \\
\hline Restaurants, cafes, bars, pubs & $87(64 \%)$ \\
recreation & $52(39 \%)$ \\
School, kindergarten, playground & $51(38 \%)$ \\
centre & $50(37 \%)$ \\
Church & $40(30 \%)$ \\
Library & $39(29 \%)$ \\
Rec centre, pool, cinema, gym/health, craft & $36(27 \%)$ \\
Community centre, community garden & $34(25 \%)$ \\
Shops, mall, supermarket, doctor's surgery & $20(15 \%)$ \\
Farmers' market, festivals, galas & $7(5 \%)$ \\
Bus-stop & $6(4 \%)$ \\
The street & $4(3 \%)$ \\
Neighbours' house & $4(3 \%)$ \\
None, don't know & $14(10 \%)$ \\
Miscellaneous & $9(7 \%)$
\end{tabular}

Table 11: Third places identified by respondents

The most frequently cited third places were food-related. Restaurants, cafes, bars and pubs, were cited by nearly two-thirds (64 per cent) of respondents. A break-down of this finds that cafes were cited by 36 per cent of total respondents followed by the pub (15 per cent of respondents), and restaurants and bars (13 per cent of respondents). While many participants referred to 'cafes' or 'the pub' in general, many participants cited specific names of places in their neighbourhood. For example, in Karori the cafes and bars: One Fat Bird, The Pickle Jar and the Karori Park Cafe were cited on several occasions by different respondents' as examples of third places in their suburb. In the South Coast Suburbs (mainly Lyall Bay), the café Maranui was cited by several respondents as a local third place. In addition, several respondents who cited the pub, bar or restaurant as a third place also included the description of an activity held at that 
particular venue that may have been the reason for it hosting frequent, casual, voluntary and happily anticipated gatherings of people. For example, five respondents from Karori referred to the pub quiz night held at two local establishments. The second most commonly cited third places were those that were nature-related and located outside. Twenty-four respondents cited the park as a third place, and 15 respondents from the Southern Coast suburbs cited the beach. A few other respondents that also cited walking tracks, a sports field or a bush reserve. The third most commonly cited third places were connected to or involved children: the school (33 respondents), kindergarten or playcentre (13 respondents), and the playground (5 respondents). Similar to the foodrelated third places, respondents cited activities or events that occur at these places. For example, a few respondents noted 'school events', 'school sports events' and 'school fairs' as fitting the third place description by Oldenburg (1989), and one respondent cited 'school pick-ups' and 'drop-offs' where parents have a brief opportunity in the morning and afternoon to interact with one another. Included in the miscellaneous bracket, but related to children, was a respondent who cited 'kids parties' as also fitting the third place description. What was also found was that 14 respondents either cited 'none' or 'don't know' when asked to identify third places in their neighbourhood. Eight respondents either were unsure or could not think of any, four respondents said 'none', one respondent did not understand the question, and one other said there 'probably was a lot [third places]' but they were 'not interested'. Nonetheless, it appears that most of the respondents held the belief that third places still exist in their neighbourhood. Down the list of third places cited by respondents included a wide variety of clubs, organisations and groups (27 per cent), the community centre and garden ( 25 per cent) and retail-based venues (15 per cent). Finally, there were a few 'miscellaneous' places cited ( 7 per cent) including, events advertised in a Karori Facebook group, open homes, a local maths tutoring business, a cooking school and one respondent referenced a neighbouring suburb.

Asking participants about the places in their neighbour that host frequent, casual, voluntary and happily anticipated gatherings of people revealed that food-related establishments, natural or outdoor places, the school, and places of recreation fit the description of local third places. The final part of answering the first sub-question was to gather information about respondents' own favourite place in their neighbourhood. Table 12 summarises the responses below. 


\begin{tabular}{r|c} 
Favourite place & \# of respondents \\
\hline Park & $35(23 \%)$ \\
Beach & $33(22 \%)$ \\
Nature place & $21(14 \%)$ \\
Café & $18(12 \%)$ \\
Library & $9(6 \%)$ \\
Shop & $7(5 \%)$ \\
Street & $5(3 \%)$ \\
Place of outdoor recreation & $4(3 \%)$ \\
Kindergarten/School & $4(3 \%)$ \\
Supermarket & $4(3 \%)$ \\
Bar/pub & $4(3 \%)$ \\
Sport's club facilities & $3(2 \%)$ \\
Restaurant & $1(1 \%)$ \\
Marae & $1(1 \%)$ \\
Home & $1(1 \%)$
\end{tabular}

Table 12: Favourite local places of respondents

The most frequently cited favourite place of respondents were places of nature, including the park, beach or other nature places such as walking tracks or bush reserves. The park was cited by 23 per cent of total respondents. If broken down by gender, the top three most commonly cited third places by males were in line with the overall sample, with 25 per cent citing the beach or a place of nature or outdoor recreation, and 13 per cent citing the park. The top most commonly cited favourite places by females almost mirrored that of males where the park ( 27 per cent) and the beach ( 23 per cent) were the two most commonly cited favourite places, followed by 15 per cent of females who cited a place of nature or outdoor recreation. The three respondents who identified as 'non-binary' (two respondents) and 'other' (one respondent) cited the beach, park, and shop as their favourite places. When broken down by age, the same patterns are found where in all of the different age groups, the beach or park were the most commonly cited favourite place. Table 13 summarises the responses by age group. For the older age groups of 55-64 and 65-74, references to places of nature or outdoor recreation came up equal with the beach. In addition to the results before, there was one respondent less than 18 years of age and, one participant who was $75+$ years who completed the survey. Both respondents cited a place of nature or for outdoor recreation as their favourite place. 


\begin{tabular}{l|llllll} 
& $18-24$ & $25-34$ & $35-44$ & $45-54$ & $55-64$ & $65-74$ \\
\hline Beach & $\mathbf{2 5 \%}$ & $20 \%$ & $20 \%$ & $23 \%$ & $\mathbf{2 3 \%}$ & $\mathbf{2 9 \%}$ \\
Park & $\mathbf{2 5 \%}$ & $\mathbf{3 0 \%}$ & $\mathbf{2 7 \%}$ & $\mathbf{2 6 \%}$ & $14 \%$ & $14 \%$ \\
Library & $8 \%$ & & $2 \%$ & $8 \%$ & $14 \%$ & $14 \%$ \\
Bar/pub & $8 \%$ & $10 \%$ & $2 \%$ & & & \\
Shop & $17 \%$ & $5 \%$ & $7 \%$ & & $5 \%$ & \\
Nature/outdoor rec & $8 \%$ & $10 \%$ & $13 \%$ & $18 \%$ & $\mathbf{2 3 \%}$ & $\mathbf{2 9 \%}$ \\
Café/restaurant & $8 \%$ & $15 \%$ & $16 \%$ & $13 \%$ & $14 \%$ & \\
Sport's clubroom & & $10 \%$ & $2 \%$ & & & \\
Supermarket & & & $4 \%$ & & & \\
Kindergarten/School & & & $4 \%$ & $3 \%$ & & \\
The street & & & $2 \%$ & $3 \%$ & $9 \%$ & \\
Miscellaneous & & & & $3 \%$ & & $14 \%$ \\
Marae & & & & $3 \%$ & & \\
Not applicable & & & & $3 \%$ & & \\
Home & & & & &
\end{tabular}

Table 13: Favourite place by age group

In Karori, the amount of respondents who cited the park was higher than the total average (28 per cent). Figure 6 visually represents the favourite places of Karori residents. Of the Karori respondents who cited the park as their favourite place, approximately three-quarters specifically cited 'Karori Park'. Karori Park is the largest recreational park in Karori that features a football and cricket sports ground, a 1 kilometre loop track, changing rooms, a café, outdoor exercise machines, and a playground. Its accessibility means that it is popular with residents of all ages and abilities. In addition to parks, almost one quarter of respondents from Karori cited a place of nature or of outdoor recreation as their favourite place. A further breakdown of those that chose natural places reveals that eight respondents from Karori cited either the Wrights Hill Reserve or Johnston's Hill Reserve as their favourite place.

Furthermore, four respondents cited the local wildlife sanctuary (Zealandia), and two respondents noted that the bush tracks around and within Karori cemetery were their favourite place. Other respondents referred to bush tracks or reserves more generically. Cafés represented the third most popularly cited (12 per cent) favourite place of Karori residents. Of those who cited the café as their third place, four cited Gipps Street Deli and three cited the café that is attached to Karori Park. Shops, the library, the bar/pub and school were also places referenced by residents. Despite a reminder in the survey question for respondents to think of a place that is outside of their home or workplace, one respondent noted that this was their favourite place. While 'the home' is not traditionally considered to be a third place, critics of the third place concept argue that third places should be defined by the use for which the place serves, rather than for its physical characteristics (Purnell, 2015). 


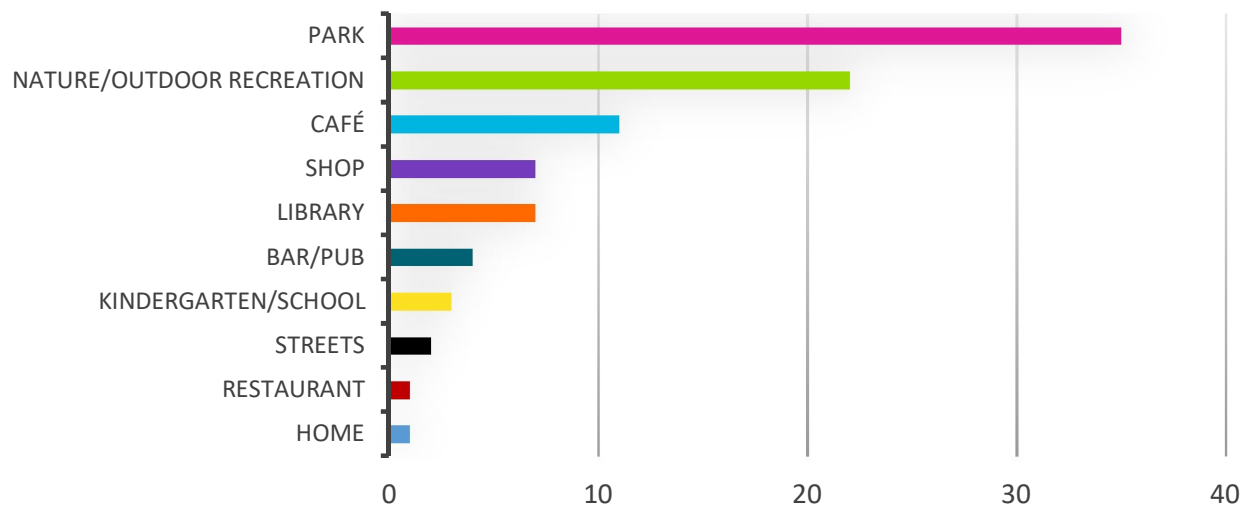

Figure 6: Karori residents' favourite place

Figure 7 visually represents the favourite places of Southern Coast suburbs residents. Of those that reside in the Southern Coast suburbs just over half (56 per cent) cited the beach as their favourite place. Similar to residents' in Karori, respondents from the Southern Coast rated highly the café as their third place, with more than one reference to Maranui and the Spruce Goose as favourite cafés of Lyall Bay residents. In contrast to Karori however, was that sport clubrooms (soccer) was among the top favourite places for residents in the Southern Coast suburbs. It may be important to note that the three respondents who cited a sport club as their third place were all from Island Bay. There was one place that could not be classified into a particular category, as the respondent provide a response that could either be interpreted as a street name in their respective suburb or as a pool in the central city.

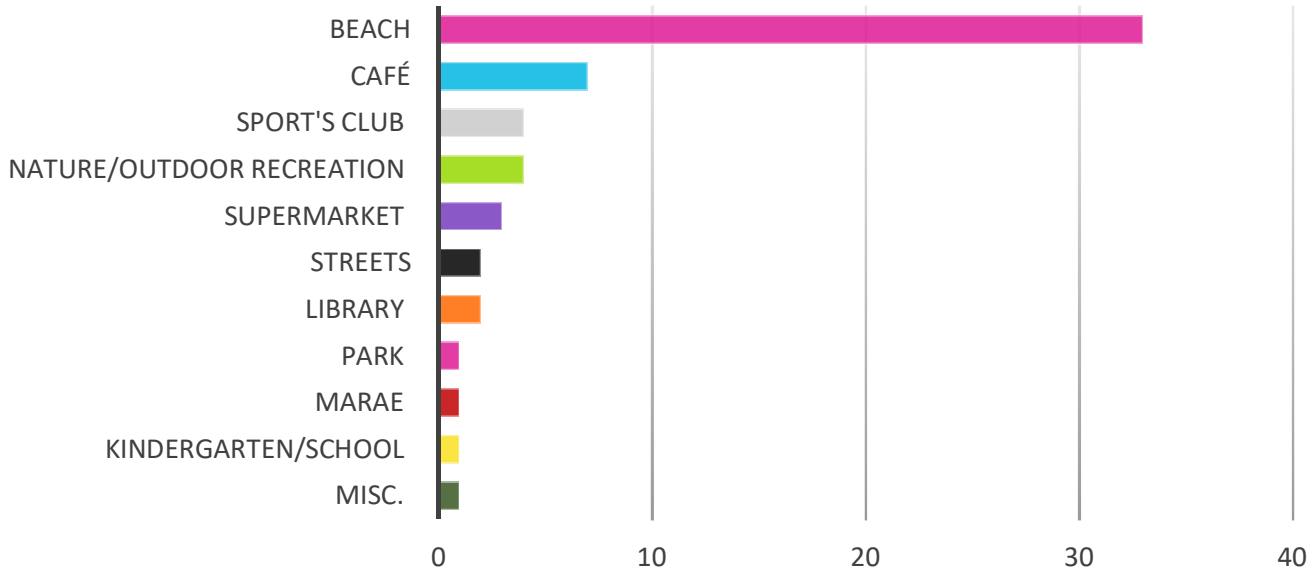

Figure 7: Southern Coast residents' favourite place

The first sub-research question intended to help find the meaning of third places, and the second sub-question was developed to help answer the second part of the main 
research question, which aims to understand the value respondents attribute to third places in their neighbourhood. As the survey question asking respondents about their favourite place in the neighbourhood is not directly associated with the description of a 'third place' (such as is survey question 38), a question was included in the survey asking respondents to select up to eight characteristics that they think describe this place. These eight characteristics are the ones conceived by Oldenburg (1989) that he considers represent a 'third place'. Table 14 shows the amount of respondents who selected each third place characteristic.

\begin{tabular}{|c|c|}
\hline Third place characteristic & $\begin{array}{c}\text { \# of respondents who } \\
\text { selected this } \\
\text { characteristic }\end{array}$ \\
\hline $\begin{array}{l}\text { It is a place where people can come and go } \\
\text { as they please and no one is required to play } \\
\text { host }\end{array}$ & $78 \%$ \\
\hline $\begin{array}{l}\text { It is a place where there are people from all } \\
\text { walks of life, and there are no set formal } \\
\text { criteria of membership and inclusion }\end{array}$ & $75 \%$ \\
\hline $\begin{array}{l}\text { It is located not far from where I live and I } \\
\text { can frequent it at hours of the day or night } \\
\text { that suit me }\end{array}$ & $70 \%$ \\
\hline $\begin{array}{l}\text { It is a place that gives me an urge to return, } \\
\text { recreate and recapture the experience I feel } \\
\text { when I am there }\end{array}$ & $59 \%$ \\
\hline $\begin{array}{l}\text { It is a place that does not feel or look } \\
\text { extravagant but has wholesome } \\
\text { characteristics }\end{array}$ & $52 \%$ \\
\hline $\begin{array}{l}\text { It offers a welcoming environment and has a } \\
\text { 'homely feel' }\end{array}$ & $39 \%$ \\
\hline $\begin{array}{l}\text { It is a place where there are 'regulars' who } \\
\text { visit it often. These people give the place its } \\
\text { tone and set the mood, but also are there to } \\
\text { help someone new to feel welcome }\end{array}$ & $34 \%$ \\
\hline $\begin{array}{l}\text { Engaging in conversation is the main activity } \\
\text { in this place }\end{array}$ & $11 \%$ \\
\hline
\end{tabular}

From Table 14, one can interpret that respondents' favourite places are on neutral ground, are inclusive, and accessible and accommodating. The most commonly cited characteristic ( 78 per cent of respondents) is that it is on neutral ground. Oldenburg (1989) argues that in the city and its neighbourhoods there must be places where people 
can "come and go as they please, in which no one is required to play host, and in which all feel at home and comfortable" (Oldenburg, 1989, p. 22). Secondly, a large majority of respondents believe their favourite place to be a leveller. Oldenburg (1989) states that a third place should be an inclusive place that is accessible to the general public.

Furthermore, just over half of total respondents believe their favourite place to have a low profile and a playful mood that makes them want to visit that place again. Similar to the findings made by Hawkins and Ryan (2013), Laing and Royle (2013), and Slater and Koo (2010) the act of engaging in conversation was not rated highly by respondents (11\%). Other characteristics that respondents felt were less important include that is was a 'home away from home' and that it is a place with 'regulars'.

\begin{tabular}{rr|r}
$\begin{array}{r}\text { \# of } \\
\text { raracteristics } \\
\text { selected }\end{array}$ & $\begin{array}{r}\text { respondents } \\
\text { respor }\end{array}$ & $\begin{array}{r}\text { cumulative } \\
\text { frequency }\end{array}$ \\
\hline 1 & $8(5.5 \%)$ & $5.5 \%$ \\
2 & $12(8.3 \%)$ & $13.8 \%$ \\
3 & $18(12.4 \%)$ & $26.2 \%$ \\
4 & $27(18.6 \%)$ & $44.8 \%$ \\
5 & $35(24.1 \%)$ & $69 \%$ \\
6 & $22(15.2 \%)$ & $84.1 \%$ \\
7 & $17(11.7 \%)$ & $95.9 \%$ \\
8 & $6(4.1 \%)$ & $100 \%$
\end{tabular}

Table 15: total characteristics selected by respondents

While it is interesting to understand what characteristics respondents attribute to their third place, this question can only tell us the popularity of each third place characteristic on its own. Oldenburg (1989) claims that a third place possesses all eight characteristics and that these qualities are universal and essential to an informal public life. Research on third places after 2010 has challenged the salience of Oldenburg's third place criteria however, these studies have only called into question one or two particular characteristics. Taking this into account, this study aimed to test how important these characteristics in a 2019 New Zealand context, and therefore had a question asking respondents to choose up to as many characteristics as they like that describe their favourite place. Table 15 summarises the number of characteristics that were selected 
by respondents. The median number of characteristics that were chosen by respondents was five. The average number of characteristics selected was 4.6, with a standard deviation of 1.78. There were six respondents who selected all eight characteristics, where four respondents cited food venues (café, bar, pub) and two cited the beach.

\section{Research Question 2: Third places and SoC}

The second research question of this thesis asks about the relationship between residents' perceptions of their third place and SoC in a neighbourhood. As described in chapter four, each respondents' SoC was calculated by adding up their scores (based on the 7-point Likert scale) for each of the 12 SoC questions, and then dividing their total score by 12 to find their average SoC overall. ' 1 ' in the survey question corresponded with 'strongly disagree' and a low SoC, and '7' in the survey question corresponded with 'strongly agree' and a high SoC. From an inspection of the data, the lowest score found for SoC was ' 3 ' from a respondent residing in Lyall Bay, and the highest score found for SoC was '7' from a respondent residing in Island Bay. Overall the average SoC for all survey respondents was 5.09. As seen in Table 16, the average SoC for each suburb demonstrates that the Southern Coast suburbs had a slightly higher average SoC than Karori.

\begin{tabular}{r|r|l|l} 
Suburbs & SoC & SD & $N$ \\
\hline Southern Coast & & .724 & 160 \\
suburbs & 5.122 & & \\
Karori & 5.063 & .737 & 99 \\
All & 5.085 & .707 & 61
\end{tabular}

Table 16: SoC scores (neighbourhood and total)

A Pearson's product-moment correlation analysis was run to assess the relationship between respondents' SoC on the one hand, and visits to third places, perceived quality of third places, and distance to third places (from their place of residence) on the other. The Pearson product-moment correlation was used to answer the sub-research questions of this study as it is used to determine the strength and direction of a linear relationship between two continuous variables. Table 17 presents the Pearson correlation coefficients $(r)$ for the correlations between SoC and all three of the third place variables.

\begin{tabular}{l|l|l|l} 
& $\begin{array}{l}\text { Visits } \\
\text { to TP }\end{array}$ & $\begin{array}{l}\text { Quality } \\
\text { of TP }\end{array}$ & $\begin{array}{l}\text { Distance } \\
\text { to TP }\end{array}$ \\
\hline SoC & .078 & $.194^{*}$ & -.089 \\
SoC Karori & .075 & $.248^{*}$ & -.087 \\
SoC SC Suburbs & .062 & .118 & -.072
\end{tabular}

Table 17: Pearson correlation statistics between variables 
*. Correlation is significant at the 0.05 level (two-tailed).

Preliminary analysis showed relationships to be linear in nature as assessed by scatter plots, with the data exhibiting a few outliers, mainly for the quality measure and the visit measure. The analysis was run twice, including and excluding the outliers however, this did not affect the results, so the outliers were included in the analysis. SoC was evaluated to be normally distributed by the Shapiro-Wilks test $(p>0.05)$ however, all three of the third place variables were not. To check whether the nonnormality of the data affected the results, a Spearman's rank order correlation was performed, but there was little change in the coefficients. It has been argued that the Pearson's test is relatively robust to deviations from normality so the results were proceeded with for the data presentation in this section (Cohen, 1988). As seen in Table 17 , there was a statistically significant small positive correlation between SoC and quality of third place, $r=.194, p<.05$. In the suburb of Karori, there also was a statistically significant small positive correlation between SoC and quality of third place, $r=.248$. In the Southern Coast suburbs, there was a small positive correlation between SoC and third place quality however, it was not statistically significant. Perceptions of third place quality therefore explained 3.8 per cent of the variability in SoC overall, and for Karori this slightly increased to 6.2 per cent. Overall, there was a very weak correlation between SoC and the other two third place variables, visits to third place and distance to third place from the respondents' home, $r=.078$ and $r=$ .089 respectively. The very weak correlation between $\mathrm{SoC}$ and visits to third place, and distance to third place was also seen for Karori and the Southern Coast suburbs. The Pearson product-moment correlation analysis provided above helps answer SRQ2.1 and SRQ2.2, whereby no statistical correlations between SoC and distance and visits to third places were found. The analysis also helps answer SRQ2.3 where a statistically significant small positive correlation was found between $\mathrm{SoC}$ and quality of third places.

To answer the entirety of the second research question of this study, a standard multiple regression analysis was performed to control for certain demographic variables that have been previously tested in related literature (Francis et al., 2012; French et al., 2014). A regression test was used to help answer the second research question because it is used to predict a continuous dependent variable based on multiple independent variables. In this case, this study is interested to understand the association between residents' perceptions of their third place and their SoC, whilst controlling for eight 
demographic variables. Three separate regressions were performed for the three third place variables because they will separately help answer the sub-research questions: SRQ2.1, SRQ2.2, and SRQ2.3.

\section{SRQ2.1: Quality}

A multiple regression was run to predict SoC from perceived quality of third places, age, gender, education, income, home ownership, children at home, marital/de facto status, and length of residence. There was linearity as assessed by partial regression plots and a plot of studentised residuals against the predicted values. There was homoscedasticity, as assessed by visual inspection of a plot of studentised residuals versus unstandardized predicted values. There was no evidence of multicollinearity as assessed by tolerance values greater than 0.1 There were no studentised deleted residuals greater than \pm 3 standard deviations, no leverage values greater than 0.2 , and values for Cook's distance above \pm 1 . The assumption of normality was met as assessed by a Q-Q Plot. The multiple regression statistically significantly predicted SoC, $F(9$, $112)=3.3, p<0.005$. The quality variable added statistically significantly to the prediction $(p<0.05)$. Regression coefficients and standard errors can be found in Table 18.

\begin{tabular}{l|l|l|l}
\hline Variable & $\boldsymbol{B}$ & $\boldsymbol{S} \boldsymbol{E}_{\boldsymbol{B}}$ & $\boldsymbol{\beta}$ \\
\hline Quality & .256 & .089 & $.249^{*}$ \\
Age & .037 & .059 & .066 \\
Gender & .206 & .144 & .124 \\
Education & -0.21 & .055 & -.033 \\
Income & -.040 & .041 & -.094 \\
Home ownership & -.216 & .144 & -.186 \\
Children at home & .215 & .155 & .148 \\
Marital status & -.126 & .150 & -.081 \\
Length of residence & .086 & .055 & .161 \\
\hline
\end{tabular}

Table 18: Regression results - SoC and third place quality

SRQ2.2: Distance

A multiple regression was run to predict SoC from perceived distance of a third place from a participant's home, age, gender, education, income, home ownership, children at home, marital/de facto status, and length of residence. The multiple regression statistically significantly predicted $\mathrm{SoC}, F(9,112)=2.644, p<0.05$. The distance variable did not statistically significantly add to the prediction. Regression coefficients and standard errors can be found in Table 19. 


\begin{tabular}{l|l|l|l}
\hline Variable & $\boldsymbol{B}$ & $\boldsymbol{S E}_{\boldsymbol{B}}$ & $\boldsymbol{\beta}$ \\
\hline Distance & -.164 & .092 & -.161 \\
Age & .034 & .060 & .060 \\
Gender & .179 & .148 & .108 \\
Education & .016 & .056 & .026 \\
Income & -.020 & .042 & -.047 \\
Home ownership & -.133 & .146 & -.114 \\
Children at home & .265 & .159 & .183 \\
Marital status & -.130 & .153 & -.083 \\
Length of residence & .097 & .056 & .182 \\
\hline
\end{tabular}

\section{Table 19: Regression results - SoC and third place distance}

SRQ2.3: Visits

A multiple regression was run to predict SoC from how often a participant visited their third place from a participant's home, age, gender, education, income, home ownership, children at home, marital/de facto status, and length of residence. The multiple regression statistically significantly predicted $\operatorname{SoC}, F(9,112)=2.416, p<0.05$. The visits variable did not statistically significantly add to the prediction. Regression coefficients and standard errors can be found in Table 20 .

\begin{tabular}{l|l|l|l}
\hline Variable & $\boldsymbol{B}$ & $\boldsymbol{S E}_{\boldsymbol{B}}$ & $\boldsymbol{\beta}$ \\
\hline Visits & & & \\
Age & .022 & .060 & .039 \\
Gender & .227 & .148 & .137 \\
Education & -.005 & .056 & -.008 \\
Income & -.018 & .042 & -.043 \\
Home ownership & -.159 & .146 & -.137 \\
Children at home & .225 & .160 & .155 \\
Marital status & -.116 & .156 & -.074 \\
Length of residence & .092 & .057 & .173 \\
\hline
\end{tabular}

Table 20: Regression results - SoC and third place visits

\section{Research Question 3: Third places and neighbouring}

As described in chapter four, this research has two measures for the social capital dimension of neighbouring, which are the average amount of neighbours a participant has (NGHBR 1), and the average frequency of interaction a participant has with their neighbours (NGHBR 2). From an inspection of the data participants knew a median of 6-7 people by name in their neighbourhood. Participants had a median of 1-2 neighbours that they would feel comfortable talking to about private matters, have over to their house for a cup of tea, and would feel comfortable asking them to look after their mailbox if they went on holiday. Participants had a median of zero neighbours that they dislike. On average, participants said hello to their neighbours and/or had an informal chat at least once a week, give and/or receive help to their neighbours a few times a year, and participate in an activity with their neighbours once a year. A question 
was included to attest whether participants are satisfied with the degree of relationships they hold with their neighbours and on average, most are satisfied with the type and frequency of interactions (as described above). A further summary of both neighbouring measures and separated for each suburb is provided below in Table 21.

\begin{tabular}{r|r|l|l|l|l|l} 
Suburbs & NGHBR1 & SD & $\boldsymbol{N}$ & NGHBR2 & SD & $\boldsymbol{N}$ \\
\hline Southern Coast & & .82 & 61 & 3.369 & .846 & 61 \\
suburbs & 2.53 & & & & & \\
Karori & 2.76 & .89 & 99 & 3.557 & .955 & 99 \\
All & 2.68 & .87 & 160 & 3.486 & .917 & 160
\end{tabular}

Table 21: Descriptive statistics for neighbouring scores

A product-moment Pearson correlation analysis was run to assess the relationship between both neighbouring scores and respondents' visits to third places, perceived quality of third places, and distance to third places (from their place of residence). The Pearson product-moment correlation was used to answer the sub-research questions of this study's third research question as it can determine the strength and direction of a linear relationship between two continuous variables. Table 22 presents the Pearson correlation coefficients $(r)$ for the correlations between both neighbouring scores and all three of the third place variables. Preliminary analysis showed relationships to be linear in nature as assessed by scatter plots, with the data exhibiting no outliers. Both neighbouring scores were evaluated to be normally distributed by the Shapiro-Wilks test $(p>0.05)$ however, all three of the third place variables were not. To check whether the non-normality of the data affected the results, a Spearman's rank order correlation was performed, but there was little change in the coefficients. As seen in Table 22, there was no correlation between 'neighbouring 1' and visits to third place, and perceived quality of third place, $r=-.064$, and $r=.028$, respectively. There was a statistically significant small negative correlation between 'neighbouring 1 ' and distance to third places, $r=$ $.173, p<0.05$. In the suburb of Karori, there was no correlation between 'neighbouring 1 ' and visits to third place, and perceived quality of third place however, there existed a small positive correlation between distance to third places and 'neighbouring 1'. In the Southern Coast suburbs, there was also no correlation between 'neighbouring 1' and both visits to third places and perceived quality of third places. In contrast to Karori, there existed a small negative correlation between 'neighbouring 1' and distance to third places in the Southern Coast suburbs. Overall, there was no correlation between the number of neighbours a respondent knew and two of the third place variables, visits and perceived quality. There was however, a statistically significant negative correlation between the number of neighbours a respondent knew with distance to third places 
(from their home). In saying this, the overall correlation between distance to third places and 'neighbouring 1' is not an accurate representation of the data, as there was a small positive correlation between these two variables in Karori. As seen in Table 22, there was no correlation between 'neighbouring 2' and visits to third places and perceived quality of third places however, there was a small negative correlation between 'neighbouring 2' and distance to third places, $r=-.125$. For the Southern Coast suburbs, there was no correlation between 'neighbouring 2' and visits to third places, and perceived quality of third places, $r=.041$ and -.099 respectively however, there was a small negative correlation with distance to third places, $r=-.118$. For Karori, there was no correlation between 'neighbouring 2' and all three of the third place variables, $r=-$ $.086, .024$, and .090 respectively. Overall, how often respondents interact with their neighbours had no correlation with how often they visit their third place or how they perceive the quality of their third place, and had a small negative correlation with how far away they live from their third place, although not statistically significant.

\begin{tabular}{l|l|l|l} 
& $\begin{array}{l}\text { Visits } \\
\text { to TPs }\end{array}$ & $\begin{array}{l}\text { Quality } \\
\text { of TPs }\end{array}$ & $\begin{array}{l}\text { Distance } \\
\text { to TPs }\end{array}$ \\
\hline NGHBR 1 & -.064 & .028 & $.173^{*}$ \\
NGHBR 1 Karori & -.082 & .095 & .115 \\
NGHBR 1 SC Suburbs & .011 & -.080 & .254 \\
NGHBR 2 & -.054 & -.021 & .125 \\
NGHBR 2 Karori & -.086 & .024 & .110 \\
NGHBR 2 SC Suburbs & .041 & -.099 & .118
\end{tabular}

Table 22: Pearson correlation statistics for neighbouring scores

*. Correlation is significant at the 0.05 level (two-tailed).

To answer the entirety of the third research question of this study, a standard multiple regression analysis was performed to control for certain demographic variables that have been previously tested in related literature (Francis et al., 2012; French et al., 2014). A regression test was used to help answer the third main research question because it is used to predict a continuous dependent variable based on multiple independent variables. In this case, this study is interested to understand the association between residents' perceptions of their third place and their level of neighbouring, whilst controlling for eight demographic variables. Three separate regressions were performed for the three third place variables. These regression analyses are aligned with intentions of SRQ3.1, SRQ3.2, and SRQ3.3. Because this research had two measures for neighbouring, separate regressions were run for both measures. 
SRQ3.1: Quality

A multiple regression was run to predict the first neighbouring measure (neighbouring

1) from perceived quality of third places, age, gender, education, income, home ownership, children at home, marital/de facto status, and length of residence. All assumptions were met. The multiple regression statistically significantly predicted neighbouring $1, F(9,112)=5.567, p<0.0005$. The quality variable did not statistically significantly add to the prediction however, the length of residence variable added statistically significantly to the prediction $(p<0.005)$. Income and education also added statistically significantly to the prediction $(p<0.05)$. Regression coefficients and standard errors can be found in Table 23.

\begin{tabular}{l|l|l|l}
\hline Variable & $\boldsymbol{B}$ & $\boldsymbol{S E}_{\boldsymbol{B}}$ & $\boldsymbol{\beta}$ \\
\hline Quality & .093 & .105 & .072 \\
Age & .012 & .069 & .018 \\
Gender & .233 & .169 & .111 \\
Education & .129 & .065 & $.165^{*}$ \\
Income & -.106 & 0.49 & $-.200^{*}$ \\
Home ownership & -.246 & .170 & -.167 \\
Children at home & .129 & .183 & .071 \\
Marital status & .054 & .177 & .027 \\
Length of residence & .240 & .065 & $.357^{* *}$ \\
\hline
\end{tabular}

Table 23: Regression results - neighbouring 1 and third place quality

*. Correlation is significant at the 0.05 level (two-tailed).

** Correlation is significant at the 0.005 level (two-tailed).

A multiple regression was run to predict the second neighbouring measure

(neighbouring 2) from perceived quality of third places, age, gender, education, income, home ownership, children at home, marital/de facto status, and length of residence. All assumptions were met. The multiple regression statistically significantly predicted neighbouring $1, F(9,112)=3.666, p<0.0005$. The quality variable did not statistically significantly add to the prediction however, the length of residence variable added statistically significantly to the prediction $(p<0.005)$. Regression coefficients and standard errors can be found in Table 24.

\begin{tabular}{l|l|l|l}
\hline Variable & $\boldsymbol{B}$ & $\boldsymbol{S E}_{\boldsymbol{B}}$ & $\boldsymbol{\beta}$ \\
\hline Quality & .002 & .112 & .002 \\
Age & .041 & .074 & .057 \\
Gender & .264 & .180 & .125 \\
Education & .125 & .069 & .158 \\
Income & -.068 & .052 & -1.27 \\
Home ownership & .080 & .181 & .054 \\
Children at home & .384 & .195 & .209 \\
Marital status & -.156 & .189 & -.078 \\
Length of residence & .215 & .069 & $.318^{*}$ \\
\hline
\end{tabular}

Table 24: Regression results - neighbouring 2 and third place quality 


\section{SRQ3.2: Distance}

A multiple regression was run to predict the first neighbouring measure (neighbouring 1) from perceived distance of third places from a participant's home, age, gender, education, income, home ownership, children at home, marital/de facto status, and length of residence. All assumptions were met. The multiple regression statistically significantly predicted neighbouring $1, F(9,112)=5.600, p<0.0005$. The distance variable did not statistically significantly add to the prediction however, the length of residence variable added statistically significantly to the prediction $(p<0.005)$. Income and education also added statistically significantly to the prediction $(p<0.05)$.

Regression coefficients and standard errors can be found in Table 25.

\begin{tabular}{l|l|l|l}
\hline Variable & $\boldsymbol{B}$ & $\boldsymbol{S}_{\boldsymbol{B}}$ & $\boldsymbol{\beta}$ \\
\hline Distance & .105 & .106 & .082 \\
Age & .002 & .069 & .003 \\
Gender & .263 & .171 & .125 \\
Education & .128 & .065 & $.164^{*}$ \\
Income & -.103 & .048 & $-.193^{*}$ \\
Home ownership & -.238 & .168 & -.162 \\
Children at home & .122 & .183 & .067 \\
Marital status & .044 & .177 & .022 \\
Length of residence & .234 & .065 & $.349^{* *}$ \\
\hline
\end{tabular}

Table 25: Regression results - neighbouring 1 and third place distance

A multiple regression was run to predict neighbouring 2 from perceived distance of third places from a participant's home, age, gender, education, income, home ownership, children at home, marital/de facto status, and length of residence. All assumptions were met. The multiple regression statistically significantly predicted neighbouring $1, F(9,112)=3.672, p<0.0005$. The distance variable did not statistically significantly add to the prediction however, the length of residence variable added statistically significantly to the prediction $(p<0.05)$. Regression coefficients and standard errors can be found in Table 26.

\begin{tabular}{l|l|l|l}
\hline Variable & $\boldsymbol{B}$ & $\boldsymbol{S E}_{\boldsymbol{B}}$ & $\boldsymbol{\beta}$ \\
\hline Distance & .024 & .113 & .019 \\
Age & .039 & .074 & .055 \\
Gender & .270 & .182 & .128 \\
Education & .123 & .069 & .156 \\
Income & -.068 & .051 & -.127 \\
Home ownership & .077 & .179 & .052 \\
Children at home & .380 & .195 & .207 \\
Marital status & -.158 & .189 & -.079 \\
Length of residence & .214 & .069 & $.316^{*}$ \\
\hline
\end{tabular}

Table 26: Regression results - neighbouring 2 and third place distance 


\section{SRQ3.3: Visits}

A multiple regression was run to predict neighbouring 1 from how often a participant visited their third place from a participant's home, age, gender, education, income, home ownership, children at home, marital/de facto status, and length of residence. The multiple regression statistically significantly predicted SoC, $F(9,112)=5.442, p<$ 0.0005 . The visits variable did not statistically significantly add to the prediction however, the length of residence variable added statistically significantly to the prediction $(p<0.005)$. Income and education also added statistically significantly to the prediction $(p<0.05)$. Regression coefficients and standard errors can be found in Table 27.

\begin{tabular}{l|l|l|l}
\hline Variable & $\boldsymbol{B}$ & $\boldsymbol{S E}_{\boldsymbol{B}}$ & $\boldsymbol{\beta}$ \\
\hline Visits & -.006 & .087 & -.006 \\
Age & .008 & .069 & .012 \\
Gender & .237 & .170 & .113 \\
Education & .138 & .065 & $.176^{*}$ \\
Income & -.101 & .048 & $-.190^{*}$ \\
Home ownership & -.223 & .168 & -.152 \\
Children at home & .139 & .184 & .076 \\
Marital status & .048 & .179 & .024 \\
Length of residence & .240 & .065 & $.357^{* *}$ \\
\hline
\end{tabular}

Table 27: Regression results - neighbouring 1 and third place visits

A multiple regression was run to predict neighbouring 2 from how often a participant visited their third place from a participant's home, age, gender, education, income, home ownership, children at home, marital/de facto status, and length of residence. The multiple regression statistically significantly predicted SoC, $F(9,112)=3.677, p<$ 0.005 . The visits variable did not statistically significantly add to the prediction however, the length of residence variable and the 'children at home' variable both added statistically significantly to the prediction $(p<0.05)$. Regression coefficients and standard errors can be found in Table 28 .

\begin{tabular}{l|l|l|l}
\hline Variable & $\boldsymbol{B}$ & $\boldsymbol{S} \boldsymbol{E}_{\boldsymbol{B}}$ & $\boldsymbol{\beta}$ \\
\hline Visits & -.025 & .092 & -.277 \\
Age & .041 & .074 & .058 \\
Gender & .262 & .180 & .124 \\
Education & .127 & .069 & .161 \\
Income & -.069 & .051 & -.129 \\
Home ownership & .082 & .179 & .055 \\
Children at home & .388 & .195 & $.211^{*}$ \\
Marital status & -.163 & .190 & -0.82 \\
Length of residence & .214 & .069 & $.316^{*}$ \\
\hline
\end{tabular}

Table 28: Regression results - neighbouring 2 and third place visits 


\section{Results Summary}

The first research question of this study intended to establish the meaning and value of third places for residents of three neighbourhoods in Wellington. To answer this question, two sub-questions were used to identify where respondents liked to go in their neighbourhood to socialise and meet fellow residents. Upon discovering this information, the extent to which these places could be considered as third places was examined through determining their characteristics. It was found that:

- Respondents met fellow residents through their children, in the street or being neighbours;

- Eating or drinking venues were the most commonly cited examples of generic third places by respondents;

- Natural places, including the beach and the park were the most commonly cited favourite places of respondents;

- Respondents from Karori most commonly cited the park as their favourite place and respondents from the Southern Coast suburbs most commonly cited the beach as their favourite place;

- The third place characteristics that were most commonly associated with respondents' third places were that they were on neutral ground and acted as a leveller;

- Most respondents attributed five out of the eight third place characteristics to their favourite place.

The second research question of this study intended to understand the relationship between participants' perceptions of third place and SoC in a neighbourhood. To answer this question, three sub-questions were used to identify the association between $\mathrm{SoC}$ and a participant's perception of the quality of third place, the distance to their third place from their home, and how often they visit their third place. It was found that:

- There exists a small significant positive correlation between the perceived quality of third places and SoC both overall and for the neighbourhood of Karori;

- There exists no correlation between the perceived distance of third places from participants' home and SoC overall, and for both suburbs investigated separately; 
- There exists no correlation between how often participants' visit their place and SoC overall, and for both suburbs investigated separately;

- Controlling for all demographic variables, the third place quality measure added statistically significantly to the prediction of third SoC.

The third research question of this study intended to understand the relationship between participants' perceptions of third place and level of neighbouring in a neighbourhood. To answer this question, three sub-questions were used to identify the association between neighbouring and a participant's perception of the quality of third place, the distance to their third place from their home, and how often they visit their third place. It was found that:

- There exists a small significant positive correlation between the perceived distance of third places and the number of neighbours a participant knows;

- There exists a small positive correlation between the perceived distance of third places with how often a participant interacts with their neighbours however, it is not statistically significant;

- There exists a positive correlation between the perceived distance of third places and the number of neighbours a participant knows in both Karori and the Southern Coast suburbs however, it is not statistically significant;

- There exists no correlation between the perceived quality of third places and the number of neighbours a participant knows (neighbouring 1), and how often they interact with their neighbours (neighbouring 2);

- There exists no correlation between how often participants' visit their place and how many neighbours a participant knows (neighbouring 1), and how often they interact with their neighbours (neighbouring 2);

- The length of residence measure added statistically significantly to the prediction of how many neighbours a respondent knows in their neighbourhood (neighbouring 1), and to the prediction of how often a respondent interacts with their neighbours (neighbouring 2);

- The income and education variables added statistically significantly to the prediction of how many neighbours a respondent knows in their neighbourhood. 


\section{Chapter six: Discussion}

Until now there has been a paucity of empirical research on how third places, as a feature of the built environment, are associated with individual level dimensions of social capital in a neighbourhood. This thesis examined the relationship between residents' perceptions of specific features of their third place (frequency of visits, quality, and distance from a participant's home) with certain dimensions of social capital: SoC and neighbouring. This thesis was underpinned by a social capital conceptual framework. In addition to exploring the social capital - third place nexus, an integral part of this thesis was to identify the meaning and value New Zealanders attribute to third places, and whether the characteristics of such places (as defined by Oldenburg, 1989) remain relevant in a modern New Zealand context. This chapter discusses the results of this study in light of existing literature (as described in chapter three) and summarises the most pertinent findings with potential implications of these findings for policy and practice. The chapter ends by considering the study's strengths and limitations.

\section{Research Question 1: The meaning and value of the third place}

This study sought to understand how Wellingtonians perceive third places in their neighbourhood, and the value and meaning residents attach to these places. The purpose of this question was to explore Oldenburg's (1989) third place theory in a New Zealand context as there is very little research available that does so. The importance of exploring this subject is that third places are said to encourage local social interaction between residents, which contributes to their overall well-being.

Most studies exploring Oldenburg's (1999) theory of third places do not ask their participants about what places they perceive as 'third places' as they are preoccupied with investigating whether one specific type of place is a third place. For example, researchers have focused on exploring whether a bookshop, coffee store, or library, is a third place, and while useful in expanding Oldenburg's (1999) theory, these studies are limited to what the researcher perceives as a third place and do not tap into the perceptions of individuals. In addition, most of these studies were conducted in the United States, and it would only be an assumption to say whether these types of places would be perceived as third places in New Zealand. As the broader objective of this research is to identify the role of third places in New Zealand, this research asked respondents about their thoughts on what places in their neighbourhood they think fit 
Oldenburg's (1999) third place definition. This approach is consistent with the methods used in Jeffres et al.'s (2009) study where open-ended questions were used to ask respondents where they congregate outside of the home or workplace. Jeffres et al. (2009) is also the only other existing quantitative study that asks respondents what places they perceive to be third places. This thesis found that respondents cited the following top three places when asked to list examples of neighbourhood third places 1) 'food-related' (restaurants, bars, cafes), 2) 'nature-related' (walking tracks, park, beach) or 3) 'child-oriented places' (including the school, kindergarten and/or the playground). Furthermore, over half of total respondents first met others in their neighbourhood through their children or at events hosted by their children's school. This study also asked respondents to note their own neighbourhood third place and it was found that nature-related places i.e. the park, the beach, walking tracks, or a bush reserve, were the most commonly cited places. Respondents from the Southern Coast suburbs who live near the sea most commonly cited the beach as their third place, and respondents from Karori most commonly cited the park. The findings of this study are similar to Jeffres et al.'s (2009) results where they found that the top three most commonly cited examples of third places by respondents were 1) 'community centres' 2) 'coffee shops', and 3) 'restaurants and cafes'. However, nature-related places such as 'parks' were the fifth most commonly cited example of third places in Jeffres et al.'s (2009) study.

Community centres were also noted by respondents of this study to be examples of third places however, they were not as common (eighth most commonly cited third place). Hickman's (2013) qualitative study found that the most popularly cited third places by respondents were either food-related places or nature-related places in their neighbourhood, which mirrors the results found in this study. Hickman (2013) found that the most commonly cited third places were local shops however, this study did not replicate these findings as shops were cited by only 20 respondents. The differences in respondents' perceptions between this study and related literature could be due to the chosen study location. Jeffres et al.'s (2009) study was based in the United States, and Hickman's (2013) was based in the United Kingdom. The results of this research and that of Hickman (2013) and Jeffres (2009) have in common the types of third places identified by respondents however, the order of popularity of these places differ. What can be deduced from these results is that New Zealanders most commonly perceive third places as places of nature, and that the type of that natural place depends on the topography of the neighbourhood. For suburbs close to the sea, residents cited the beach, whereas residents living near bushland or parks cited walking tracks or the 
closest park to their house. This research also found that while nature-related places were the chosen 'third places' by respondents, people mainly met one another through their children or activities hosted by their child's school. As articulated in chapter three, there has been little empirical research on the third place in New Zealand so the slight differences in findings may be due to cross-cultural differences in respondents' perceptions. Another explanation of the differences could be due to availability of these places. In comparison to the location of this research, Jeffres et al.'s (2009) study was nation-wide and included respondents who live in the country where the presence of third places is rare or non-existent, and Hickman's (2013) study was conducted in deprived neighbourhoods that have poor infrastructure and amenities.

In line with the methods of Hawkins and Ryan (2013) and Slater and Koo (2010) this study asked respondents about the importance of eight characteristics of third places as defined by Oldenburg (1989). This research found that the median number of characteristics selected by respondents as defining their 'third place' was only five. Characteristics that were considered not that important by respondents were that their third place had to have a homely feel, regulars that set the mood, and was a place to engage in conversation. In their quest to claim mainstream art venues/museums as third places, Slater and Koo (2010) found that 'engaging in conversation' was rated as the least important characteristic by respondents. The results of this study mirror those of Slater and Koo (2010) as it was rated as the least important characteristic with only 11 per cent of respondents reporting 'engaging in conversation' as an important feature of their third place. Slater and Koo (2010) argue that a third place does not necessarily have to be a place for conversation as people prefer their own personal space within the third place (whilst still considering the larger space as intimate and friendly). Hickman (2013) also argues that Oldenburg's conceptualisation of social interaction as conversing verbally is too restrictive as people simply value seeing familiar faces.

The most commonly cited characteristic as a feature of respondents' third places in this study was accessibility (78 per cent of respondents). This means that respondents strongly value the ability to come and go freely and not play 'host' when visiting their third place. This result contradicts that of Hawkins and Ryan (2013) who found that accessibility was not an important characteristic however, their study was of festivals as third places (that required a purchased ticket for entry). Hawkins and Ryan (2013) also contested the importance of third places fulfilling Oldenburg's conceptualisation of third places as having a 'low profile'. This study found that the requirement for a third 
place to have a low profile was considered moderately important (52 per cent of respondents).

Hawkins and Ryan's (2013) and Slater and Koo's (2010) studies found that the third place they were investigating did not meet all of Oldenburg's (1989) eight characteristics however, they used their findings as an opportunity to challenge the salience of third place theory and argue that these places can still be considered third places. Hawkins and Ryan (2013) and Slater and Koo (2010) argue that latest third places are emerging under the wider criteria of accessibility, comfort, sociability and activities, which are characteristics not originally conceptualised by Oldenburg (1989). Their critical approach was not taken by Laing and Royle (2013) who investigated whether a bookshop could be considered a third place and found that because it did not exhibit one of the third-place criteria, bookshops cannot be considered third places. Oldenburg (1989) did not give a systematic empirical assessment of any of his founding theoretical claims and in addition to Laing and Royle (2013) many other studies have taken Oldenburg's (1989) characteristics as given (Williams \& Hipp, 2019). The findings in this thesis resonate with Hawkins and Ryan's (2013) and Slater and Koo's (2010) argument as several respondents noted activities or events that occur in their neighbourhood such as the pub quiz, kids' parties, school sports events and open homes, as examples of third places. Purnell (2015) argues that a third place should not be defined by how it looks or feels, but by the purpose which the place serves. Purnell (2015) defines social events within homes as third places and uses an example of a neighbourhood ritual where residents share a meal every Wednesday night. This thesis' results support Purnell's (2015) argument where 'activities' or 'events' were prevalent as examples of third places by respondents. Considering Oldenburg's (1989) argument that traditional third places are vanishing, academics have called for more research on new and emerging third places based on the argument that place factors are important in shaping social and human capital. The findings of this research support and contribute empirically to the new, and increasingly popular, debate challenging the salience of Oldenburg's (1989) third place theory as they build on or complement findings found in similar studies. Uniquely, the findings of this research also reveal new information on the role of third places in a New Zealand context. For Wellingtonians, third places mean local places that are accessible and inclusive, and do not exist for the sole purpose of engaging in conversation. Respondents' value third places as places where all are equal within the space and which offer them personally the novelty of being able to 
come and go at their leisure. In addition to this, third places are not necessarily physical places or spaces but can also be activities or events that occur locally. The findings of this research demonstrated that Wellington residents have almost two distinct neighbourhood third places. Firstly, for Wellingtonians a third place is a place of nature that exists as a place to escape to, and is welcoming, friendly and safe, and offers individuals the opportunity to engage in non-verbal communication with familiar faces whilst retaining a sense of their own private space. Secondly, for Wellingtonians a third place is an activity hosted in an inclusive place where people can gather voluntarily and informally to develop informal associations with others.

\section{Research Questions 2 and 3: Third places and Social Capital}

Many empirical studies demonstrate that various individual and ecological factors are associated with facets of social capital, one of which (and the least researched) is the built environment. Particularly, research on this subject has overwhelmingly focussed on the role of walkability in facilitating social interaction between residents. This thesis is intended to contribute to the growing body of evidence that better designed neighbourhoods maximise social interaction between residents, and this in turn creates positive mental and physical health outcomes. As discussed in chapter three, this research focused on one specific feature of the built environment the third place, and its association with two facets of social capital: SoC and neighbouring. This research intended to produce similar findings to those found in existing literature, specifically regarding the association between social capital with quality and distance to local amenities. Except for work by Francis et al. (2012), studies have not tended to conceptualise local amenities/infrastructure as third places. Considering this, this research followed Francis et al.'s (2012) approach to make further contributions to third place theory as well. Evidence on the association between social capital and how often individuals visit their third place was non-existent, therefore the novelty of this study was that it was intended to address a gap in the literature by further exploring this relationship.

\section{Association between quality of third places and Social Capital}

This research investigated the relationship between perceived quality of third places and two facets of social capital: SoC and neighbouring (including measures of social networks and social support). It was found that the perceived quality of third places was positively related with SoC and found to be statistically significant. This means that respondents who perceived their third place to be of good quality or to have good quality attributes had a stronger SoC. A positive relationship was found between SoC 
and both neighbouring measures, but these relationships were not statistically significant. The significant-relationship between SoC and the quality measure was the only significant relationship found in this research. Related literature has found that individuals who perceive third places to be a good quality have a stronger SoC. This thesis has produced consistent findings. For example, Francis et al. (2012) found a statistically significant positive association between subjective quality of parks, community centres, shops, and schools with SoC after adjustment for demographic variables. Francis et al. (2012) suggest that aspects of quality thought to stimulate social interaction in third places include connected pedestrian pathways and meeting areas, shaded plazas with benches for conversation, and activity generators (e.g. food). These claims link to the findings found in the first research question as respondents highly rated children-oriented places (school, playground, kindergarten) as third places because they can serve as activity generators to meet other parents, for example at school pick/drop offs, school fairs, and kids parties. In Karori, the most-commonly cited third place was Karori Park, which also acts as an activity generator as it has a café attached and is connected by a well-kept $1 \mathrm{~km}$ round loop track for pedestrians, allowing for opportunities to converse. French et al. (2014) also found that perceptions of neighbourhood aesthetics and infrastructure of nature-related third places (walkways and cycling tracks) were positively associated with SoC, after adjusting for demographic variables. French et al. (2014) argue that perceptions of neighbourhood aesthetics, which can include third places, are important because the appearance of such places or features lead residents to make inferences about others in their neighbourhood. The authors argue that these inferences influence social interaction in the neighbourhood, and therefore affects SoC (French et al., 2014). Furthermore, Francis et al. (2012) argue that there is significant evidence in the literature that demonstrates the presence of green space in a neighbourhood is associated with multiple positive psychosocial outcomes, including SoC. While this thesis found no relationship between both neighbouring measures and quality of third places, Wood et al. (2008) found a positive statistically-significant association between perceived adequacy of facilities and social capital, which included measures such as social networks (a feature of neigbouring). As a measure, the quality of the built environment and of third places is hard to quantify and generalise across multiple studies. The measures used in this research are not the same as those used in related studies. It is therefore difficult to be sure that there exists a relationship between the quality of third places and social capital. 


\section{Association between distance to third places and Social Capital}

Another feature investigated in this research was perceived distance to third places from a respondent's home. It was found that perceived distance to a third place from a respondent's home was negatively associated with $\mathrm{SoC}$ but that it was positively associated with both neighbouring measures. However, these relationships were not statistically-significant. The overall relationship between social capital and perceived distance to third places in this study is inconclusive due to the different directions in relationships for SoC and neighbouring. These results were to be expected as while there has been evidence of positive relationships between distance to third places and social capital there is no consensus on this relationship in the overall literature. In their systematic literature of social capital and the built environment Mazumdar et al. (2018) found that access to destinations (meaning places within a walkable distance) is significantly associated with social capital however, 15 per cent of significant relationships and 30 per cent of all relationships were not in the expected direction. Studies that have found a positive association include Francis et al. (2012) where they found that perceived distance to public open space (which the authors define as an example of a third place) was positively associated with SoC. Their study found that respondents who reported to live five to fifteen minutes from public open space had a weaker SoC than those living less than five minutes away. Their findings were statistically-significant ( $p=.002)$. In addition, van den Berg et al. (2015) tested the association between an individual having a social interaction with a local tie (a component of the neighbouring measure used in this research) with distance to neighbourhood facilities. The authors found a positive association between social interaction and the respondent living within less than $1 \mathrm{~km}$ of a supermarket and/or less than $1 \mathrm{~km}$ of an outdoor sports facility. Van den berg et al. (2015) claim that the presence of local facilities provides opportunities for contact with fellow residents and therefore increases the likelihood of interaction. The reason for a negative association between distance to third places and $\mathrm{SoC}$, and a weak positive association between distance to third places and both neighbouring measures (as found in this research), could be explained by the number of third places within walking distance from a respondent's home. For example, Francis et al. (2012) found that the number of destinations within 800 metres of an individual's home was negatively related to social capital. The authors suggest that an optimum amount and mix of third places is required to increase social capital because some types of places may discourage social interaction, especially if they are exposed to traffic. Findings from this study support 
Francis et al.'s (2012) claims as many of the third places identified by respondents (from research question one) are located either on the main artery road or on other main roads in each of the three neighbourhoods.

\section{Association between frequency of visitation to third places and Social Capital}

The final characteristic of the third place that was investigated in this study was the frequency of visits a respondent makes at their third place. As mentioned in chapter three, this research sought to further explore this domain as there has been very little research on whether how often one spends time at one's third place is associated with social capital. The justification for exploring this relationship is that passive, face-toface contact of repeated and increasing length is important for developing connections with others, and third places may act as facilitators for developing these connections however, not enough is known about their role (Francis et al., 2012). No relationship was found between frequency of visits to one's third place and both social capital variables (SoC and neighbouring). These findings were to be expected as there is not enough evidence in the literature to suggest whether there is a significant association between these two variables, and studies have produced inconsistent findings. For example, Francis et al. (2012) found that the frequency by which people use local amenities or public open spaces was not significantly associated with SoC. The authors note that if people visit third places the frequency by which they do so does not affect their SoC. Johnson (2010) who investigated whether there was an association between the frequency of going to the library (an example of a third place) and social capital, also found no overall significant association. In contrast, Kuo et al. (1998) found that the use of green space in an inner-city hosing development predicted the strength of social ties between residents and $\mathrm{SoC}$ in older adults. While these are significant findings, Kuo et al. (1998) study was conducted in area closer to a Central Business District therefore their results are not directly comparable to the findings of this thesis. Cabrera and Najarian (2015) found that individuals who made use of their local shops and businesses (including the yoga studio, gym, and café) knew more people in their neighbourhood than those who did not. The reason that this research may have not found similar findings is due to the types of third places preferred by respondents in this research. For example, the most commonly-cited third places were nature-related places (beach, park) and individuals who visit these places are most likely to have brief and non-verbal interactions with others as they are most likely mobile when visiting or are there for their own recreational pleasure. These claims are reinforced by the research of 
Du Toit et al. (2007) who investigated neighbourhood walking and sociability and found that walking for transport, rather than walking for recreation (as people do in nature-related third places) explained the association between SoC and neighbourhood walkability.

\section{Implications for policy and practice}

Research on the built environment argues that neighbourhood infrastructure, including third places, has an impact on people's quality of life in many ways and, it suggests that one of the most important is in facilitating social interaction (and therefore social capital). Many studies argue that the neighbourhood is losing its importance due to the mobility and accessibility afforded by cars, and the social opportunities created by the internet and social media. In saying this, others attest that the neighbourhood will always be an important resource for less mobile or technologically-inept residents such as people working from home, the elderly, parents of young children, single car households, disabled and the socio-economically disadvantaged. Local policy makers and planners therefore face the issue of ensuring the physical attributes of a neighbourhood can positively affect the social 'behaviour' of its residents (Hickman, 2013). Oldenburg (1989) attests that third places in the neighbourhood are vehicles for maximising social interaction that build social capital and therefore contribute to residents' overall quality of life. Due to the increased population projections in Wellington and the demand for new housing subdivisions, the results of this study provide scope for policy makers and planners to provide for the presence of third places in new neighbourhoods. Based on this study's results two of the main suggestions for building social capital at the neighbourhood level are 1) providing for particular types of third places and 2) ensuring the third places are of high quality or have high quality attributes. Providing for places of nature such as public parks, playgrounds, walking tracks, and places that promote and encourage activities where others can meet and interact would benefit residents of those neighbourhoods as they would be regularly used. As the results of this study suggest it is important that third places are perceived to be places that are accessible (where people can come and go as they please) and are inclusive (where there are no set formal criteria of membership and inclusion). In light of this, issues of degradation and maintenance would need to be considered, as would ensuring that these places cater for a range of interests and activities. Additionally, for places such as parks, planners would have to address heavy traffic and appropriate access points. Since nature-related places and schools were popularly-identified third 
places by respondents, community leaders could promote community-based programmes or campaigns that encourage activities in these spaces to allow for residents to interact and meet one another. Even though the frequency of visiting third places was not associated with social capital, local policy makers should not discount the benefits associated with increasing the use of third places such as feelings of restoration from exposure to nature, the greater patronage and improvement of nearby businesses and local economies, and enhanced feelings of safety (Francis, 2010). The findings of this research have demonstrated that high-quality third places may provide viable settings for building facets of social capital such as $\mathrm{SoC}$ and neighbouring within environments in which people live. Considering this, local policy makers and planners should allocate resources to investigate the perceptions of people living within their cities for the purpose of empowering residents and designing liveable and lively neighbourhoods. In early 2019 the Wellington City Council released a discussion document on 'planning for growth' project which was intended to involve residents in the planning process for densifying existing neighbourhoods and/or developing new neighbourhoods on greenfield land to accommodate a growing population. The Council's inclusive approach recognises the value of residents' perceptions of their neighbourhoods, which sets a good practice that can be followed by other city councils in New Zealand. The benefits of having good levels of social capital in a neighbourhood are numerous (including increased participation in community affairs and better physical and mental health) therefore policies that support high quality third places and recognise the perceptions of residents are warranted (Francis et al., 2012).

\section{Limitations}

This study had a few limitations that could be addressed in future studies. Firstly, an assessment of causality was limited by the cross-sectional nature of this research and by the small sample size. As a cross-sectional study, it cannot be determined whether high quality third places (or third places with high quality features) strengthens $\mathrm{SoC}$, or if people with a stronger SoC rate the quality of their third place to be higher. The sample size of this research was relatively small, as it was limited to the 160 individuals out of the 195 individuals who accessed the survey. Of the 160 respondents, 18 were from Island Bay, 43 were from Lyall Bay, and 99 were from Karori. These small sample sizes are not necessarily reflective of the wider population overall in Wellington, and for each of the suburbs. Furthermore, the survey sample was characterized by a large proportion of respondents who identified as New Zealand European, female, aged 35 - 
44 and earned over $\$ 100,000$. These demographics do not represent a true sample of the Wellington population overall, and in each of the suburbs and therefore may have contributed to the inconclusive results reflected in this study. Future research may address these limitations through a survey tool that could reach a wider audience that may be more representative of the population. Longitudinal studies that investigate the relationship between social capital and the presence of high-quality third places in a neighbourhood are also warranted as it would help establish causation.

Another limitation of this study is its focus on subjective or perceived measures of third place quality, distance and frequency of visits. Limitations of self-administered surveys include the potential for recall bias however, the survey did reverse score some questions in the survey tool to prevent some of the acquiescent response bias. This study chose to focus on subjective measures of third places because residents' perceptions of the neighbourhood have been found to be stronger predictors of SoC compared to objective measures of the built environment (French et al., 2014). Residents make inferences about other residents in their neighbourhood based on their perceptions of the neighbourhood built environment, and this can influence their willingness to interact with other residents and ultimately their SoC (French et al., 2014). In saying this, future studies would benefit from including objective measures of third places (as well as subjective measures), such as measuring the actual distance to a third place from a respondent's home, and to expand upon features of third place quality. Objective measures of third place quality could help expand upon the tacit features of a third place that individuals appreciate, but are not necessarily aware of (Francis et al., 2012). For example, Francis et al. (2012) reference literature that has found that an important feature of third place quality is the ability to both see how a space is designed to move around in, but also how it physically feels to move through that space. French et al. (2014) argue that objective and subjective measures that aim to capture the same attribute may differ. The authors provide the example of an objective measure of street connectivity that is defined as the count of three-way interactions in a participant's neighbourhood, whereas the subjective measure may include an informal network of paths and cut-throughs that are not captured by the objective measure (French et al., 2014). It is proposed that future studies use both subjective and objective measures to account for the limitations of both types of measures as it will advance understanding of the complex interplay between both. 


\section{Chapter seven: Conclusion}

The overarching aim of this thesis was to understand how the features of the built environment in a neighbourhood can contribute to building successful towns and cities that benefit their overall inhabitants. To achieve this, three research questions were employed in this thesis to ask residents in three different Wellington neighbourhoods about their perceptions of third places and their own social capital.

The first research question was designed to tap into residents' perceptions of third places in their neighbourhood and to understand the meaning and value that is attributed to them. Two types of third place that were commonly identified by respondents were: 1) nature-related places such as parks, walking tracks and beaches, and 2) activityinducing places such as schools (fairs, events) and bars (pub-quiz). For respondents, it is important that a third place is inclusive and accessible. A major implication of these findings is for planners when designing new neighbourhoods (or redeveloping existing neighbourhoods) to ensure that there are places of nature for residents to informally interact with others in their neighbourhood. Informal social interaction between residents is important because it creates a SoC among residents and therefore improves their quality of life and/or well-being.

The second and third research questions of this thesis aimed to explore the association between social capital and perceptions of third places. These questions were used to understand in more detail what features of third places help foster a SoC between residents and encourage neighbouring behaviours in a neighbourhood. The three features of third places that were tested in this thesis were quality, distance (from a respondent's home), and frequency of visits. It was found that the quality of third places tended to be associated with higher levels of SoC. The implications of this finding are that urban planners should not just provide for the incorporation of third places in new neighbourhoods but ensure that the types of third places and their attributes are of high quality. If a neighbourhood has third places of higher quality residents feel more inclined to socially interact with others from their neighbourhood. Social interaction helps to foster SoC and this in turn helps facilitate social capital.

The findings of this research make a good contribution to the literature as the results provide a foundational groundwork for investigating the relationship between the built environment and social capital in a New Zealand context. The results of this study have built upon the existing critique of third place theory, especially regarding the salience of particular characteristics of third places as defined by Oldenburg (1989). In addition, 
contributions have been made to the growing research body investigating the role of the built environment, and its specific features, on facets of social capital as the findings of this study have reinforced existing claims. 


\section{References}

Adam, F., \& Roncevic, B. (2003). Social Capital: recent debates and reserach trends. Social Science Information , 42, 155-183.

Adler, P. S., \& Kwon, S.-W. (2002). Social Capital: Prospects for a New Concept. Academy of Management Review, 27, 17-40.

Aldrich, D. P., \& Meyer, M. A. (2015). Social capital and community resilience. American Behavioural Scientist, 59, 254-269.

Andriani, L. (2013, January). Social Capital: A road map of theoretical frameworks and empirical limitations. London, United Kingdon.

Appleyard, D. K. (1981). Livable Streets. Berkeley, CA: University of California Press.

Araya, R., Dunstan, F., Playle, R., Thomas, H., Palmer, S., \& Lewis, G. (2006). Perceptions of social capital and the built environment and mental health. Social science \& medicine, $62,3072-3083$.

Baldwin, C., \& King, R. (2018). Social Sustainability, Climate Resilience and Communitybased Urban Development: What about the People? Routledge.

Banwell, K. (2017). Planning for Resilient Communities: And Every Other Day: Learning from the Canterbury 2010-2012 Earthquake Sequence.

Baron, S., Field, J., \& Schuller, T. (2000). Social Capital: Critical Perspectives. Oxford: Oxford University Press.

Baum, F. E. (2003). Ziersch: Social capital. Journal of Epidemiology and Community Health, $57,320-323$.

Bhandari, H., \& Yasunobu, K. (2009). What is Social Capital? A comprehensive Review of the Concept. Asian Journal of Social Science, 37(3), 480-510.

Cabrera, J. F., \& Najarian, J. C. (2015). How the built environment shapes spatial bridging ties and social capital. Environment and Behavior, 47, 239-267.

Campbell, C., Wood, R., \& Kelly, M. (1999). Social capital and health. In Health Education Authority.

Cattell, V. (2001). Poor people, poor places, and poor health: the mediating role of social networks and social capital. Social science \& medicine, 52, 1501-1516.

Chavis, D., Hogge, J. H., McMillan, D. W., \& Wandersman, A. (1986). Sense of community through Brunswik's lens: a first look. Journal of Community Psychology, 14(1), 24-40.

Cheshire, L. (2015). 'Know your neighbours': disaster resilience and the normative practices of neighbourhing in an urban context. Environment and Planning, 47(5), 1081-1099.

Christoph, J. (2009). Locating intermediality: Socialization by communication and consumption in the popular cultural third places of the music club and football stadium. Culture Unbound: Journal of Current Cultural Research, 1.2, 331-348.

Chu, A., Thorne, A., \& Guite, H. (2004). The impact on mental well-being of the urban and physical environment: an assessment of the evidence. Journal of Public Mental Health, 4, 17-32.

Claridge, T. (2004). Social Capital and natural resource management. Brisbane, Queensland, Australia. 
Coleman, J. S. (1988). Social Capital in the creation of human capital. American Journal of Sociology, 94, S95-S120.

Corcoran, J., Zahnow, R., Wickes, R., \& Hipp, J. (2018). Neighbourhood land use features, collective efficacy and local civic actions. Urban Studies, 55, 2372-2390.

Creswell, J. W., \& Creswell, J. D. (2018). Rsearch design: qualitative, quantitative, and mix methods approaches. SAGE Publications.

De Vaus, D. (2014). Surveys in social research (Sixth ed.). Sydney: Allen \& Unwin.

DeFilippis, D. (2001). The myth of social capital in community development. Journal of housing policy debate, 781-806.

Du Toit, A., Skuse, A., \& Cousins, T. (2007). The political economy of social capital: Chronic poverty, remotness and gender in the rural Eastern Cape. Social Identities, 13, 521-540.

Evans, G. W. (2003). The built environment and mental health. Journal of urban health, 80, 536-555.

Forbes, M. (2016). The big squeeze: Wellington's population could almost double in next 30 years. Retrieved from www.stuff.co.nz: https://www.stuff.co.nz/national/82678797/thebig-squeeze-wellingtons-population-could-almost-double-in-next-30-years

Francis, J. (2010). Associations between public space and mental health in new residential developments. The University of Western Australia.

Francis, J., Giles-Corti, B., Wood, L., \& Knuiman, M. (2012). Creating sense of community: The role of public space. Journal of environmental pyschology, 32(4), 401-409.

Freiler, C. (2004). Why Strong Neighbourhoods Matter: Implications for Policy and Practice. Toronto: Strong Neighbourhoods Task Force.

French, S., Wood, L., Foster, S. A., Giles-Corti, B., Frank, L., \& Learnihan, V. (2014). Sense of community and its association with the neighbourhoods built environment.

Environment and Behaviour, 46, 677-697.

Grootaert, C., \& Van Bastler, T. (2002). Understanding and measuring social capital: A multidisciplinary tool for practitioners. The World Bank.

Grootaert, C., Narayan, D., Jones, V. N., \& Woolcock, M. (2004). Measuring social capital: An integrated questionnaire. The World Bank.

Hanibuchi, T., Kondo, K., Nakaya, T., Shirai, K., Hirai, H., \& Kawachi, I. (2012). Does walkable mean sociable? Neighborhood determinants of social capital among older adults in Japan. Health \& Place, 18, 229-239.

Hanifan, L. J. (1916). The Rural School Community Centre. Annals of the American Academy of Political and Social Sciences, 67, 130-138.

Hanlin, C. E., Bess, K., Conway, P., Evans, S. D., McCowan, D., Prilleltensky, I., \& Perkins, D. (2008). Community psychology. In The Sage handbook of qualitative research in psychology (pp. 524-540). Los Angeles: Sage.

Harpham, T., Grant, E., \& Thomas, E. (2002). Measuring social capital within health surveys: key issues. Health Policy and Planning, 17, 106-111.

Hawkins, J. C., \& Ryan, L. A. (2013). Festival spaces as third places. Journal of place management and development, 6, 192-202. 
Heimerl , F., Lohmann, S., Lange, S., \& Ertl, T. (2014). Word cloud explorer: Text analytics based on word clouds. 47th Hawaii International Conference on System Sciences, (pp. 1833-1842).

Hickman, P. (2013). "Third places" and social interaction in deprived neighbourhoods in Great Britain. Journal of Housing and the Built Environment, 28, 221-333.

Hinckson, E. A., McGrath, L., Hopkins, W., Oliver, M., Badland, H., Mavoa, S., \& Kearns, R. A. (2014). Distance to school is associated with sedentary time in children: findings from the URBAN study. Frontiers in public health, 2, 151.

Infometrics. (2016). Regional Hotspots. Retrieved from static.infometrics.co.nz: http://static.infometrics.co.nz/files/RegionalHotSpots03e.pdf

Jacobs, J. (1961). The Death and Life of Great American Cities. New York: Random House.

Jeffres, L. W., Bracken, C. C., Jian, G., \& Casey, M. F. (2009). The impact of third places on community quality of life. Applied Research in Quality of Life, 4, 333.

Jenks, M., \& Dempsey, N. (2007). Defining the neighbourhood: Challenges for empirical research. Town Planning Review, 78, 153-177.

Johnson, C. A. (2010). Do public libraries contribute to social capital?: A preliminary investigation into the relationship . Library \& information science research, 32, 147155.

Jones, C., \& Shen, J. (2014). Neighbourhood social capital, neighbourhood disadvantage, and change of neighbourhood as predictors of school readiness. Urban Studies Research.

Kawachi, I., \& Berkman, L. (2000). Social Cohesion, Social Capital, and Health. In Social Epidemiology (pp. 174-190).

Kearny, A. R. (2006). Residential development patterns and neighborhood satisfaction: impacts of density and nearby nature. Environment and Behaviour, 38, 112-139.

Kingston, S., Mitchell, R., Florin, P., \& Stevenson, J. (1999). Sense of community in neighbourhoods as a multi-level construct. Journal of Community Psychology, 27, 681694.

Krishna, A., \& Shrader, E. (1999, June). Social Capital Assessment Tool. Washington D.C.

Kuo, F. E., Sullivan, W. C., \& Wiley, A. (1998). Fertile ground for community: inner-city neighbourhood common spaces. American Journal of Community Psychology, 26, 823851 .

Laing, A., \& Royle, J. (2013). Examining chain bookshops in the context of "third place". International Journal of Retail \& Distribution Management, 41, 27-44.

Lawson, K. (2004). Libraries in the USA as traditional and virtual "third places". New library world, 105, 125-130.

Leyden, K. M. (2003). Social capital and the built environment: the importance of walkable neighbourhoods. American Journal of Public Health, 93, 1546-1551.

Lochner, K., Kawachi, I., \& Kennedy, B. P. (1999). Social Capital: a guide to its measurment. Health and Place, 5, 259-270.

Lund, H. (2003). esting the claims of new urbanism: local access, pedestrian travel and neighboring behaviours. Journal of the American Planning Association, 69, 414-428. 
Mair, H. (2009). Club life: Third place and shared leisure in rural Canada. Leisure Sciences, 31, 450-465.

Mannarini, T., Tartaglia, S., Fedi, A., \& Greganti, K. (2006). Image of neighborhood, selfimage and sense of community. Journal of environmental psychology, 26, 202-214.

Mazumdar, S., Learnihan, V., Cochrane, T., \& Davey, R. (2018). The built environment and social capital: A systematic review. Environment and Behaviour, 50(2), 119-158.

McMillan, D. W., \& Chavis, D. M. (1986). Sense of community: A definition and theory. Journal of Community Psychology, 14, 513-517.

Mehta, V. (2007). Lively streets: Determining environmental characteristics to support social behavior. Journal of planning education and research, 27, 165-187.

Mehta, V., \& Bosson, J. K. (2010). Third places and the social life of streets. Environment and Behavior, 42, 779-805.

Mohnen, S. M., Völker, B., Flap, H., Subramanian, S. V., \& Groenewegen, P. P. (2015). The influence of social capital on individual health: is it the neighbourhood or the network? Social Indicators Research, 121, 195-214.

Moore, S., \& Kawachi, I. (2017). Twenty years of social capital and health research: a glossary. Journal of Epidemology and Community Health, 71(5), 513-517.

Nasar, J. L. (1995). Does neotraditional development build community? Journal of Planning Education and Research, 23, 58-68.

Nasar, J. L., \& Julian, D. A. (1995). The psychological sense of community in the neighborhood. Journal of the American Planning Association, 61, 178-184.

Neuman, W. L. (2005). Social research methods: quantitative and qualitative approaches (Sixth ed.). London: Allyn and Bacon.

New Zealalnd Productivity Commission. (2017). Better Urban Planning. Retrieved from www.productivity.govt.nz:

https://www.productivity.govt.nz/sites/default/files/MASTER\%20COMPILED\%20Bett er\%20urban\%20planning\%20with\%20corrections\%20May\%202017.pdf

Nordstrom, O. A., \& Steier, L. (2015). Social capital: a review of its dimensions and promise for future family enterprise research. . International Journal of Entrepreneurial Behavior \& Research, 21, 801-813.

Obst, P., Smith, S. G., \& Zinkiewicz, L. (2002). An exploration of sense of community, Part 3: Dimensions and predictors of psychological sense of community in geographical communities. Journal of community psychology, 30, 119-133.

Oidjarv, H. (2018). The Tale of Two Communities: Residents' Perceptions of the Built Environment and Neighbourhood Social Capital. Sage Open, 8, 1-20.

Oldenburg, R. (1989). The great good place: Cafe, coffee shops, community centers, beauty parlors, general stores, bars, hangouts, and how they get you through the day. Paragon House Publishers.

Oldenburg, R., \& Brissett, D. (1982). The Third Place. Qualitative sociology, 5, 265-284.

Orford, J. (2008). Community Psychology: challenges, controversies and emerging consensus. John Wiley \& Sons. 
Patulny, R. V., \& Svendsen, G. L. (2007). Exploring the social capital grid: bonding, bridging, qualitative, quantitative. International Journal of Sociology and Social POlicy, 27, 3251.

Paxton, P. (1999). Is social capital declining in the United States? A multiple indicator assessment. American Journal of sociology, 105, 88-127.

Peoples, C. E. (2015). Bowling alone but eating together: Exploring the role of gathering places as community social capital in small towns. Ames, Iowa.

Perkins, D. D., \& Long, D. A. (2002). Neighbourhood Sense of Community and Social Capital: A Multi-level Analysis. In A. Fisher, C. Sonn, \& B. Bishop, Psychological sense of community: Research applications, and implications (pp. 291-318). New York.

Perkins, D. D., Flourin, P., Rich, R., Wandersman, A., \& Chavis, D. M. (1990). Participation and the social and physical environment of residential blocks: Crime and communtiy context. American Journal of Community Psychology, 18(1), 83-115.

Plas, J. M., \& Lewis, S. E. (1996). Environmental factors and sense of community in a planned town. American journal of community psychology, 24, 109-143.

Pooley, J. A., Cohen, L., \& Pike, L. T. (2005). Can sense of community inform social capital? The Social Science Journal, 42, 71-79.

Poortinga, W. (2005). Social relations of social capital Individual and community health effects of bonding social capital. Social Science \& Medicine, 63, 255-270.

Portes, A. (1998). Social Capital: Its origins and Applications in Modern Sociology. Annual review of sociology, 24, 1-24.

Power, A., \& Wilson, W. J. (2000). Social Exclusion and the Future of Cities. London.

Purnell, D. (2015). Expanding Oldenburg: homes as third places. Journal of Place Management and Development, 8, 51-62.

Putnam, R. D. (2000). The Collapse and Revival of American Community. Simon \& Schuster Paperbacks.

Qasem, M. A., \& Gul, S. B. (2014). Effect of item direction (positive or negative) on the factorial construction and criterion related validity in Likert scale. Asian Journal of Research in Social Sciences and Humanities, 4(4), 114-121.

Raman, S. (2010). Designing a liveable compact city: physical forms of city and social life in urban neighbourhoods. Built environment, 36, 63-80.

Renalds, A., Smith, T. H., \& Hale, P. J. (2010). A systematic review of built environment and health. . Family \& community health, 33, 68-78.

Saegert, S., \& Carpiano, R. M. (2017). Social support and social capital: A theoretical synthesis using community psychology and community sociology approaches. Washington D.C: American Psychological Association.

Salazar, M. S. (2015). The dilemma of combining positive and negative items in scales. Psicothema, 27(2), 192-200.

Sanyal, S., \& Routray, J. K. (2016). Social Capital for disaster risk reduction an managment with empirical evidences from Sundarbans of India. International journal of disaster risk reduction, 19, 101-111. 
Sarason, S. B. (1974). The Psychological sense of community: Prospects for a community psychology. Jossey-Bass.

Scott, K. O., Dolan, E., Banwell, K., Witten, K., \& Kearns, R. (2015). Community Formation. Literature Review of factors that enhance place-based social relations in a compact city Retrieved from. Retrieved from sustainablecities.org.nz:

http://sustainablecities.org.nz/wp-content/uploads/Community-formationliteraturereview.pdf

Simmons, J. P., Nelson, L. D., \& Simonsohn, U. (2011). False-Positive Psychology: Undisclosed Flexibility in Data Collection and Analysis Allows Presenting Anything as Significant. Pyschological Science, 22(11), 1359-1366.

Skjaeveland, O., \& Garling, T. (1997). Effects of interactional space on neighbouring. Journal of environmental psychology, 23, 181-198.

Slater, A., \& Jung Koo, H. (2010). A new type of "Third Place"? Journal of place management and development, $3,99-112$.

Soukup, C. (2017). Computer-mediated communication as a virtual third place: building Oldenburg's great good places on the world wide web. New Media \& Society, 8, 147155.

Stats NZ. (2016). National Population Projections. Retrieved from www.stats.govt.nz: http://archive.stats.govt.nz/browse_for_stats/population/estimates_and_projections/Nati onalPopulationProjections_HOTP2016.aspx

Stone, W. (2001). Measuring social capital. Melbourne, Australia.

Sue, V. M., \& Ritter, L. A. (2007). Conducting online surveys . Los Angeles: SAGE Publications.

Tieman, T. K. (2008). Grower-only farmers' markets: public spaces and third places. The Journal of Popular Culture, 41, 467-487.

Tzanakis, M. (2013). Social capital in Bourdieu's, Coleman's and Putnam's theory: Empirical evidence and emergent measurement issues. Educate, 13, 2-13.

Unger, D. G., \& Wandersman, A. (1985). The important of neighbours: The social, cognitive, and affective components of neighbouring. American Journal of Community Psychology, 13, 139-169.

van den Berg, P., Aretze, T., \& Timmermans, H. (2015). A multilevel analysis of factors influencing local social interaction. Transportation, 42, 807-826.

Van Dyck, D., Cardon, G., Deforche, B., Sallis, J. F., Owen, N., \& De Bourdeaudhuij, I. (2010). Neighborhood SES and walkability are related to physical activity behavior in Belgian adults. Preventive medicine, 50, S74-S79.

Veenstra, G., Luginaah, I., Wakefield, S., Birch, S., Eyles, J., \& Elliot, S. (2005). Who you know, where you live: social capital, neighbourhood and health. Social science \& medicine, 60, 2799-2818.

Völker, B., Flap, H., \& Lindenberg, S. (2006). When are neighbourhoods communities? Community in Dutch neighbourhoods. European Sociological Review, 23, 99-114.

Walsh, S. E., \& LaJoie, A. S. (2018). Influence of Built Environment Quality and Social Capital on Mental Health of Residents of Assisted Living Communities in Louisville, Kentucky. Gerontology and Geriatric Medicine, 4. 
Waxman, L. (2006). The coffee shop: Social and physical factors influencing place attachment. Journal of Interior Design, 31, 35-53.

Wellington City Council. (2015). Wellington Urban Growth Plan. Retrieved from wellington.govt.nz: https://wellington.govt.nz/ /media/your-council/plans-policies-andbylaws/plans-and-policies/a-to-z/wgtn-urban-growth/wgtn-urban-growth-plan2015.pdf

Westlund, H. (2006). Social capital in the knowledge economy: Theory and empirics. Springer Science \& Business Media.

Whitehead, M. (2003). Love thy neighbourhood - rethinking the politics of scale and Walsall's struggle for neighbourhood democracy. Environment and Planning A, 35, 277-300.

Williams, P., \& Pocock, B. (2009). Building ‘community' for different stages of life: physical and social infrastructure in master planned communities. Community, Work \& Family, $13,71-87$.

Wilson, G., \& Baldassare, M. (1996). Overall "sense of community" in a suburban region: The effects of localism, privacy, and urbanization. Environment and Behavior, 28, 27-43.

Winter, I. C. (2000). Social capital and public policy in Australia. Australian Institute of Family Studies.

Witten, K., Blakely, T., Bagheri, N., Badland, H., Ivory, V., Pearce, J., \& Scholfield, G. (2012). Neighborhood built environment and transport and leisure physical activity: findings using objective exposure and outcome measures in New Zealand. Environmental Health Perspectives, 120, 971-977.

Wollcock, M. (1998). Social Capital and Economic Development: Toward a Theoretical Synthesis and Policy Framework. Theory and Society, 27, 151-208.

Wood, L. (2006). Social capital, Neighbourhood Environments and Health: development of measurement tools and exploration of links through qualitative and quantitative research. The University of Western Australia.

Wood, L., \& Giles-Corti, B. (2008). Is there a place for social capital in the psychology of health and place? Journal of environmental psychology, 28, 154-163.

Wood, L., Giles-Corti, B., \& Bulsura, M. (2012). Streets apart: Does social capital vary with neighbourhood design? Urban Studies Research.

Wood, L., Shannon, T., Bulsura, M., Pikora, T., McCormack, G., \& Giles-Corti, B. (2008). The anatomy of the safe and social suburb: An exploratory study of the built environment, social capital and residents' perceptions of safety. Health \& Place, 14, 15-31.

Woolcock, M., \& Narayan, D. (2000). Social Capital: Implications for Development Theory, Research, and Policy. World Bank Research Observer, 15, 225-249.

Xu, Q., Perkins, D. D., \& Chow, J. C. (2010). Sense of community, neighbouring and social capital as predictors of local political participation in China. American journal of community psychology, 45, 259-271.

Yuen, F., \& Johnson, A. J. (2017). Leisure spaces, community, and third places. Leisure Sciences, 39, 295-303. 


\section{Appendix One: Survey Questionnaire}

\section{NEIGHBOURHOOD SOCIAL INTERACTION SURVEY}

Dear participant,

Thank you for your interest in participating in this survey. We are interested to find out how the public spaces in your neighbourhood helps you socialise and build connections with other residents. With your help we hope to understand how public spaces can impact on peoples' lives and wellbeing, as this knowledge can be used to improve future urban environments. Please read the following information before deciding whether or not to take part. If you decide to participate, thank you. If you decide not to participate, thank you for considering this request.

Each set of questions are accompanied by some instructions. Please read them carefully. There are no right or wrong answers, we are only interested in your opinion. If you prefer not to answer a question just move on to the next.

By completing the survey you will have the opportunity to go into the draw to win one of four $\$ 100$ grocery vouchers. Good luck!

\section{PARTICIPANT INFORMATION}

Neighbourhood Social Interaction Survey

Researcher: Grace Turner, School of Geography, Environment and Earth Sciences, Victoria University of Wellington

Dear participant,

Thank you for your interest in participating in this survey. Please read through the following information that covers:

- $\quad$ background to this research;

- data collection; and

- your consent to participate in this research.

The survey will provide the data to be used in my thesis, a requirement to be fulfilled as part of a Master's degree in Environmental Studies at Victoria University of Wellington.

\section{What is the aim of the project?}

Creating and maintaining local social connections can be dependent on certain characteristics of the neighbourhood's physical environment. This project aims to identify what features of your neighbourhood's urban physical environment helps you build social connections with your neighbours and feel attached to the community. Specifically, this project wants to know how public spaces (such as schools, cafés, parks, or local shops) in your neighbourhood help you meet and interact with people that live nearby.

\section{How you can help?}

You have been invited to participate in this research because your household is situated in the Wellington suburbs of Lyall Bay or Island Bay. If you agree to take part you will complete a survey. The survey should take you approximately 20 minutes to complete.

\section{What will happen to the information you give?}

This research is confidential. Your individual response to the survey will not be identifiable in the final thesis. Survey data will be grouped, which means that the data will be aggregated and analysed as a whole. All material will be kept confidential. No other person besides myself and my supervisor Dr. Wokje Abrahamse will see the raw data. If you feel the need to withdraw from this study, you may do so prior to 16 November 2018.

Once you submit the survey, it will impossible to retract your answer. 
Personal details, such as your name and email address will be collected only for those who wish to enter the prize draw. All personal details will be received independently from the survey, as you will be asked to click on a separate link to enter the draw. The data sets from the survey and the prize draw entry are not linked so your individual responses to the survey questions will remain unidentifiable.

\section{What will the project produce?}

The information from this research will be used in my Master's thesis, and it may be used in conference presentations and academic publications. The final thesis will be submitted for assessment to the School of Geography, Environment and Earth Sciences, and will later be deposited in Victoria University's library database. The data collected from the survey will be destroyed within five years of the study's completion.

\section{If you have any questions or problems, who can you contact?}

If you have any questions, either now or in the future, please feel free to contact either myself or my supervisor:

Student: $\quad$ Supervisor:

Grace Turner

Wokje Abrahamse

Senior Lecturer

School of Geography, Environment and Earth Sciences

044635217

turnergrac1@myvuw.ac.nz wokje.abrahamse@vuw.ac.nz

\section{Human Ethics Committee (HEC) information}

If you have any concerns about the ethical conduct of the research you may contact the Victoria University HEC Covenor: Dr Judith Loveridge. Email hec@vuw.ac.nz or telephone 044636028.

Sincerely,

Grace Turner

\section{PARTICIPANT CONSENT}

If you would like to continue and complete the survey, please answer the question below making sure you understand the terms and conditions stated in the information section sector.

Do you understand that any information you provide will be kept confidential to the research and the supervisor. Do you understand the published results will not use your name, and that opinions will be attributed to you in any way that will be identifying to you.

Do you consent to talk part in this research and proceed with the survey?

$\begin{array}{ll}\bigcirc & \text { Yes } \\ \mathrm{O} & \text { No }\end{array}$

If you selected 'no', please skip to the end of the survey. 


\section{Your neighbourhood}

To gain a better understanding of how you use certain features of your neighbourhood's physical environment and how you interact with others, we would like to know a bit about you and your use of the neighbourhood. Please answer the following four questions.

1.1 Where do you usually live?

1.2 How long have you lived at the address given in the previous question?

Less than 1 year, or

O years

\subsection{Who lives with you at your usual address?}

Mark the space or spaces which apply to you.

I live alone

My wife or husband, partner or de facto

O My mother and/or father

My daughter(s) and/or son(s)

Oy sister(s) and/or brother(s)

My grandparent(s)

My grandchild(ren)

O My flatmate(s)

O Other, e.g. STEP-SON, MOTHER-IN-LAW. Please state:

1.4 Thinking about the dwelling that you usually live in, do you yourself:

Hold it in a family trust?

Own or partly own it, with or without a mortgage? Or

O Neither of these

1.5 On average, please estimate how many hours during the week and on the weekend you spend in your neighbourhood during daytime hours (8:00am - 6:00pm).

\begin{tabular}{|l|c|c|c|c|c|}
\hline & $\begin{array}{c}0-10 \\
\text { hours }\end{array}$ & $\begin{array}{l}11-20 \\
\text { hours }\end{array}$ & $\begin{array}{l}21-30 \\
\text { hours }\end{array}$ & $\begin{array}{l}31-40 \\
\text { hours }\end{array}$ & $\begin{array}{l}41-50 \\
\text { hours }\end{array}$ \\
\hline $\begin{array}{l}\text { Monday - } \\
\text { Friday }\end{array}$ & 0 & 0 & 0 & 0 & 0 \\
$\begin{array}{l}\text { On the } \\
\text { weekend }\end{array}$ & 0 & 0 & & & \\
\hline
\end{tabular}




\section{Your sense of community}

2.1 The following question contains statements that people might make about your neighbourhood. How strongly do you agree or disagree with the follow statements [Please circle the number that is closest to your answer]

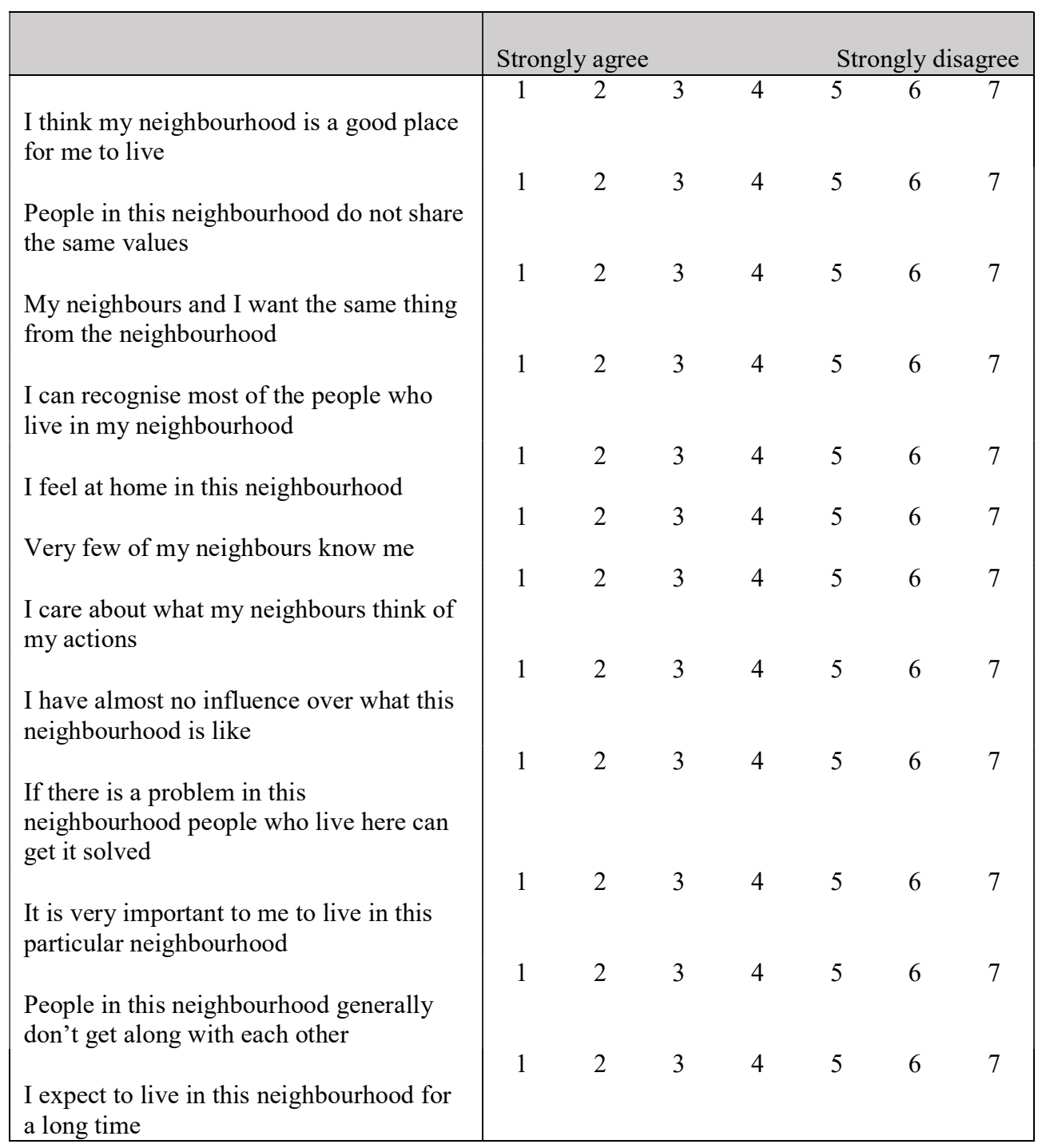




\section{Your attachment to the neighbourhood}

3.1 The following question contains statements that people may feel towards their neighbourhood. How strongly do you agree or disagree with the follow statements [Please circle the number that is closest to your answer]

\begin{tabular}{|c|c|c|c|c|c|c|c|}
\hline & \multicolumn{4}{|c|}{ Strongly disagree } & \multicolumn{3}{|c|}{ Strongly agree } \\
\hline $\begin{array}{l}\text { Everything about my neighbourhood is a } \\
\text { reflection of me }\end{array}$ & 1 & 2 & 3 & 4 & 5 & 6 & 7 \\
\hline $\begin{array}{l}\text { My neighbourhood says very little about who I } \\
\text { am }\end{array}$ & 1 & 2 & 3 & 4 & 5 & 6 & 7 \\
\hline $\begin{array}{l}\text { I feel that I can really be myself in this } \\
\text { neighbourhood }\end{array}$ & 1 & 2 & 3 & 4 & 5 & 6 & 7 \\
\hline $\begin{array}{l}\text { My neighbourhood reflects the type of person I } \\
\text { am }\end{array}$ & 1 & 2 & 3 & 4 & 5 & 6 & 7 \\
\hline I feel relaxed when I am in this neighbourhood & 1 & 2 & 3 & 4 & 5 & 6 & 7 \\
\hline I feel happiest when I am in this neighbourhood & 1 & 2 & 3 & 4 & 5 & 6 & 7 \\
\hline My neighbourhood is my favourite place to be & 1 & 2 & 3 & 4 & 5 & 6 & 7 \\
\hline $\begin{array}{l}\text { I really miss my neighbourhood when I'm away } \\
\text { from it for too long }\end{array}$ & 1 & 2 & 3 & 4 & 5 & 6 & 7 \\
\hline $\begin{array}{l}\text { My neighbourhood is the best place for doing the } \\
\text { things I enjoy most }\end{array}$ & 1 & 2 & 3 & 4 & 5 & 6 & 7 \\
\hline $\begin{array}{l}\text { For doing the things I enjoy most, no other place } \\
\text { can compare to my neighbourhood }\end{array}$ & 1 & 2 & 3 & 4 & 5 & 6 & 7 \\
\hline $\begin{array}{l}\text { My neighbourhood is not a good place to do the } \\
\text { things I most like to do }\end{array}$ & 1 & 2 & 3 & 4 & 5 & 6 & 7 \\
\hline $\begin{array}{l}\text { As far as I am concerned, there are better places } \\
\text { to be than in my neighbourhood }\end{array}$ & 1 & 2 & 3 & 4 & 5 & 6 & 7 \\
\hline
\end{tabular}




\section{Your social networks}

We would like to know how you connect and interact with others in your neighbourhood.

4.1 We want to know how many people you know by name that live in your neighbourhood. Please read the following statements and select an answer for each one that you agree with most.

\begin{tabular}{|l|c|c|}
\hline & True & False \\
\hline $\begin{array}{l}\text { I know the name of one or more persons who live in the house(s) } \\
\text { next door }\end{array}$ & 0 \\
$\begin{array}{l}\text { I know the name of one or more persons who live in houses on my } \\
\text { street }\end{array}$ & 0 & 0 \\
$\begin{array}{l}\text { I know the name of one or more persons who live in other parts of } \\
\text { my neighbourhood }\end{array}$ & 0 & 0 \\
\hline
\end{tabular}

4.2 We are interested to know how many people you know in your neighbourhood, and how close to them you are. Please read the following statements and select an answer for each one that you agree with the most.

How many people in your neighbourhood do you know that fit each of the descriptions listed below?

\begin{tabular}{|l|l|l|l|l|l|l|l|l|}
\hline & 0 & 1 & 2 & 3 & 4 & 5 & 6 & $\begin{array}{c}7 \text { or } \\
\text { more }\end{array}$ \\
\hline $\begin{array}{l}\text { Neighbour(s) that you feel } \\
\text { comfortable talking to about } \\
\text { private matters or call on for } \\
\text { help }\end{array}$ & 0 & 0 & 0 & 0 & 0 & 0 & 0 & 0 \\
$\begin{array}{l}\text { Neighbour(s) that your } \\
\text { household would have over } \\
\text { for a cup of tea or dinner } \\
\text { once in a while }\end{array}$ & 0 & 0 & 0 & 0 & 0 & 0 & 0 & 0 \\
$\begin{array}{l}\text { Neighbour(s) that you feel } \\
\text { comfortable asking to look } \\
\text { after my mailbox when I go } \\
\text { on holiday }\end{array}$ & 0 & 0 & 0 & 0 & 0 & 0 & 0 & 0 \\
$\begin{array}{l}\text { Neighbour(s) that you don't } \\
\text { know well but would smile } \\
\text { at and/or have an informal } \\
\text { chat if you saw them on the } \\
\text { street }\end{array}$ & 0 & 0 & 0 & 0 & 0 & 0 & 0 & 0 \\
$\begin{array}{l}\text { Neighbour(s) that you do not } \\
\text { get along with or do not like }\end{array}$ & 0 & 0 & 0 & 0 & 0 & 0 & 0 & 0 \\
\hline
\end{tabular}


Relatives in your

neighbourhood

Friends in your

neighbourhood

4.3 How often have you engaged in any of the following? Please read the following statements and select an answer for each one that you agree with the most.

\begin{tabular}{|c|c|c|c|c|c|c|c|}
\hline & $\begin{array}{l}\text { Neve } \\
\quad r\end{array}$ & $\begin{array}{l}\text { Once } \\
\text { a } \\
\text { year }\end{array}$ & $\begin{array}{l}\text { A } \\
\text { few } \\
\text { times } \\
\text { a } \\
\text { year }\end{array}$ & $\begin{array}{c}\text { At } \\
\text { least } \\
\text { once } \\
\text { a } \\
\text { mont } \\
\text { h }\end{array}$ & $\begin{array}{l}\text { At } \\
\text { least } \\
\text { once } \\
\text { a } \\
\text { week }\end{array}$ & $\begin{array}{l}\text { Alm } \\
\text { ost } \\
\text { daily }\end{array}$ & $\begin{array}{l}\text { Does } \\
\text { not } \\
\text { appl } \\
\text { y to } \\
\text { me }\end{array}$ \\
\hline $\begin{array}{l}\text { Said hello or "good morning" to a } \\
\text { neighbour(s) }\end{array}$ & 0 & 0 & 0 & 0 & 0 & 0 & 0 \\
\hline Had an informal chat with a neighbour(s) & 0 & 0 & 0 & 0 & 0 & 0 & 0 \\
\hline $\begin{array}{l}\text { Given help to a neighbour(s) (ex: lent a } \\
\text { tool, gave spare baking ingredient, } \\
\text { looked after mailbox or animal while on } \\
\text { holiday) }\end{array}$ & 0 & 0 & 0 & 0 & 0 & 0 & 0 \\
\hline $\begin{array}{l}\text { Received help from a neighbour(s) (ex: } \\
\text { borrowed a tool, asked for a spare baking } \\
\text { ingredient, asked a neighbour to look } \\
\text { after mailbox or feed animal while on } \\
\text { holiday) }\end{array}$ & 0 & 0 & 0 & 0 & 0 & 0 & 0 \\
\hline $\begin{array}{l}\text { Participated in an activity with a } \\
\text { neighbour(s) (ex: had dinner together, } \\
\text { had street BBQ, went for a walk) }\end{array}$ & 0 & 0 & 0 & 0 & 0 & 0 & 0 \\
\hline $\begin{array}{l}\text { Discussed emergency preparedness with } \\
\text { a neighbour(s) }\end{array}$ & 0 & 0 & 0 & 0 & 0 & 0 & 0 \\
\hline
\end{tabular}

4.4 We are interested to know how satisfied you are with your relationships with others in your neighbourhood. Please read the following statement and select an answer for each one that you agree with the most.

How satisfied are you with the relationships you have with others in your neighbourhood?

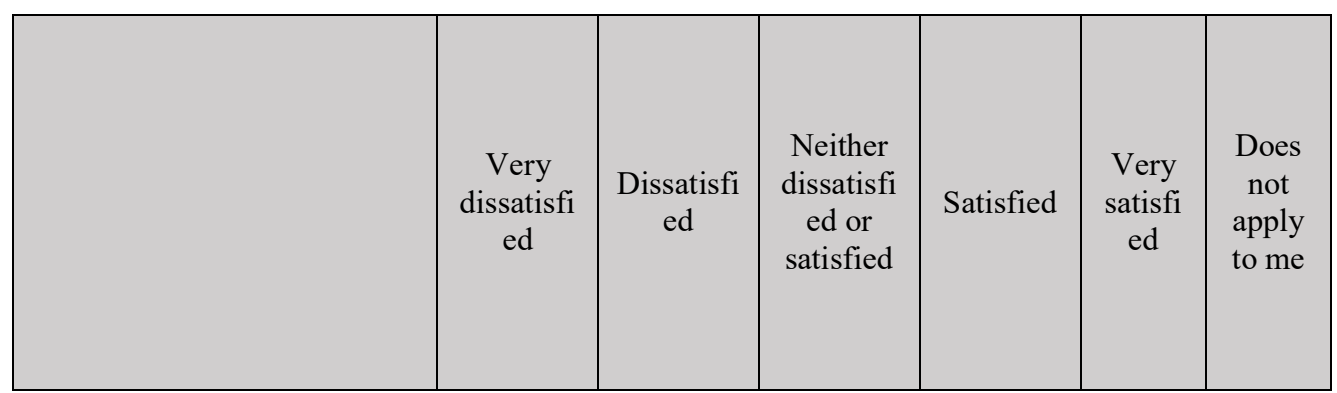




\begin{tabular}{|l|c|c|c|c|c|c|}
\hline Neighbours & 0 & 0 & 0 & 0 & 0 & 0 \\
$\begin{array}{l}\text { Relatives in your } \\
\text { neighbourhood }\end{array}$ & 0 & 0 & 0 & 0 & 0 & 0 \\
$\begin{array}{l}\text { Friends in your } \\
\text { neighbourhood }\end{array}$ & 0 & 0 & 0 & 0 & 0 & 0 \\
\hline
\end{tabular}

\section{Places for interaction in your neighbourhood}

5.1 What physical features of your neighbourhood's urban environment do you think make it easier for you to meet and greet other residents in your neighbourhood? List as many features as you would like.

\begin{tabular}{|c|c|c|c|c|c|}
\hline $\mathrm{O}$ & $\begin{array}{l}\text { Low density } \\
\text { housing }\end{array}$ & $\mathrm{O}$ & High density housing & $\mathrm{O}$ & $\begin{array}{l}\text { Medium density } \\
\text { housing }\end{array}$ \\
\hline $\mathrm{O}$ & Wide streets & $\mathrm{O}$ & Narrow streets & O & Cul-de-sacs \\
\hline O & Local shops & $\mathrm{O}$ & Green space (parks) & 0 & $\begin{array}{l}\text { Recreation } \\
\text { centre/facilities }\end{array}$ \\
\hline $\mathrm{O}$ & Busy streets & $\mathrm{O}$ & Quiet streets & $\mathrm{O}$ & $\begin{array}{l}\text { Street } \\
\text { connectivity/network }\end{array}$ \\
\hline $\mathrm{O}$ & $\begin{array}{l}\text { Other - please } \\
\text { specify: }\end{array}$ & & & & \\
\hline
\end{tabular}

5.2 How did you first meet the people you are close to within your neighbourhood? [Please shade all those relevant]

\begin{tabular}{|c|c|c|c|c|c|}
\hline $\mathrm{O}$ & $\begin{array}{l}\text { Does not apply } \\
\text { to me }\end{array}$ & $\mathrm{O}$ & Through church & $\mathrm{O}$ & Met at local shops \\
\hline $\mathrm{O}$ & $\begin{array}{l}\text { Being } \\
\text { neighbours }\end{array}$ & $\mathrm{O}$ & Through community group & $\mathrm{O}$ & Met in community group \\
\hline $\mathrm{O}$ & $\begin{array}{l}\text { Through } \\
\text { children/school }\end{array}$ & $\mathrm{O}$ & Through pets & $\mathrm{O}$ & Met in local café \\
\hline $\mathrm{O}$ & Through sport & $\mathrm{O}$ & Met in park/bushland & $\mathrm{O}$ & Through clubs \\
\hline $\mathrm{O}$ & Met in street & $\mathrm{O}$ & Bus stop & $\mathrm{O}$ & Online \\
\hline $\mathrm{O}$ & $\begin{array}{l}\text { Other - please } \\
\text { specify: }\end{array}$ & & & & \\
\hline
\end{tabular}


5.3 Within your neighbourhood, what types of places host regular, voluntary, informal and happily anticipated gatherings of individuals beyond the realms of home and work? List as many types of places as you like. (An example of a type of place may be a restaurant or a café, a park, a shop, a library, a community centre or a child's school)

5.4 What is your favourite place in your neighbourhood?

5.5 What makes this place your favourite place? List as many factors are you like.

5.6 How often do you USUALLY go to your favourite place in your neighbourhood?

O Never

Once a year

O A few times a year

At least once a month

At least once a week

Daily

5.7 How close is your favourite place in your neighbourhood from your house?

Very close (within walking distance; 5 minute walk)

O Close (within walking distance; 15 minute walk)

O Further away (more than a 15 minute walk)

5.8 To what extent do you agree or disagree with the following statements about your favourite place?

\begin{tabular}{|l|c|c|c|c|c|c|}
\hline & $\begin{array}{c}\text { Strongl } \\
\mathrm{y} \\
\text { disagre } \\
\mathrm{e}\end{array}$ & $\begin{array}{c}\text { Disagre } \\
\mathrm{e}\end{array}$ & $\begin{array}{c}\text { Neither } \\
\text { disagree } \\
\text { or agree }\end{array}$ & $\begin{array}{c}\text { Agree } \\
\text { It has a friendly atmosphere }\end{array}$ & $\begin{array}{c}\text { Stron } \\
\text { gly } \\
\text { agree }\end{array}$ & $\begin{array}{c}\text { Does not } \\
\text { apply to } \\
\text { me }\end{array}$ \\
I feel comfortable there & 0 & 0 & 0 & 0 & 0 & 0 \\
I feel safe there & 0 & 0 & 0 & 0 & 0 & 0 \\
It is attractive & 0 & 0 & 0 & 0 & 0 & 0 \\
It is well maintained & 0 & 0 & 0 & 0 & 0 & 0 \\
There are a variety of things \\
to do there
\end{tabular}




\begin{tabular}{|l|c|c|c|c|c|c|} 
I often see people there & 0 & 0 & 0 & 0 & 0 & 0 \\
$\begin{array}{l}\text { I often see people I know } \\
\text { there }\end{array}$ & 0 & 0 & 0 & 0 & 0 & 0 \\
It has adequate seating & 0 & 0 & 0 & 0 & 0 & 0 \\
\hline
\end{tabular}

5.9 For this question, we would like you to imagine your ideal hang-out place in your neighbourhood. This can be imaginary or real. How strongly do you agree or disagree with the follow statements [Please circle the number that is closest to your answer].

\begin{tabular}{|c|c|c|c|c|c|c|c|}
\hline & \multicolumn{4}{|c|}{ Strongly agree } & \multicolumn{3}{|c|}{ Strongly disagree } \\
\hline $\begin{array}{l}\text { people can come and go as they please } \\
\text { and no one is required to play host. }\end{array}$ & 1 & 2 & 3 & 4 & 5 & 6 & 7 \\
\hline $\begin{array}{l}\text { It is inclusive. It is a place where there are } \\
\text { people from all walks of life and there are } \\
\text { no set formal criteria of membership and } \\
\text { inclusion. }\end{array}$ & 1 & 2 & 3 & 4 & 5 & 6 & 7 \\
\hline $\begin{array}{l}\text { Maintaining entertaining conversation is } \\
\text { the main activity in this place. }\end{array}$ & 1 & 2 & 3 & 4 & 5 & 6 & 7 \\
\hline $\begin{array}{l}\text { It is an accessible and accommodating } \\
\text { place. It is located not far from where I } \\
\text { live and I can frequent it at hours of the } \\
\text { day or night that suit me. }\end{array}$ & 1 & 2 & 3 & 4 & 5 & 6 & 7 \\
\hline $\begin{array}{l}\text { There are regulars. It is a place where } \\
\text { there are people who frequent often that } \\
\text { give it its tone and set the mood, but also } \\
\text { are there to help someone new to feel } \\
\text { welcome. }\end{array}$ & 1 & 2 & 3 & 4 & 5 & 6 & 7 \\
\hline $\begin{array}{l}\text { It has a low profile. It is a place that does } \\
\text { not feel or look extravagant but has } \\
\text { wholesome characteristics. }\end{array}$ & 1 & 2 & 3 & 4 & 5 & 6 & 7 \\
\hline $\begin{array}{l}\text { The mood is playful. Frequenting the } \\
\text { place gives off an urge to return, recreate } \\
\text { and recapture the experience one feels } \\
\text { when they are there. }\end{array}$ & 1 & 2 & 3 & 4 & 5 & 6 & 7 \\
\hline $\begin{array}{l}\text { It is a home away from home. It offers a } \\
\text { congenial environment and has a 'homely } \\
\text { feel'. }\end{array}$ & 1 & 2 & 3 & 4 & 5 & 6 & 7 \\
\hline
\end{tabular}


5.10 Which community activities do you participate in, WITHIN your neighbourhood?

\begin{tabular}{|c|c|c|}
\hline & Yes & No \\
\hline $\begin{array}{l}\text { Groups (mother's group, book club, church meetings, art } \\
\text { groups, political groups, Rotary) }\end{array}$ & O & $\mathrm{O}$ \\
\hline Public events (cinema, theatre, sports event, festivals, fairs) & $\mathrm{O}$ & $\mathrm{O}$ \\
\hline Volunteer work (schools, community group, church) & $\mathrm{O}$ & $\mathrm{O}$ \\
\hline
\end{tabular}

5.10.1 Overall, how often would you participate in these community activities WITHIN your neighbourhood?
O Never
$O$ Once a year
O A few times a year
O At least once a month
At least once a week
O Daily

5.10.2 Do you have children that currently attend or attended within the last two years a day-care, pre-school, or primary/intermediate school in your neighbourhood?
O Yes
O No
Prefer not to say

\section{About you}

The next set of questions is about you. These questions will provide us an insight into some of the characteristics of the people who have filled out our survey. We will only use averages and aggregates, and your information will not be individually identifiable.

6.1 What age range do you belong? Please shade only one circle. 

O $18-24$
O $25-34$
○ $35-44$
○ $45-54$
○ $55-64$
O $65-74$
O $75+$
Prefer not to say

\subsection{Are you? Please shade only one circle.}
O Male
O Female
O Non-binary
O Other
Prefer not to say

6.3 What ethnic group do you belong to? Mark the space or spaces which apply to you.

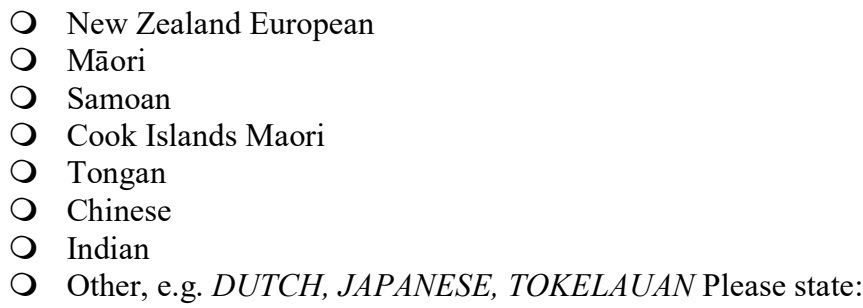

\subsection{What is your highest qualification gained?}

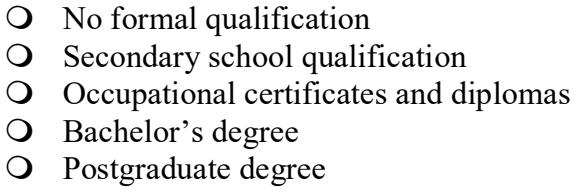

6.5 From all sources, what was your income before tax over the past 12 months?
O Zero income
O $\$ 1-\$ 20,000$
O $\$ 20,001-\$ 30,000$
O $\$ 30,001-\$ 40,000$
O $\$ 40,001-\$ 50,000$
○ $\$ 50,001-\$ 60,000$
O $\$ 60,001-\$ 40,000$
O $\$ 70,001-\$ 80,000$
O $\$ 80,001-\$ 90,000$
O $\$ 90,001-\$ 100,000$
O $\$ 100,001-\$ 150,000$
O $\$ 150,001$ or more 
Thank you for participating in this survey.

If you have any comments that you would like to share about the preceding topics please write them here.

If you would like to enter the prize draw, please click on this link to enter your email address (only one entry per person is allowed).

Email address:

If you have entered the draw for the prize, this will be drawn at the end of the survey at the end of December 2018. The winners will be notified by email. 


\section{Appendix Two: Survey Advertisement}

Have a say on the places and connections you have in your neighbourhood

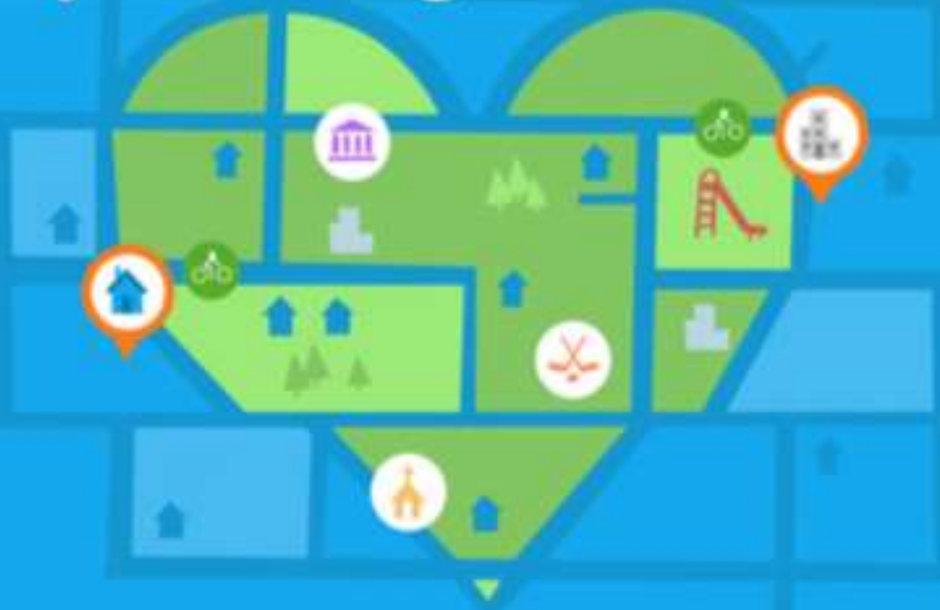

\section{Win one of four $\$ 100$ supermarket} vouchers!

Participate in an 15 minute online survey about the connections you have with fellow residents in your neighbourhood, and tell us about the local places you like to visit in your community. You can go into the draw to win one of four $\$ 100$ supermarket vouchers. You have a good chancel. The survey can be found at:

http:/lvuw.qualtrics.com/jfe/form/SV_6JeACFmQWGqbxnn or scan the QR code below 